


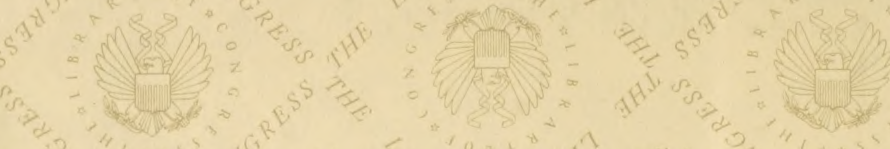

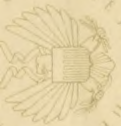

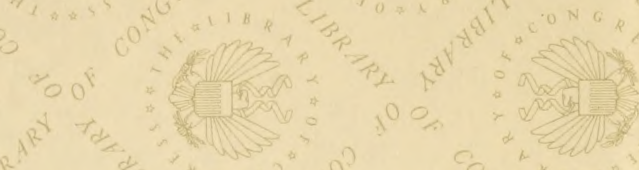

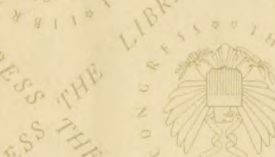

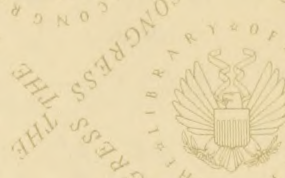

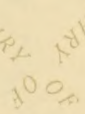

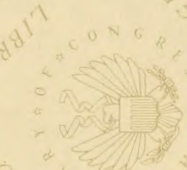

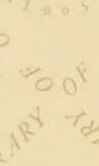

$\frac{10}{2}$

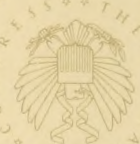

$1 \% 01$

in

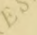

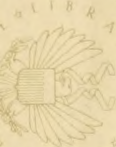

o?

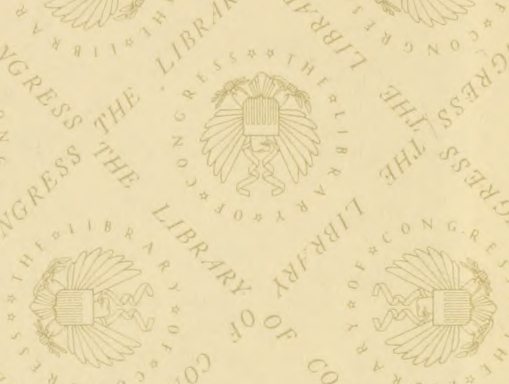

$\sum_{0 \rightarrow-1}^{\infty}$

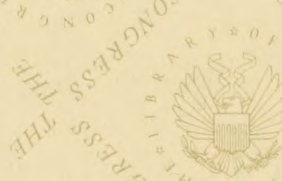

20

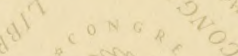

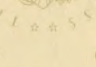

ave

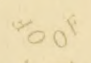

(it)
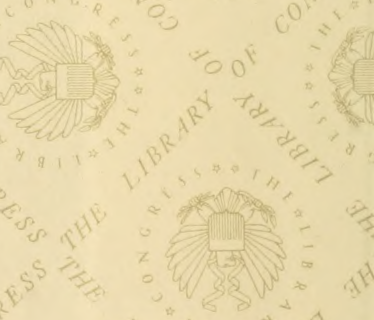

$A^{4}+\frac{1}{2} / 2,2$
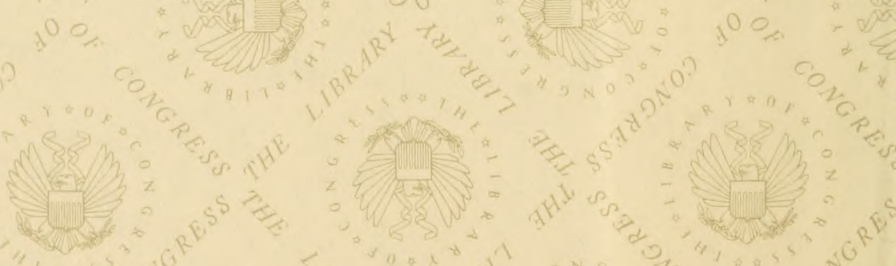

End

20.040
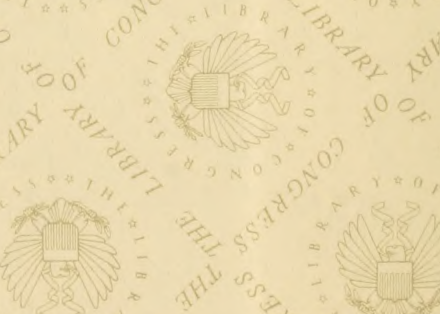

8 , 580

tor a

$100^{\circ}$

(f) 


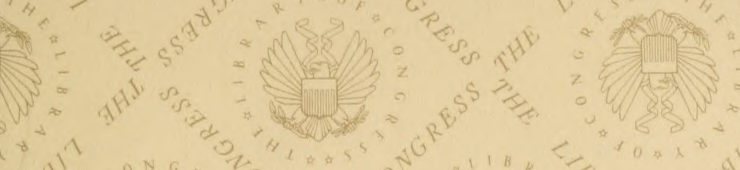

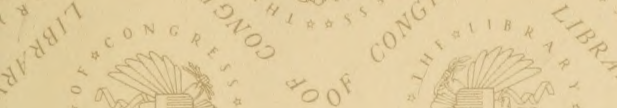

${ }^{0}$,

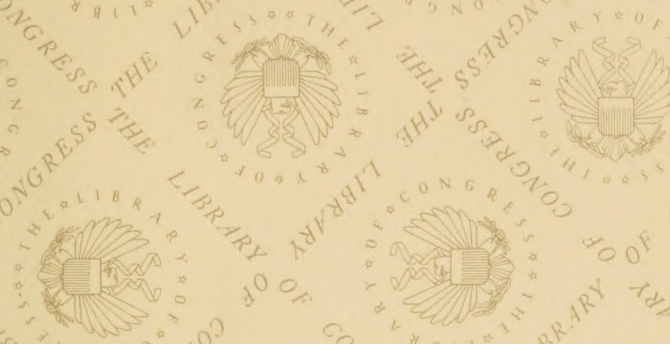

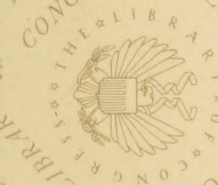

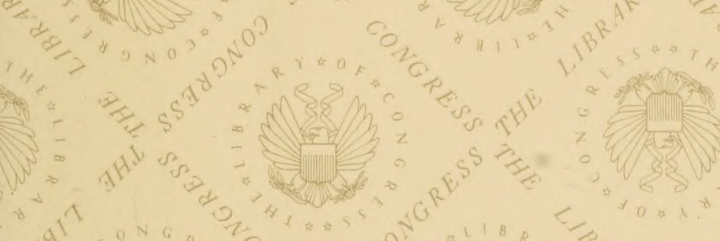
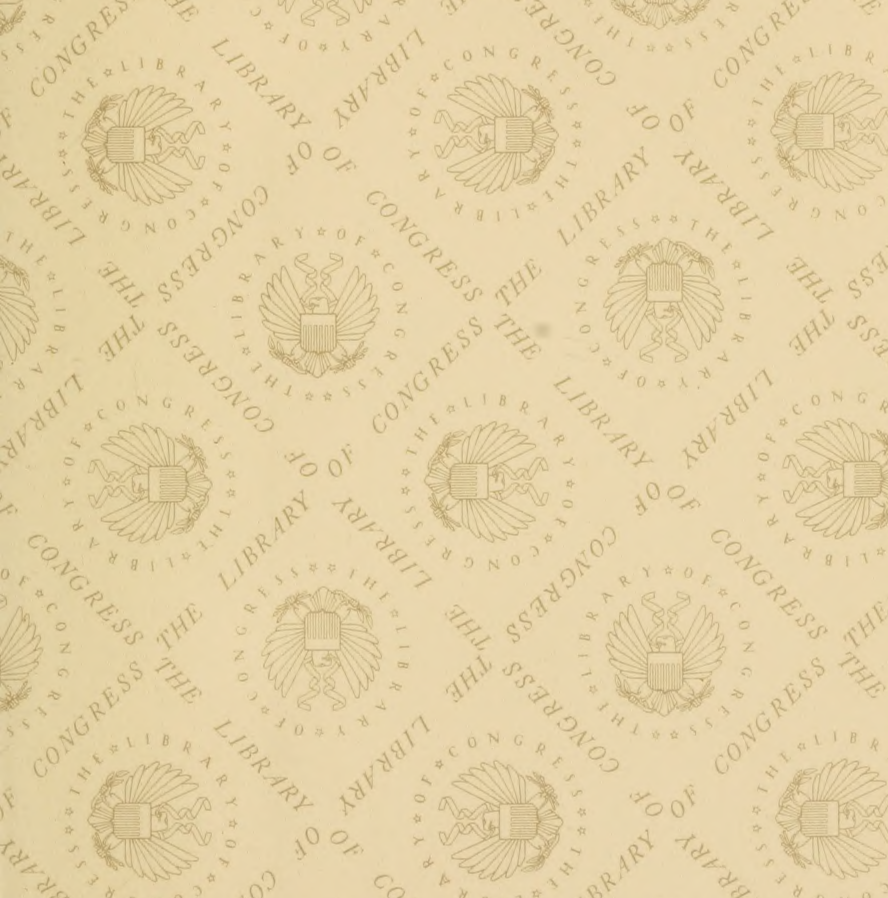

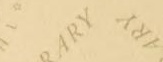

100 $P$

\section{Fon स 3}




T H ${ }^{\circ} \mathrm{E} \quad \mathrm{F}$ A R M。 


\section{PUBLICATIONS OF GE0. E. \& F. W. WOODWARD,}

\section{PARK ROW, N. Y. \\ Woodward's Country Homes.}

A practical work, with 122 Designs and Plans of Country Houses of mederate cost, with illustrated description of the manner of constructing Balloon firames. Extra binding. $\$ 1.50$.

\section{Woodward's Graperies and Horticul- tural Buildings.}

A practical work on the Design and Construction of all classes of Buildings for Growing Plants and Ripening Fruit under Glass. 60 illustrations. $\$ 1.50$.

\section{The House.}

A New Manual of Rural Architecture; or, How to Build Dwellings, Barns, Stables and Out-Buildings of all kinds. With a Chapter on Churches and School-Houses. Cloth. $\$ 1.50$.

\section{- The Garden.}

A New Mandal of Practical Horticulture; or, How to Cultivate Vegetables, Fruits and Flowers. With a Chapter on Ornamental Trees and Shrubs. Cloth. $\$ 1.00$.

\section{The Farm.}

A New Manual of Practical Agriculture; or, How to Cultivate all the Field Crops. With an Essay on Farm Management, etc. Cloth. $\$ 1.00$.

\section{The Barn-Iard.}

A New Manual of Cattle, Horse, an? Sheep Husbandry; or, How to Breed and Rear the Various species of Domestic Animals. Cloth. $\$ 1.00$.

Either of the above sent post-paid on receipt of price.

\section{ESTABLISHED 1846. \\ TTI I I ORTCUITURIST.}

Two Dollars and fifty Cents per Annum.

\section{A MONTHLY MAGAZINE}

For every one who has a grapevine, a city yard, an acre lot, a garden, a vineyard, an orchard, a country seat, a farm, who has a house to build, outbuildings to erect, or a home to embellish and beautify.

GEO. E. \& F. W. WOODWARD, Publishers, No. 37 Park Row, N. Y. 


\section{THE FARM:}

\section{A M A N U A L}

\section{quatical \\ Agriculture;}

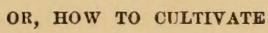

\section{ALL THE FIELD CROPS:}

\section{EMBRACING}

A THOROUGH EXPOSITION OF THE NATURE AND ACTION OF SOILS AND MANURES THE PRINCIPLES OF ROTATION IN CROPPING; DIRECTIONS FOR IRRIGATING, DRAINING, SUBSOILING, FENCING, AND PLANTING HEDGES; DESORIPTIONS OF AGRICULTURAL IMPLEMENTS; INSTRUCTIONS IN THE CLLTIVATION OF THE VARIOUS FIELD CROPS, OROHARDS, ETC., ETC. ;

WITH A MOST VALUABLE

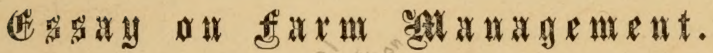
BY D. H. JACQUES,

Author of "The Garden," "The House," "Domestic Animals," "How to do Business," "How to Behave," eto.

To render agriculture more productive and beneficisl to all, it is necessary that its principles should be better understood, and that we should profit more from the experience of each other.

JUDGR BURL.

エEVISED EDITION.

iNew $\mathfrak{0} \mathfrak{o r k}$

G E O. E. \& F. W. WO O D W A D, No. 37 Park Row, Office of "The Horticulturist." 1866. 
Entered, according to Act of Congress, in the year 1866 , by D. H. J A C U E S,

In the Clerk's Office of the District Court of the United States for the Southern District of New York.
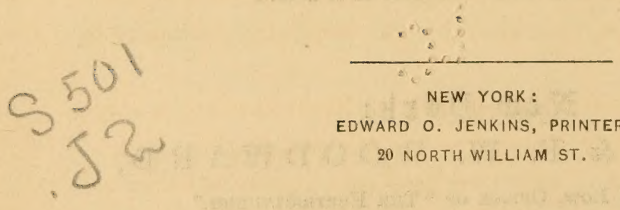

EDWARD O. JENKINS, PRINTER,

20 NORTH WILLIAM ST. 


\section{PREFACE.}

Becreving that good books on farming can hardly be too greatly multiplied, and that a cheap manual, embodying not only comprehensive practical directions for the cultivation of the various field crops, but also a brief exposition of the fundamental principles which underlie all the operations of the farm, is a special want st the present time, we have essayed, in the wurk now before the reader, to supply this lack. How well we have succeeded, we leave it for the public to judge.

In the details of cultivation we have been intentionally brief, because we believed that the mass of those ints whose hands this book would fall, stand less in need of these than of the information condensed into the first six or seven chapters.

Having a correct notion of the fundamental principles of agricultural science, and with clear outlines of the common practical operations of farming before him, any intelligent man will readily, by means of observation and experience, make himself master of the minor details. Without the theoretical part, the rules of practice laid down in most agricultural works are liable constantly to lead astray.

In the preparation of this little book we have consulted a large number of the best agricultural works-American, English, French, and German-to some of which we have been largely indebted for facts and suggestions. In addition to the formal credit given in the body of the work, we take pleasure in mentioning the following 
works as among those from which we have received more or less valuable aid :

Stephens' Bools of the Farm.

The American Farmer's Encyclopedia.

Allen's American Farm Book.

Agricultural Reports of the Patent Office.

Fessenden's Complete Farmer.

Thaer's Principles of Agriculture and Manures.

Beatty's Southern Agriculture.

White's Gardening for the South.

Norton's Scientific Agriculture.

Dana's Muck Manual.

Boussingault's Economie Rurale.

Downing's Fruits and Fruit Trees.

Munn's Practical Land Drainer.

Tucker's Annual Register.

Harris' Rural Annual.

The Country Gentleman.

The American Agriculturist.

The Southern Cultivator.

Hoping that his little book will aid largely, in its humble way, iu the promotion of agricultural progress, and prepare the way for many a larger and better work, the author most respectfully dedi. cates it

TO THE YOUNG FARMERS OF AMERICA. 


\section{IN T R O D U C T I ON.}

Agrictlture may be said to have had its origin when it was ordained that man should earn his bread by the sweat of his brow. From that time to the present, among all nations and tribes of men, more or less attention has been given to the cultivation of the earth; although in the earlier stages of social progress the principal reliance of mankind for subsistence has been first upon the chase, and then upon flocks and herds. Man is first a hunter, then a shepherd or herdsman, and then a farmer.

Of the existence of agriculture as one of the prominent occupations of the people among the ancient Israelites, we have many notices in the Bible. We gather from various scattered passages in the books of sacred history and prophecy that they had plows; that they turned the soil up into ridges; that they plowed with two oxen; that they sowed the seed broadcast from a basket and plowed it in; that they used hoes or mattocks for extirpating the weeds; that when the grain was ripe they cut it with a sickle or a scythe; that it was bound into sheaves and carried in carts immediately to the threshing floor or to the barn; that threshing was variously performed by means of a threshing-machine or instrument (Isaiah xviii. 27,28 ), cart wheels, the treading of horses and cattle, and beating with poles; and that the grain was winnowed by being thrown up against the wind by means of a shovel.

Among the ancient Greeks, agriculture received great attention, and was evidently conducted with great skill and success; in fact, it seems to have been much the same thing as at the present day, our superiority consisting more in the improved implements we use than in our better knowledge of the art and science of cultivation. 
The Romans probably derived their knowledge of agriculture from the Greeks and other older nations, adding to it from their own experience. They well understood the nature of soils and the use of manures, and practiced irrigation and underdraining. The lioman farmers, Pliny tells us, were very particular in drawing straight and equal-sized furrows. They always plowed three times at least before they sowed. The furrows in the first plowing were usually nine inches deep.

In the early days of Rome, when they praised a good man they called him an agriculturist and a good husbandman; and he was thought to be very greatly honored who was thus praised.

The first of modern countries to improve the practice of agriculture was Flanders; and the Flemings or Belgians have continued to this day the model farmers of Europe. Their whole country resembles a series of gardens Their farms are small, and they devote their efforts to three grand points-the accumulation of manures, the destruction of weeds, and the frequent and deep pulverization of the soil. They were the first among the moderns to raise crops for the purpose of plowing them in.

Nowhere at the present time is agriculture pursued with greater skill and success than in England; and there is in that country a steady and continued progress both in the science and the art of cultivation.

American agriculture commenced at the point which that of England had reached at the time her colonies were planted on the shores of the Western Continent. It has not kept pace, we are sorry to say, with that of the mother country. A virgin soil, abounding in all the elements of the highest fertility, and requiring at first but slight tillage to produce large crops, the abunclance and cheapness of new lands, and the lack of persistent, steady effort, which soon became an American characteristic, led at once to a superficial and exhausting mode of cultivation which has resulted in reducing thousands of acres of once fertile soil to a barren wilderness.

But there has been a reaction. American husbandry is now 
rapidly improving, and we shall not long be left behind by the leading agricultural nations of Europe. The old or exhaustivo system is giving place to the new or fertiiizing system, under which the productiveness of lands is constantly increased instead of being diminished. The worn-out lands of Virginia and the other old States have, in many instances, under the new system, been restored to more than their original fertility. This will go on till the older States will rival, if not excel, the new in productiveness.

The conditions requisite for the improvement of agriculture, and the elevation of the agriculturist to the high social position to which his contributions to the general welfare and the prosperity of the State entitle him, are thus happily stated by Hon. L. Chandler Ball, in a late agricultural address:

"1. By adopting a higher standard of education, both general and professional.

“ 2 . By a more thorough cultivation of the soil, by which its fertility shall be increased, and permanently maintained.

" 3 . By the more general introduction of improved implements of husbandry, by which farm and household labor may be more easily and more economically performed.

“ 4. By improving the breeds of domestic stock, and rearing only those animals which are the best of their respective kinds.

"5. Iy growing only those roots, grains, grasses, and fruits which are the most nutritious and the most productive.

“6. By pursuing that particular branch of industry which gives the strongest probabilities of success; having reference to climate, soil, markets, and amount of foreign and domestic competition.

“ 7 . By making the business of farming attractive to educated men, and the farm-house and all its surroundings pleasant th refinel taste and cultivated manners."

The extensive demand for books on farming, and the wide circulation of agricultural papers and magazines, show that " a redeeming spirit" is truly abroad among our farmers. The vast amount of sound agricultural teachings which is now being almost univer- 
sally diffused, can not fail to show itself everywhere in a rapid and permanent improvement of our system of cultivation.

But much still remains to be done. Ignorance and prejudice are obstinately blind and deaf. There is much of both to be yet overcome. We send this little book out into the world to aid as it may in the work. 


\section{0 N T E N T S.}

\section{I-SOILS.}

Importance of the Subject-The Organic and the Inorganic Parts of SoilsOrigin of Each-Classification of Soils-Heavy Soils-Light Soils-Crops adapted to Each Sandy Soils-Ciayey Soils-Limy Soils-Loamy SoilsMarly Soils-Alluvial Soils-Vegetable Molds - Subsoils-Analysis of Soils - Professor Johnson's Tabular View-The Causes of Fertility and of Barrenness-How to Ascertain the Per-centage of Sand in any Soil-A Test for Lime-Physical Properties of Soils-Texture-The Value of the impalpable Powder in Soils-A Mechanical Analysis-Consistency of Soils-Depth of Soil-Colors of Soils-Humidity-Influence of Subsoils-Position and Form of Surface-Improvement of Soils-Management of Clayey Soils-Draining -The Addition of Sand, Lime, Plaster of Paris, etc.-Fall Plowing-Paring and Burning-Management of Sandy Soils-Vegetable or Peaty Soils-Management of Subsoils-Subsoil Plowing-Benefits of Subsoiling......Page 13

\section{II.-MANURES.}

Necessity of Manures-Why the Soil of a Forest does not become ExhaustedExhaustion of Cultivated Soils-Decrease of Productiveness of the Soils of New York-Instructive Facts-Land, like Animals and Plants, must be Fed-Food of Plants-Organic and Inorganic Substances found in PlantsBoth made up from their Food-Where Plants obtain their Food-What the Different Crops Take from the Soil-A Tabular View-Classification of Manures-Vegetable Manures-Green Crops as Manures-Advantages of Green Manures-Straw, Leaves, etc--Sea-Weed-Composition of Sea-Weed-Cotton Seed-Turf-Swamp Muck-Great Value of Muck-Muck and Ashes-How to Compost Muck-Animal Manures-Stable Manures-Value of Urine-How to Preserve and Apply it--Waste of Manures by Fermentation-How to avoid it -Hog Manure-The Manure of Fowls-How to Treat it-Guano-Composition of Guano-Fish Manures-Night Soil-How to Preserve and Compost Night Soil-Flesh, Blood, etc., as Manures-Bones-Process of Dissolving BonesMineral Manures-Lime-Marls-Green Sand-Gypsum-Major Dickinson's Method of Applying Mineral Manures to Seeds-Common Salt-Other Salts -Ashes-Management of Manures-Fermentation-Overhauling ManuresDrawing Manure in Winter-A Caution in reference to Quicklime-Burying Manure-Importance of Texture-Composts-Irrigation............ 


\section{III.--ROTATION OF CROPS.}

Theory of Rotations-The Three Grand Classes of Crops-The Grain Crops The Root Crops-The Grass Crops-Systems of Rotation-Benefits of Rotation in Cropping-Astonishing Neglect of a Great Source of Profit..Page 45

$$
\text { IV.--DRAINING. }
$$

Bad Effects of Excess of Moisture - How Draining remedies them-Ten Reasons for Underdraining-Conditions Requiring Drainage-Practical DirectionsExamination of the Field-Draining Springy Ground-Direction of DrainsDepth and Distance Apart-Digging-Implements - A Ditcher's Level-Materials and Construction-Brush-Wood Drains-Stone Drains-Different kinds of Stone Drains-Tile Drains-Rationale of their Aetion-Will Draining Pay?-A Farmer's Reply-Some Facts-Estimates-Economy of Tiles 51

\section{V.-FENCES.}

Requisites of a Good Fence-Various kinds of Fence-Stone Fence-The Zigzag Fence-Posts and Rails-The best Wood for Posts-Board Fence The Sunken Fence-The Wire Fence Illustrated-Cost of Wire Fence-Wire Netting-Hurdle Fence-Hedges-Causes of Failure in Cultivating Hedges - The hest Hedge Plants-Directions for Planting and Trimming-IIedges for the South-How to Form a Hedge of Cherokee or Macartney Rose-A Hint or Two-Are Fences Necessary?-No Fences in France, Belgium, etc. -The Ohio Farmer's Opinion ............................... 61

\section{VI.-AGRICULTURAL IMPLEMENTS AND THEIR USE.}

The Plow-Ancient Plows-Modern Improvements-The Eagle Plow-The -Michigan Plow-The Double Mold-Board Plow-The Subsoil Plow-The Harrow The Cultivator-The Horse Hoe-The Field Roller-Seed Sowers -The Horse Rake-Mowers, Reapers, etc.-Conclusion............. 73

\section{VII.-FARM MANAGEMENT.}

Introductory-Capital - Livestock-Implements-Seeds-Labor-Recapitula tion of Estimates - Size of Farm-Laying Out Farms Fences-Gates-Buildings-Choice of Implements--Choice of Animals-Soils and their Management-Manures-Rotation of Crops-Operations in Order of Time-Conclu-

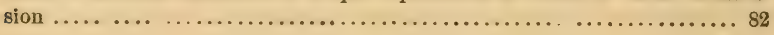

\section{VIII.-FARM CROPS.}

Indian Corn-Wheat-Rye-The Oat-Barley-Rice-Buckwheat-MilletHow to Shock Grain-Potato-Sweet Potato-Turnip-Kohl Rabi-CarrotParsnep-Beet-Chinese Yam-The Grasses-Timothy-Meadow Grass-Red Top--The Feseue Grasses--Orchard Grass-Egyptian Grass-German Millet or Hungarian Grass-The Clovers-Other Grasses-Cotton-SugarCane-Chinese Sugar-Cane-Imphee-Broom Corn-Flax-Hemp-

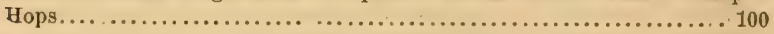

\section{IX.-THE ORCHARD.}

Laying Out Orchards-Squares-Quincunx-Soil and Situation-PlantingCultivation-Profits of Apple Culture...................... 14c 


\section{T H E F A R M.}

I.

\section{SOILS.}

For the reason that a plant wonld die in a vacuum, for the same reason it would die in a sol destitute of the bases necessary for its organic constitution. . . . For to live is to com. bine, and without elements no combination would be postible.-liaspail.

\section{I.-CLASSIFICATION OF SOILS.}

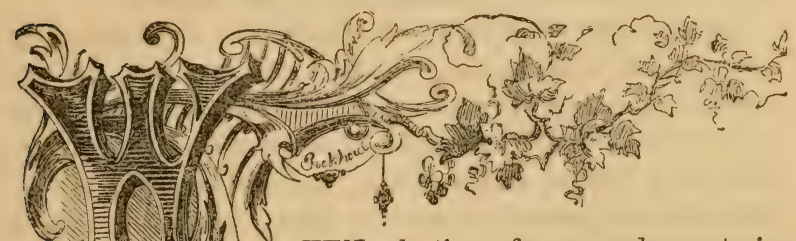

HEN selecting a farm, or when entering upon the cultivation of one already in possession, the farmer should, first of all, turn his attention to an investiga-

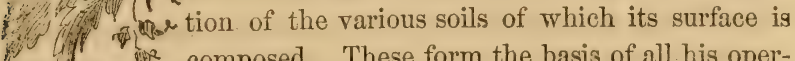
(ail a composed. These form the basis of all his operin degree upon the skill with which he avails himself of the capabilities and adaptations of each. He should be familiar with their several characteristics, understand the various methods of improving them, and know to what crops each is best adapted. To aid him in this investigation is the object of this chapter.

All soils adapted to agricultural purposes are composed of two classes of substances--organic and inorganic. The inorganic 
parts are derived from the decay of animal and vegetable inat ter. There must have been a time, in the geological history of the earth, when the soil was destitute of these elements. A low grade of animal and vegetable life was possible without them. Living things found nourishment in the crumbled rocks, which formed the primitive soil. Enriched by their decay, it became capable of sustaining a higher order of existence. The result gradually attained, we see in the present condition of the earth's surface.

The organic part of the soil is generally called vegetable mold, but scientific writers designate it as humus. To be fertile, a soil must contain a considerable portion of this organic matter; but we know of no rule by which to determine precisely what quantity is essential. Probably from five to ten per cent. must be present in all permanently rich, strong soils.

Besides ministering directly to the growth of plants, by furnishing them with a portion of their necessary food, this vegetable mold or humus promotes fertility by improving the texture of the soil, making sandy land more tenacious and clayey land more friable; and by giving it a darker color, and thus increasing its power of absorbing heat. More than fifty per cent. of humus, however, in a moist soil has an injurious effect, rendering it what is called sour.

We have already hinted at the origin of the inorganic portions of the soil, in speaking of the crumbled rocks which nourished the first living things. The process of decomposition or crumbling down is still going on under our eyes. Some rocks crumble very slowly, others more rapidly; but all wear away more or less. Each rock gives its own peculiar character to the soil which it forms.

Of the various soils several distinct classifications may be made. It will be well for us, at the outset, to consider them all as embraced in two grand classes-heavy or light. The distinction indicated by these terms is familiar to every farmer. He knows, too, that it is a predominance of clay which constitutes a soil heavy, and that an excess of sand or gravel makes a 
woil what is called light. We will look at these two classes of soils a little more in detail.

1. Heavy Soils.-Heavy soils, also often denominated cold and wet, are listinguished for their affinity for water, their tenacity, their softness when wet, and their hardness when dry. They are comparatively difficult to cultivate, and require more skill and caution In their management than light soils; but they are generally fertile, and not easily exhausted. They not only hold securely the various solid manures applied to them, till they are required for the support of the growing crops, but greedily absorb the fertilizing gases brought within their reach by the air and the rains. They are admirably adapted to wheat, oats, Indian corn, and the various grasses; hence they are sometimes styled grass lands. They of course exist in great diversity, and vary much in value, but are generally susceptible of being mado highly productive.

2. Light Soils.-Light soils are easily cultivated, friable, dry, and warm; but their porousness facilitates the escape of both the water and the manure applied to them, and renders them liable to drouth and exhaustion. They are particularly adapted to rye, barley, buckwheat, and the tap-rooted plants. The English farmers sometimes distinguish them as turnip soils.

Although soils contain small quantities of a large number of substances, they are chiefly made up of what are sometimes called the three primitive earths-silex (including sand and gravel), clay, and lime. As either of these predominates, it gives its peculiar character to the soil, whence we have the arrangement into three grand classes-silicious, argillaceous, and calcareous, or, in other words, sandy, clayey, and limy soils.

1. Sandy Soils.-A soil containing not less than seventy per cent. of sand may be considered sandy, in the sense in which the term is here used.

2. Clayey Soils.-Clay with a mixture of not more than twenty per cent. of sand forms a clayey soil.

3. Limy Soils.-Limy or calcareous soils are those in which lime, exceeding twenty per cent., becomes the distinguishing 
characteristic. Crlcareous soils may be either calcareous clays, calcareous sands, or calcareous loams, according to the proportions of clay or sand that may be present in them.

4. Loamy Soils.--Loamy soils are intermediate between those denominated sandy and those with predominant clayey characteristics. There are sandy loams, clayey loams, calcareous loams, and vegetabie loams.

5. Marly Soils.--Soils containing lime, but in which the proportion does not exceed 20 per cent, are sometimes called marly.

6. Alluvial Soils.-Soils made up of the washings of streams are called alluvial. They contain portions of every kind of soil existing in the surrounding country, and are generally loany and very fertile.

7. Vegetable Mclds. - When decayed vegetable and animal matter or humus exists in so great a proportion as to give the preduminant character to a soil, it sometimes receives the nam of vegetable mold.

8. Subsoils.-The stratum or bed on which a soil immediately rests is called the subsoil. Subsoils, like soils, may bo either silicious, argillaceous, or calcareous.

\section{II.-ANALYSIS OF SOILS.}

Chemical analysis shows that the organic parts of a soil are composed of carbon, oxygen, nitrogen, and hydrogen. The inorganic parts of a fertile soil, in addition to the silex, clay, and lime, of which we have already spoken, contain smaller quantities of magnesia, p tash, soda, sulphur, phosphorus, chlorine, oxyd of iron, and oxyd of manganese. All these are essentia! to independent fertility.

It may be remasked here, that while chemical science is a highly useful ally of agriculture, its decisions must, for the present, be held subject to reversal by practical experiments. This lack of perfect and universal reliability comes from the imperfection of the most careful analyses, and from the influence of conditions of which chemistry can not take cognizance; and not from the unsoundness of chemical theories. 
Professor J. F. W. Johnson has given the following tabular view of the composition of soils of different degrees of fertility:

\begin{tabular}{|c|c|c|c|}
\hline IN ONE HUNDRED POUNDS. & $\begin{array}{l}\text { Fertice } \\
\text { without } \\
\text { Manure. }\end{array}$ & $\begin{array}{c}\text { Fertile } \\
\text { with } \\
\text { Manure. }\end{array}$ & $\begin{array}{c}\text { Very } \\
\text { Barren. }\end{array}$ \\
\hline 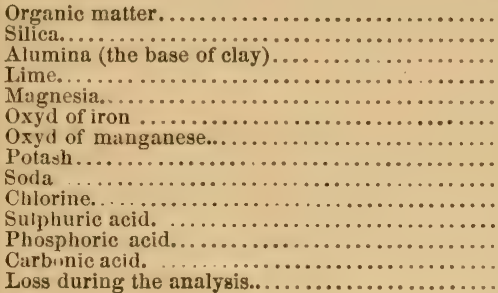 & $\begin{array}{r}9.7 \\
64.3 \\
5.7 \\
5.9 \\
.9 \\
6.1 \\
.1 \\
.2 \\
.4 \\
.2 \\
.2 \\
.4 \\
4.0 \\
1.4\end{array}$ & $\begin{array}{r}5.0 \\
83.3 \\
5.1 \\
1.8 \\
.8 \\
3.1 \\
.8\end{array}$ & $\begin{array}{r}4.0 \\
77.5 \\
9.1 \\
.4 \\
.1 \\
8.1 \\
.1\end{array}$ \\
\hline & 100.0 & 100.0 & 100.0 \\
\hline
\end{tabular}

The soil of which the composition is given in the first column contained all the elements required for the growth of plants, and so long as these remain unexhausted will produce good crops without manure.* Some of the alluvial soils of the West are of this character. They will all be found to contain every one of these constituents. The proportions may vary in soils of equal fertility. This is immaterial, so long as there shall be a sufficient quantity of each to supply the wants of the crop. The soil the analysis of which is recorded in the second column lacked potash, soda, and chlorine. These are essential, and therefore the soil, in its natural condition, was barren; but as these constituents are all supplied in considerable quantity by ordinary manuring, fertility was thus easily attained. In the third column half the inorganic substances present in the first are entirely lacking, and two others-lime and magnesia-are greatly reduced in their proportion. No ordinary manuring would supply all these deficiencies, and therefore the soil was, in a practical point of view, hopelessly barren.

Does not this illustration make the cause of fertility on the 
one hand and of barrenness on the other perfectly obvious! Here it is in the compass of a nut-shell. A soil is fertile (as a general rule) when it contains in sufficient quantity all the substances which plants require, and barren when some of these substances are either entirely wanting or deficient in quantity. The exceptions to the first part of this rule are an unfavorable physical condition and the presence of certain substances in hurtful excess.

The time is coming when every farmer, thoroughly educated at an agricultural college, will possess both the knowledge and the apparatus necessary for making any required analysis of soils, but at present we must, in general, be content with the knowledge of their composition which we are able to obtain by a few simple processes.

To ascertain the per-centage of sand which a soil may contain, dry a quantity thoroughly; weigh it; boil it in water; stir it in a convenient vessel, and when the sand has settled pour off the liquid, which will hold the fine clay, etc., in suspension; after doing this a few times nothing will remain in the bottom of the vessel but nearly pure sand, which may be dried and weighed, and the quantity will show whether the soil be sandy, loamy, or clayey.

Any considerable quantity of lime in a soil is readily detected by pouring upon it a little muriatic acid, which may be obtained at any apothecary shop. So soon as this acid comes in contact with lime, if there be any, a brisk effervescence will take place, owing to the bubbling up and escape of carbonic acid gas. This simple test would save many a farmer from the expensive mistake of applying lime to land which already contains a sufficient quantity of that important element of fertility.

\section{III.-PHYSICAL PROPERTIES OF SOILS.}

In judging of the value of a soil, the nature and proportions of the elements of which it is composed are not the only circumstances to be considered. Its physical properties must also be taken into account. 
1. Texture of Soils.-Considered in reference to tezture, a soil may be described as essentially a mixture of in impalpablo powder with a greater or smaller quantity of visible particles of all sizes and shapes. Now, although the visible particles are absolutely essential, their effects are, as it were, indirect; the impalpable powder alone exerting a direct influence upors vegetation, by entering into solution with the witer and acids with which it comes in contact; for plants are incapable of taking in solid matier however minutely dirided; and it is in s liquid or gaseous form only that their food can be received. From this it will be readily understood how a soil may possess all the elements of fertility and yet be barren, as stated in a provious section, on account of some of these elements being locked up in it, as it were, in an insoluble condition. The stones and smaller visible portions of the soil are gradually but constantly crumbling down under the action of air, moisture, and other chemical agents, thus adling, from year to year, new impalpable matter to the soil. The greater the proportion of this impalpable matter, all other things being equal, the greater will be the fertility of the soil. This proportion may be ascertained with considerable accuracy by the following simple $\epsilon_{;}$.periment:

"Take a glass tube about two feet long, closed at one end; fill it about half full of water, and put into it a sufficient quantity of the soil to be examined to fill two or three inches of the tube at the bottom; then put in a cork, and having shaken the tube well, to mix its contents thoroughly, set it in an upright position for the soil to settle. Now, as the largest particles are of course heaviest, they fall first, and form the undermost layer, and so on in regular gradation, the impalpable powder forming the upper stratum. By examining the various layers and noting their profortions you may make a very good mechanical analysis of soils."

Soils must also be examined in reference to their consistency or tenacity, which is nothing more than the strength with which their molecules or particles are bound to each other by what is 
called, in the language of natural philosophy, the attraction of cohesion. Clayey soils have the greatest degree of consistency, and sandy soils the least. Both extremes are unfavorable, a medium in this respect agreeing best with vegetation.

2. Depth of Soil.-Another very important point is depth of soil. A deep soil has not only the advantage of giving the roots of plants a wider range and a greater mass of food, but it retains moisture better in seasons of drouth, and is not so readily saturated in rainy weather. For the tap-rooted plants, such as beets, carrots, parsneps, etc., depth of soil is particularly important.

3. Colors of Soits.-Soils are of various colors-black, white, gray, yellow, red, etc., and the effects and indications of these hues are not to be disregarded in estimating the value of land for agricultural purposes. The brown and red soils are generally best. They are termed warm, and are mostly loany and fertile. Yellow and gray indicate clayey soils, which are cold in their nature. Black generally indicates peat or deep vegetable mold. Dark-colored earths absorb heat more rapidly than others, but they also allow it to escape with equal readiness.

4. Humidity of Soits.-Too great moisture is not less injurious to a soil than extreme dryness. The proper medium should be sought, and where land is too wet, thorough underdraining should be practiced. But more on this point in another chapter.

5. Influence of Subsoils. - A subsoil of clay beneath a clayey soil is unfavorable; but beneath a sandy soil it is beneficial, especially if deep plowing and subsoiling be resorted to, for the purpose of improving the latter. On the same principle a sandy or gravelly subsoil is desirable under clayey soils, as it permits the infiltration of any superabundant moisture, and may ameliorate the soil by mixing with it. A calcareous or limy subsoil is beneficial to both clayey and sandy soils.

6. Position and Form of Surface.-The position in which a piece of land lies and the form of its surface increases or detracts from its value aceording to its composition. Sandy soils are 
most fertile when flat and situated lower than the surrounding country. On the declivities of hills, such soil is of less value, as it is liable to become parched by drouths and washed away by rains. Clayey soils, on the contrary, especially where the subsoil is impermeable, are favorably situated when on a hill. side. Southern and eastern exposures are favorable to early vegetation, and in a cold climate or with a clayey soil are very desirable for many crops.

\section{IV.-IMPROVEMENT OF SOILS}

Even the most valuable farms generally contain many acres which require considerable amelioration, aside from ordinary culture and manuring, to bring them into the lighest state of fertility of which they are capable; and the farmer should be well acquainted with the various means and methods to be made use of in improving each kind of soil.

The means of ameliorating soils may be divided into two classes, mechanical and chemical. The former includes draining, trenching, subsoil plowing, paring, the addition of various substances to improve texture, etc.; the latter embraces the various kinds of manures. Practically, however, the two classes run into each other, the mechanical processes leading to chemical changes, and the addition of manures to mechanical improvement.

To draining and manures, separate chapters will be devoted. We will speak here briefly of a few other means of improvement which should not be neglected.

1. Improving Clayey Soils.-One of the principal defects of clayey soils, especially where they rest upon a subsoil of the same nature, is the excess of water which is held in them. The only effectual way, in a majority of cases, to get rid of this is by thorough underdraining. This draws off by imperceptible degrees all the excess of water and opens the soil to the tree admission of the air, which in its passage throngh it imparts warmth and such fertilizing gases as it may contain. Open drains or ditches, though less effectual, are useful. In soms 
cases "water furrows," terminating in some ravine or ditch, serve a very good purpose.

To break the too great tenacity of clayey soils, sand seems to be the ingredient indicated; but so large a quantity is required to produce the desired effect, that its application on a large scale is generally consiaered impracticable. Lime is exceedingly useful as an ameliorator of clayey soils, inducing chemical combinations the mechanical effect of which is to break up the too great tenacity of the clay, while it adds, at the same time, an element of fertility which may perhaps be wanting. Gypsum or plaster of Paris has the same effect in a still more powerful degree. Ashes, coarse vegetable manures, straw, leaves, chips, etc., are also very useful, adding new materials to the soil and tending to separate its particles and destroy their strong cohesion. In cold climates, plowing clayey lands in the fall, and thus exposing them to the action of the frosts and snows, has a beneficial effect. At the South, where there is little frost, and frequent and heavy rains occur during the winter, the effect of fall plowing is very injurious. Clayey lands must never be plowed when wet.

Where a clayey soil rests upon a sandy subsoil its improvement is easier, as deep plowing, by which a portion of the subso:l is turned up and mixed with the soil, soon modifies it very sensibly.

In Europe, paring off the surface containing vegetable matter, drying, and burning it, and spreading the charred mass to which it is thus reduced upon the surface, to become again mixed with it, is frequently resorted to for the improvement of clayey soils; but this process is too expensive to be generally applicable in this country, where labor is so dear and land so cheap.

2. Improving Sandy Soils.-Sandy soils require a treatment in most respects the reverse of that applied to clayey soils. Clay is the great ameliorator, and as the quantity required to produce a lecided beneficial effect is not great, it may generally, when it can be obtained in the immediate neighborhood, be applied with profit. It should be thinly spread in the fall upon sward 


\section{SoILs.}

land previously plowed, so that the frosts of winter may act upon it and separate its particles. The land should be thoroughly harrowed in the spring and subsequently plowed, if necessary.

Lime and gypsum, which render clayey soils more friable, increase the adhesiveness of sandy soils, and when cheaply obtained furnish a profitable dressing. Ashes may also be af plied with great benefit, as may vegetable manures and vegetable mold. Sandy soils are plowed to the greatest advantage when wet, and are improved by the frequent use of a heavy roller. Pasturing sheep upon them is very beneficial.

Gravelly soils (except calcareous gravels) are more difficult of improvement than sandy soils, and are most profitably appropriated to pasturage. Sheep will keep them in the most useful condition of which they are capable.

3. Improvement of Vegetable Soils.--Soils composed mainly of humus or vegetable mold, such as are found on low, swampy levels, and sometimes called peaty soils, are generally, in their natural state, totally unfit for any profitable vegetation. When it is desirable to cultivate such a soil, the first process is to drain from it all the excess of water which it may contain. Then the hommocks, if any, must be cut off, dried, and burned, and the ashes spread over the surface; after which sand, fine gravel, ashes, air-slacked lime, and barn-yard manure should be liberally added. These soils, thus ameliorated, make valuable grass lands, but require subsequent dressings of sand, lime, ashes, etc., as their fertility decreases.

4. Management of Subsoils.-We have already spoken of the benefits resulting from mixing the soil and subsoil by deep plowing, in cases where they are of a different nature. To break up the subsoil and prepare it for mixing, and also to deepen soils and give the roots of plants a greater scope, a variety of subsoil plows have been invented. In subsoil plowing a common plow goes first and is followed in the same furrow by the subsoil plow, which thoroughly breaks up the subsoil to the depth of from twalve to sixteen inches, without displacing it. At subsequent plowings portions of this subsoil are turned up by 
allowing the common plow to run more deeply than before; but care should be taken not to bring it up too rapidly or in toc large quantities.

Besides allowing the roots of plants to penetrate more deeply in search of nutriment and moisture, subsoil plowing, by opening the stratum broken up to the action of the atmosphere, griadually prepares it to become an integral part of the soil, increases its warmth by making it a better conductor of heat, and renders it far less liable to suffer from drouth. This last point is particularly important, as subsoiled lands frequently produce excellent crops in seasons in which those subjected to common plowing alone fail to return even the seed deposited in them. Subsoil plowing should be repeated once in five or six years; going each time a little deeper than before, till the greatest practical depth is attained.

Subsoil plowing is not applicable, however, to all lands. Where the subsoil is loose and leachy, consisting of an excess of sand or gravel, it is not only unnecessary but positively injurious.

The gradual mixing of the subsoil with the soil which results from subsoil plowing is especially beneficial to lands which have been for a long time under cultivation, and have become partially exhausted. A fresh supply of the inorganic elements is thus furnished for the nourishment of vegetation, and new avenues opened to those powerful agents of fertilizing decomposition, the air and the rains.

Where underdraining is required, it should precede the subsoiling, and the surface of the drains should be sufficiently below the surface not to be disturbed by the subsoil plow.

With the exception we have noted, where the subsoil is loose and leachy, subsoil plowing, though expensive, will most certainly "pay," as experience has amply proved.

The subject of improving soils will be continued in the next two chapters, under the heads of Manures and Draining. 


\section{II.}

\section{A N URES.}

Manures, iu som s Sorm, must be considered absolutely essential to sustafning solls subjected co tillage. - Allen.

\section{I.-NECESSITY OF MANURES.}

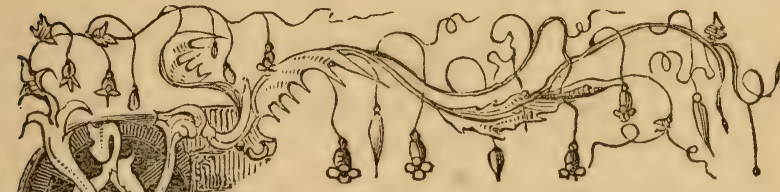

(N) 1 MNHE soils remain covered by unbroken for.. Nidun] ests, they not only retain their fertility, but actually grow richer and richer from year to year, notwithstanding the vast amount of nutritive matter annually absorbed by the roots of the growing trees. Everything thus taken from them is ultimately returned with interest. The leaves and broken twigs, and eventually the branches, trunk, and roots, in their decay, give back not only what they received from the soil, but much, in addition, that they have elaborated from the atmosphere. We receive from the hands of nature no wornout lands; but her system of otillage is very different from ours.

The productive power of soils subjected to cultivation is gradnally exhausted by the process. Some of the alluvial lands of Virginia produced large annual crops of corn and tobacco for more than a century, without any return being made to them for the elements of fertility abstracted; but these lands are $110 \mathrm{w}$ nearly valueless. The secondary "bottoms" of the Scioto and 
Miami may retain an apparently undiminished fertility for a still longer period, but they must ultimately fail, and unless a system of cultivation radically different from that now pursued be adopted, become like the worn-out lands of some of the older portions of the country. Reliable statistical tables prove beyond a doubt that, notwithstanding our improved farm implements and superior methods of cultivation, the average yield, per acre, of the cultivated lands of the State of New York has decreased considerably since 1844, when the records on which these tables are founded were commenced. In corn the decrease is nearly four bushels per acre; in wheat nearly two bushels; and in potatoes, partly owing to the rot, no doubt, twenty-two and a half bushels. The falling off would have been still greater had not deeper tillage and better husbandry furnished a partial offset to the decreased fertility of the soil.

These are instructive facts, and should cause the farmer to pause and reflect.

The fruitfulness of a soil is decreased or increased according to inexorable laws. With each crop that is taken from a plot of ground a greater or less amount of each of the elements of fertility-silex, potash, lime, soda, magnesia, chlorine, etc.-is necessarily removed. Another portion is lost in the process of cultivation independently of what is taken up by the plants. Continue this process year after year, and what must be the result? Ultimate barrenness, of course. There is no remedy but to supply in the form of manures what is thus taken away. The farmer must feed the land which feeds him and so many others, or in the end all must starve together. In the older portions of our country at least, the time has come when the importance of manuring should be more fully appreciated.

\section{II.-THE FOOD OF PLANTS.}

In burning a dried plant of any kind, we find that the greater portion of it is dissipated in the process. Generally only from three to ten per cent. is left. This is in the form of ash or ashes. The portion driven off has evidently disappeared in 
the air, in a gaseous form. It is found by a method of analysis which we can not here stop to describe, that it was composed of four elements-carbon, hydrogen, nitrogen, and oxygen. These are called the organic parts of plants.

An analysis of the incombustible portion remaining shows it to be composed, as a general rule, of these ten substancespotash, soda, magnesia, lime, oxyd of iron, oxyd of manganese, silica, chlorine, sulphuric acid, and phosphoric acid. All these substances are generally present in our cultivated crops, but not invariably; one or two of them being sometimes absent. In some species of plants one of these is wanting and in other species another, and the proportions vary greatly in different species of plants. Of these differences we shall have occasion to speak further under the head of rotation of crops.

Both the organic and inorganic parts of plants are made up from their food, which must of course consist of both organic and inorganic materials. The former are obtained partly from the soil and partly from the air; the latter come exclusively from the soil. A fertile soil must therefore contain, in sufficient quantity and in an available form, all the constituents of plants; and to maintain its fertility under cultivation, these constituents must be supplied in the form of manures so fast as they are taken up by the crops produced.

The food of plants, so far as it is derived from the soil, is all received through the roots in a state of solution; and the roots have, to a certain extent, the power of selecting their food and of rejecting whatever would prove hurtful to the plant. Deleterious agents brought in contact with them may, however, under certain circumstances, be take $\Omega$ up by mere capillary attraction, and the plant thereby poisoned.

\section{III.-WHAT THE DIFFERENT CROPS TAKE FROM THE SOII.}

In examining the ash of the different cultivated plants, wo observe, as we have already hinted, great differences in the proportions in which the various elements exist. The ash from the stem or the leaves of a plant and from the seeds of the same 
plant also varies considerably. The following table gives the composition of our most common cultivated crops :

\begin{tabular}{|c|c|c|c|c|c|c|c|c|}
\hline & $\begin{array}{l}\text { Indian } \\
\text { Corn. }\end{array}$ & Wheat. & $\begin{array}{l}\text { Wheat } \\
\text { Stialw. }\end{array}$ & Rye. & Oats. & $\begin{array}{c}\text { Po- } \\
\text { tatoes. }\end{array}$ & $\begin{array}{l}\text { Tur- } \\
\text { nips. }\end{array}$ & Hay. \\
\hline Carbonic acid... & a trace & - & - & - & - & 10.4 & - & - \\
\hline Sulphuric acid.... & & 1.0 & 1.0 & 1.5 & 10.5 & 7.1 & 13.6 & 2.7 \\
\hline Phosphoric acid .. & 49.2 & 47.0 & 3.1 & 47.3 & 43.8 & 11.3 & 7.6 & 6.0 \\
\hline Chlorine .......... & 0.3 & a trace & 06 & - & 0.3 & 2.7 & 35 & 2.6 \\
\hline Lime............ & 0.1 & 2.9 & 8.5 & 2.9 & 4.9 & 1.8 & 13.6 & 22.9 \\
\hline Magnesia ........ & 17.5 & 15.9 & 5.0 & 10.1 & 9.9 & 5.4 & 5.3 & 5.7 \\
\hline Potash ............ & 23.2 & 29.5 & 7.2 & 32.8 & 27.2 & 51.5 & 42.0 & 18.2 \\
\hline Soda............... & 3.8 & a trace & 0.3 & 4.4 & 27.2 & a trace & 5.2 & 2.3 \\
\hline Silica............. & 0.9 & 1.3 & 67.6 & 0.2 & 2.7 & 8.6 & 7.9 & 37.9 \\
\hline Iron....$\ldots \ldots \ldots$ & 0.1 & a trace & 1.0 & 0.8 & 0.4 & 0.5 & 1.3 & 1.7 \\
\hline \multirow[t]{2}{*}{ Loss.................... } & 4.5 & 2.4 & 5.7 & - & 0.3 & 0.7 & - & - \\
\hline & 100.0 & 100.0 & 100.0 & 100.0 & 100.0 & 100.0 & 100.0 & 100.0 \\
\hline
\end{tabular}

With reference to the character of their ash, we may arrange these crops into three grand classes:

1. The grains in which phosphoric acid predominates

2. The roots in which potash and soda abound.

3. The grasses in which lime is an important element.

In straw and the stems of the grasses silica is abundant. constituting from one half to two thirds of the whole weight. The wood of trees gives an ash in which lime is a prominent ingredient. There are particularly large quantities in that of fruittrees.

The foregoing facts furnish hints toward a sound system of manuring, and show how important to the farmer is a knowledge of the composition and mode of action of the various manures.

\section{IV.-CLASSIFICATION AND DESCRIPTION OF MANURES.}

Manure, in the broadest sense of the word, is anything which added to the soil, either directly or indirectly, promotes the growth of plants. All manures might be considered under two heads- organic and inorganic; but it will better serve our present purpose to arrange them in three grand classes, vegetable, animal, and mineral.

1. Vegetable Manures.

Vegetable manures are not so energetic in their action ag 
those of animal or mineral origin, but their effects are more durable; and the wise agriculturist will avail himself largely of the cheap means of ameliorating his soil which they afford.

1. Green Crops.-Plowing in green crops, such as clover, spurry, sainfoin, buckwheat, cow-peas, turnips (sown thickly), Indian corn, etc., is one of the best modes of renovating and sustaining a soil. Worn-out-lands, unsalable at ten dollars an acre, have by this means, while steadily remunerating their proprietors by their returning crops for all the outlay of labor and money, been brought up in value to fifty dollars an acre.

For the Northern States red clover has been found best fitted for a green manure; but in particular cases some other crop may be used with greater advantage. At the Sonth, the cowpea (which is no pea, but a bean) is considered the best fertilizer. R. L. Allen, in the "American Farm Book," says, "The advantages of green manures consist mainly in the addition of organic matter which they make to the soil. The presence of this aids in the liberation of those mineral ingredients which are there locked up, and which, on being set free, act with so much advantage to the crop. The roots also exert a power in effecting this decomposition, beyond any other known agents, either of nature or art. Their minute fibers are brought into contact with the elenents of the soil and they act upon them with a force peculiar to themselves alone. Their agency is far more efficacious for this purpose than the intersest heat or strongest acids, persuading the elements to give up for their own use what is essential to their maturity and perfection. By substituting a crop for a naked fallow, we have all the fibers of the roots throughout the field, aiding the decomposition which is slowly going forward in every soil.

"Clover and most broad-leaved plants draw largely for their sustenance from the air, especially when aided by the application of gypsum. By its long tap roots, clover also draws much from the subsoil; as all plants appropriate such saline substances as are necessary to their maturity, and which are brought to their roots in a state of solution, by the up-welling 
moisture from beneath. This last is frequently a great source of improvement to the soil. The amount of carbon drawn from the air in the state of carbonic acid, and of ammonia and nitric acid, under favorable circumstances of soil and crop, is very great; and when buried beneath the surface, all are saved and yield their fertility to the land; while such vegretation as decays on the surface loses much of its value by evaporation and drainage. In the green state, fermentation is rapid, and by resolving the matter of plants into their elements, it fits the ground at once for a succeeding crop."

The proper time to turn in most plants used as green manure is at the season of blossoming.

The same effects follow the plowing of grass lands, and turning under the turf; and the thicker and heavier the sward the better, since then a larger amount of organic matter in the form of roots is added to the soil.

1. Straw, Leaves, etc.-Straw, leaves, hay are usually applied to the lands after they have either been worked over by animals and mixed with their manures, or composted with other substances and decomposed; but clayey soils are benefited by their application in an undecayed state.

Potato tops or hanlm; bean haulm; weeds, pulled before they have seeded, and all kinds of vegetable refuse, are readily decomposed by the addition of a small quantity of animal substances or lime, and should be carefully composted.

3. Sea-weed.-Sea-weed and pond-weed form valuable manures. The former is particularly rich in the substances most needed by our crops, the ash containing, according to Professor Johnston, the following constituents and proportions :

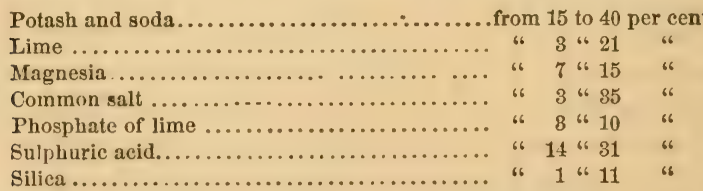

Farmers who live near the caast should embrace every op. 
portunity of getting it. It may be plowed in green or applied as a compost. In either case, it decomposes very rapidly, and its effects are immediately seen.

4. Cotton Seed.-At the South, cotton seed is much used as a manure, and is very valuable for that purpose. It is applied at the rate of from eighty to a hundred bushels per acre. It may be sown broadcast and plowed in during the winter, when it will rot before spring, or it may be left in heaps to heat till its vitality is destroyed, when it may be thrown upon the corn hills and covered with the hoe or plow.

5. Turf, MFuck, Mrud, etc.-Pich turf, full of the roots of the grasses and decayed vegetable matter, is valuable as an absorbent of animal or other manures in compost heaps. Mixing it with lime, and leaving it several weeks to decompose, is a good preparatory process.

Swamp muck, pond mud, and the scourings of old ditches, are exceedingly rich in vegetable matter, and may as well be mentioned here as anywhere else. These are all exceedingly useful as manures; but differ in richness according to the circumstances under which they have been formed. When there is no outlet for the water and sediments, and the mud, besides containing a large proportion of salts, the result of ages of evaporation, is the receptacle of the remains of myriads of minute shell-fish, animalculæ, infusoriæ, and the spawn and exuvia of frogs and other occupants, the mud is especially valuable. Such reservoirs of vegetable nutrition are mines of wealth to the farmer, if judiciously applied.

Dana, in his valuable "Muck Manual," says:

"The salts of geine* in a cord of peat are equal to the manure of one corv for three months. It is certainly very curious that Nature herself should have prepared a substance whose agricultural value approaches so near to cow-dung, the type of manures. Departing from cow-dung, and wandering through

Geine, in its agricultural sense, includes all the decomposed organic mato ters of the soil. In some form it is absolutely essential to agriculture. 
all the varieties of animal and vegetable manures, we land in a peat-bog. The substance under our feet is analyzed, and found to be cow-dung, without its musky breath of cow odor, or the power of generating ammonia, except some varieties of peat. .... The power of producing alkaline action on the insoluble geine is alone wanting to make it equal to cow-dung."

According to this statement, we have but to add an alkali in the proper proportion, to produce a manure equally valuable with cow-dung. From sixteen to twenty-four bushels, according to their strength, of wood ashes, or about sixty pounds of soda ash, will supply in full the lacking elements; but as clear cow-dung may proitably be mixed with two parts of loam or muck, so two thirds of the alkali may be omitted from the muck mixture, to make it correspond with the cow-dung compost.

"The best plan," Dana says, "for preparing the artificial manure, is to dig the peat in the fall, and mix it in the spring with eight bushels of common house ashes or twenty pounds of soda ash to every cord of muck, estimating the quantity when fresh dug, and making no allowance for shrinkage. If ashes be used, they may be mixed at once with the muck, but the soda ash should be dissolved in water and the heap evenly wet with it. In either case it must be well shoveled over. If leached or spent ashes be used, add one cord to three cords of the muck."

The salt and lime mixture, described in another section, may be added to muck in the proportions of four bushels of the misture to one cord of the muck, making a very effective manure; or the latter may be composted with stable manure or any animal matter found about the house or barn.

\section{Animal Manures.}

These comprise the flesh, blood, hair, bones, horns, excrements, ete., of animals. They contain more nitrogen than veg. etable manures, and are far more powerful.

1. Stable Mlunures.-The standard manure of this country is that from the stable and barn-yard. The principal varieties 
are those of the ox, the cow, the horse, and the sheep. Of these, that of the horse is the most valuable in its fresh state, bui is very liable, as ordinarily treated, to lose much of its value by fermentation; that of the sheep comes next; while that of the cow is placed at the bottom of the list, because the enriching substance of her food goes principally to the formation of milk. That of the ox is better. The value of each of these manures varies also with the food and condition of the animals from whom it is obtained.

The manure of any animal is richer than the food given to it, because it contains, in addition to the residuum of the food, certain particles belonging to the body of the animal. The extent to which it is animalized depends upon the thoroughness of the digestion, fatness of the animal, and the drain made upon the elements of nutrition by the system. The manure of well-kept cattle, it is readily seen, is far more valuable than that from those which are barely kept alive.

All the urine, as well as the solid excrements of animals, should be carefully preserved. It is rery rich in nitrogen and the phosphates, and some writers on agriculture contend that its value, if properly preserved and applied, is greater than that of the dung. From an experiment made in Scotland, it appears that in five months each cow discharges urine which when absorbed by loam furnishes manure enough of the richest quality and most durable effects for half an acre of ground. Think of this, ye American farmers, who are accustomed to allow so much of this richness to run to waste! The urine of three cons for one year is worth more than a ton of guano, which would cost from fifty to sixty dollars! Will you continue to wasto urine and buy guano? Various methods of preserving aná applying it will suggest themselves to the intelligent farmer. Stables may be so constructed that the liqiuid discharges of the cattle, together with the wash of the barn-yard, may be conducted to a tank or cistern, to be pumped out and applied directly to the land, or absorbed by saw-dust, charcoal dust, turf, etc., and used in that form. If allowed to stand long in the 
tank, in a liquid form, fermentation is liable to take place, and the ammonia to pass off; but a few pounds of plaster of Paris occasionally thrown in will cause the formation of the sulphate of ammonia, which will not evaporate.

But the waste of manures is not confined to thos of the liquid form. The solid excrements of the animals are often left to drain, bleach, or ferment, till the greater portion of their most valuable elements have disappeared. Stable manures should be sheltered from the sun and rain, and fermenting heaps so covered with turf or loam as to prevent the escape of the fertilizing gases. Plaster, as in the case of urine, will aid in retaining the ammonia. Boussingault, one of the most accurate of experimenters in agricultural chemistry, states that while the nitrogen in fresh horse-dung is two and seven tenths per cent., that in the fermented and dried dung is only one per cent. Horse-dung should be mixed at once with other manures, or with turf or loam, to retain its full value. The manure of sheep is strong and very active, and, next to that of the horse, is most liable to heat and decompose.

2. Hog Manure.-The manure of swine is strong and valuable. Swamp muck, weeds, straw, leaves, etc., should be thrown into the sty in liberal quantities, to be rooted over and mixed with the dung. In this way from five to ten loads of manuro per annum may be obtained from a single hog.

3. The Manure of Forols, etc.-The excrements of birds contain both the feces and urine combined, and are exceedingly rich in nitrogen and the phosphates. The manure of hens, turkeys, geese, ducks, and pigeons should be carefully collected and preserved. Do not think that because the quantity is small, it is hardly worth the trouble of collection. Professor Norton says that three or four hundred pounds of such manure, that has not been exposed to the rain or sun, is equal ir. value to from fourteen to eighteen loads of stable manure! It may be kept dry, reduced to a powder, and applied as a top dressing; or formed into a compost with muck, turf, decayed leaves, charcoal dust, or other absorbents. If exposed to tho 
weather uncovered, much of its value is quickly destroyed. The custom adopted by some farmers of mixing the excrements of fowls with unleached ashes, quick-lime, etc., is not founded on correct principles, and inevitably deteriorates the manure.

4. Guano.-Guano is formed from the excrements of seabirds, mixed with the remains of the fish on which they prey, their own carcasses, and other animal matters. It is found in tropical latitudes, where it seldom rains, and where immense numbers of sea-birds have resorted for ages, to build their nests and rear their young. Here their excrements, etc., have accumulated till beds of from fifteen to thirty feet in thickness have in some instances been formed. Of its value as a manure there can be no doubt; but circumstances must determine whether in any given case it can profitably be purchased and applied at the prices at which it is held.

Professor Norton gives the composition of a few of the leading varieties of guano as follows:

\begin{tabular}{|c|c|c|c|}
\hline VARIETY. & $\begin{array}{l}\text { Wuter, per } \\
\text { cent. }\end{array}$ & \begin{tabular}{|c|} 
Organic Slat- \\
ter aud Am- \\
moniacal Salts.
\end{tabular} & Phosphates. \\
\hline 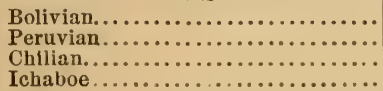 & $\begin{array}{r}5-7 \\
7-10 \\
10-13 \\
18-26\end{array}$ & $\begin{array}{l}56-64 \\
56-66 \\
50-56 \\
36-44\end{array}$ & $\begin{array}{l}25-29 \\
16-23 \\
22-30 \\
21-29\end{array}$ \\
\hline
\end{tabular}

The guano of commerce is often adulterated, and great caution should be exercised in buying it. That purchased directly from the agent in Peru, in New York, may, it is said, be relied npon as absolutely pure.

In applying guano, care should be taken that it do not come in contact with any seed, as it might destroy its vitality.

5. Fish Manures. - These are available near the sea-coast only, where they furnish an important source of fertility, which should not be neglected. The flesh of fish acts with great energy in hastening the growth of plants. It decomposes rapidly, and should be at once plowed under, or made into a well-covered compost heat.

6. Night Soil.-From the analysis of Berzelius, the excre- 
ments of a healthy man yielded-water, 733 ; albumen, 9 ; bile, 9 ; mucilage, fat, and the animal matters, 167 ; saline matters, 12 ; and undecomposed food, 70, in 1,000 parts. When freed from water, 1,000 parts left, of ash, 132; and this yielded-carbonate of soda, 8 ; sulphate of soda, with a little sulphate of potash and phosphate of soda, 8 ; phosphate of lime and magnesia, and a trace of gypsum, 100; silica, 16 .

Human urine, according to the same authority, gives in every 1,000 parts-of water, 933 ; urea, 30.1 ; uric acid, 1 ; free acetic acid, lactate of ammonia, and inseparable animal matter, 17.1; mucus of the bladder, .3; sulphate of potash, 3.7; sulphate of soda, 3.2 ; phosphate of soda, 2.9 ; phosphate of ammonia, 1.6; coinmon salt, 4.5 ; sal-ammoniac, 1.5 ; phosphates of lime and magnesia, with a trace of silica and of fluoride of calcium, 1.1.

Urea is a solid product of urine, and, according to Prout, gives-of carbon, 19.99 ; oxygen, 26.63 ; hydrogen, 6.65 ; nitrogen, 46.65 , in 100 parts. The analyses of Wœhler and Liebig differ immaterially from this. Such are the materials, abounding in every ingredient that can minister to the production of plants, which are suffered to waste in the air, and taint its purity and healthfulness. Boussingault considers the excrements of a single man during a year sufficient to produce fourteen and a half bushels of wheat.

Doubtless much of the waste of night-soil, which has been permitted in this country, has resulted from the offensive odor it imparts and the supposed difficulty of managing it. These difficulties are easily obviated in various ways. Allen, in his "American Farm Book," recommends that tight wooden boxes, with hooks on the outer side, to which a team may be attached for drawing them out, be placed under the privy. These boxes should have a layer of charcoal dust, charred peat, or plaster of Paris at the bottom, and others suceessively as they become filled. These materials are cheap, compact, and read. ily combine with the volatile gases. Sulphuric acid is more eflicient than either, but more expensive. Quick-lime will neutralize the odor, but it expels the enriching qualities; and if it he 
intended to use the night-soil, lime should never be mixed with it. Both the charcoal and peat condense and retain the gases in their pores, and the sulphuric acid of the gypsum leaves the lime, and like the free acid, combines with the ammonia, forming sulphate of ammonia, an inodorous and powerful fertilizer. Raw peat, turf, dry tan-bark, saw-dust, and leached ashes are all good; but as more bulk is needed to effect the object, their use is attended with greater inconvenience. From its great tendency to decompose, night soil should be immediately covered with earth when exposed to the air.

7. Flesh, Blood, Hair, etc.-Dead animals, the blood and offal from slaughter-houses, are among the most powerful of fertilizers-equal to guano and the other costly monures; and yet it is not uncommon to see horses or cattle that die from disease drawn out into the wood to decay on the surface of the ground. Every animal that dies should be made into compost at once. Covered with a few inches of turf or loam, decomposition goes on without the loss of the fertilizing element, and a manure of the most valuable kind is produced. In large animals the flesh should be separated from the bones, and the latter be subjected to one of the processes described in the next section.

Hair, woolen rags, leather shavings from the shoe-shops, and all other refuse animal matters, should be carefully preserved and composted, as they make very rich manure.

8. Bones. - The value of bones as a manure is just beginning to be appreciated in this country. "They unite," Professor Norton says, "some of the most efficacious and desirable organic and inorganic manures." Boiled bones have lost most of their organic parts, but are still very valuable, being rich in phosphate of lime. They are generally crushed to fine fragments in mills, and thus applied to the land. Another way of applying them is in a state of solution, by sulphuric acid (oil of vitriol). Professor Norton thus describes the process of dissolving them:

"To every hundred pounds of bones, from fifty to sixty pounds of the acil is taken; or if bone-dust be used, from twenty-five to 
forty-five pounds of the acid will be sufficient. The acid must be diluted with three times its bulk of water. The bones are placed in a tub and a portion of the acid, previously diluted, poured upon them. After standing a day, another portion of the acid may be poured on; and finally the last on the third day, if they be not already dissolved. The mass should be often stirred. It will dissolve into a kind of paste, which may be mixed with twenty or thirty times its bulk of water, and applied to the land by means of an ordinary water cart; but a more convenient method, in most cases, is to thoroughly mix the pasty mass with a large quantity of coal ashes, earth, sawdust, or charcoal dust. It can then be sown by hand or dropped from a drill machine. Two or three bushels of these dissolved bones, with half the usual quantity of yard manure, will be sufficient for an acre."

Bones make a cheap as well as a rich manure, and no thoughtful farmer will suffer one to be wasted about his house.

\section{Mineral Manures.}

1. Lime.-Lime is applied to land in three different statesas quick-lime, slaked lime, and mild or air-slaked lime. To cold, stiff, newly drained land, especially if there exist in it much of acid organic compounds, it is best to apply quick-lime or caustic hydrate (slaked lime), as it will have a more energetic effect in ameliorating it. On light soils mild or air-slaked lime is considered most beneficial. It is best to apply lime frequently and in small quantities, so as to keep it near the surface and always active.

Lime, as we have seen, is an essential ingredient in soil, being constantly needed by the plants in all their parts. It may always be added with profit wherever it does not already exist in sufficient quantity.

2. Marls.-In true marl the principal element of fertility is the lime which it contains; but its value is increased by the greater or less proportion of magnesia and phosphoric acid which are usually combined with it. 
A valuable mineral fertilizer generally called marl, but which contains comparatively little lime, abounds in parts of New Jersey and Delaware. Its predominant characteristic is a green granular mineral or sand. The carbonate of lime in shells. scattered through it, varies from ten to twenty per cent. in some specimens, while others are almost entirely destitute of it. The secret of its value lies chiefly in the from ten to twelve per cent. of potash which the best specimens contain. Magnesia is also often present. Its effects upon the light sandy soils of New Jersey are very striking indeed.

3. Gypsum.-Gypsum, or plaster of Paris, is a sulphate of lime, and has been found one of the cheapest and most powerful fertilizers derived from the mineral kingdom. In reference to the manner in which plaster acts there has been some controversy among agricultural chemists; some contending that it serves as a direct food of certain plants, while others maintain that its utility is due to its power of absorbing gases and holding them in contact with the roots of plants. Late experiments seem to prove that it acts in both these modes. When scattered over compost heaps, it is known to absorb ammonia and prevent its escape. On grass lands it is best to sow it in damp weather or while the dew is on. Sow broadcast at the rate of a bushel to the acre. Seed potatoes may be wet and rolled in plaster before planting with decided advantage; and we know of no better way of applying it to corn than to give the seed a coat before putting it in the ground. Hon. A. B. Dickenson's mode of applying plaster, lime, etc., is an excellent one. We insert his directions as given in one of his inimitable agricultural addresses: "I will tell you how you can put a coat of tar over all kinds of seed as evenly as a painter could put a coat of paint over a board with his brush. An iron kettle is the best to mix the tar and water. Have sufficient boiling water to cut the tar; mix it with the hot water; then pour in sufficient cold to make it near blood heat. Have sufficient water to stir whatever grain you put in, that the water and tar may come into eontact with every part and particle; it will then be coated 
evenly and is ready to be taken out. Shovel it into a basketfor economy the basket may be placed over a tight barrel tc catch the water; as soon as it is done draining, throw into a tight box, where you can mix and put on whatever your soil lacks. If wheat or barley, you need not fear to apply lime and salt. If oats, corn, or buckwheat, plaster and salt. And on the soils of Yates County it would be beneficial to all of the above-named grains, to steep in strong brine over night. Every species of grass seed I sow with a heavy coat, and fasten as much plaster as possible, which draws moisture in a dry season, and prevents rotting in an excessively wet one, and I never fail to have my grass seed take well."

4. Common Salt, etc.-Common salt or chloride of sodium has been in use for ages as a fertilizer, and its great value can not be disputed. As an ingredient in compost, it is of great service, and operates with an influence upon the soil which can be produced by no other stimulant, either mineral or vegetable. As to top dressing for grass lands - especially those of a loamy texture-it is invaluable. Mixed with wood ashes and lime, in the proportion of one bushel of salt to three of ashes and five of lime, it constitutes a very energetic manure for Indian corn -producing an early and vigorous germination of the seed, and acting as an efficiert protection against the ravages of the various insectivorous enemies by which the young plants are too frequently infested and destroyed.

A very useful and energetic mixture is made by the following simple process :

"Take three bushels of unslaked lime, dissolve a bushel of salt in as little water as will dissolve it, and slake the lime with it. If the lime will not take up all the brine at once--which it will if good and fresh burned-turn it over and let it lie a day and add a little more of the brine; and so continue to do till it is all taken up."

This mixture will supply plants with chlorine, lime, and soda, all of which are essential ; destroy the odor of putrefying animal matters, while it rotains the ammonia, and promotes the de. 
composition of vegetable and animal matters in the soil or compost heap to which it may be applied. The farmer should keep a quantity of this mixture constantly on hand.

Brine which has been used for salting meat or fish is still more valuable than that newly made, as it contains a portion of blood and other animal matter.

Whenever refuse nitrate of potash-that is, common saltpeter-or refuse liquid in which it has been dissolved for pickling meat, can be procured, it should be carefully preserved and mixed into a compost heap.

There are various other salts which are valuable as manures, but the high price at which they are sold precludes their use in ordinary cases.

5. Ashes.-Ashes, as we have seen, compose the entire inorganic parts of plants. Returned to the soil, they may again bo taken up by the growing vegetation. Their great usefulness as a manure is evident and undisputed. The ashes from different trees differ materially in composition and value; but all are highly useful applications to every kind of soil and crop. Johnston gives the composition of the ash from oak and beech as follows:

\begin{tabular}{|c|c|c|}
\hline PER-CENTAGE OF & Oak. & Beech. \\
\hline 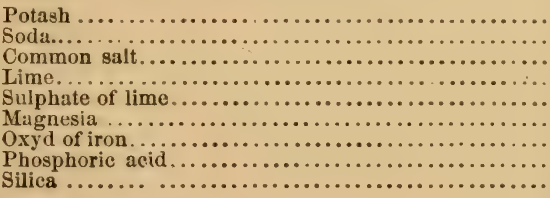 & $\begin{array}{r}8.43 \\
5.64 \\
0.02 \\
74.63 \\
1.98 \\
4.49 \\
0.57 \\
3.46 \\
0.78\end{array}$ & $\begin{array}{r}15.83 \\
2.79 \\
0.23 \\
62.37 \\
2.31 \\
11.29 \\
0.79 \\
3.07 \\
1.32\end{array}$ \\
\hline & 100.00 & 100.00 \\
\hline
\end{tabular}

"Ashes," Allen observes, "are to the earthy part of vegetables what milk is to the animal system, or barn-yard manures to the entire crop; they contain every element, and generally in the right proportions, to insure a full and rapid growth."

Leached ashes have lost some of their value, being depriver 
of the greater portion of their potash and soda, but are still very useful as manures.

Coal ashes are less valuable than wood ashes, but are by no means to be neglected by the farmer.

Soot is exceedingly valuable as a manure, and the small quantity produced should be carefully saved.

\section{IV.-MANAGEMENT OF MANURES.}

Great skill and care are requisite in the management of manures, in order to preserve them from waste and secure their greatest efficiency. Some hints on this point have already been dropped in speaking of the different kinds of manure. We have room for only a few additional suggestions.

1. Fermentation.-The comparative advantages of using fermented and unfermented manure is still under discussion among scientific agriculturists; but that great loss takes place when manure ferments uncovered by some absorbent of the fertilizing gases is clear to every observer and thinker. See to it, then, that all fermenting manure is covered with turf, muck, charcoal dust, saw-dust, or plaster, to take up and retain the ammoniacal gases as they arise.

2. Digging over Manures.-The frequent digging over of barn-yard manure, practiced by some farmers, while it promotes decomposition, also leads to great waste.

3. Hauling Manure in Winter.-The opinion is now gaining ground that when it can be conveniently done, the best way to secure to the land the greatest possible benefit from stable and barn-yard manure is to draw them at once, so fast as they are produced, to the fields where they are to be used, and either spread them at once or deposit them in heaps so small that no putrefactive fermentation will take place. In many cases, manures may be hauled in the winter with great economy, as the labor of the teams and hands is in less demand elsewhere. A correspondent of one of our agricultural journals, who hauled and spread a part of his manure in the winter and a part immediately before planting, in May, says : 
"Where the manure was applied in the winter, the corn started earlier and continued ahead through the season; it also yielded the heaviest growth and the largest, soundest ears. I have followed this plan at different times, and have always been pleased with the result. In hot weather, I plow the manure under immediately after spreading."

4. A Caution.-Neser mix quick-lime with any animal manure, as it will cause the escape of ammonia and greatly deteriorate the manure.

5. Burying Manure.-Here again doctors disagree. Some advocate burying manure very deeply, others slightly, and still others would leave it upon the surface. The best general rule, we believe, is to mix it so thoroughly as possible with every part of the soil. The roots will then be sure to find it. A few crops-onions and some of the grasses, for instance-must find their nutriment near the surface, as the roots do not extend deeply; for these a top dressing may be best.

6. Importance of Texture.-J. J. Thomas, in an excellent article on the "Effective Action of Manures," says:

"Far more important than the mere presence of fertilizing ingredients, or even the chemical condition of those ingredients; in many cases, is their mechanical texture and degree of pulverization. We have elsewhere given an instance, furnished by one of the most eminent scientific and practical cultivators of our country, where the complete crushing of the clods of an adhesive soil, and the grinding together with them into powder the manure applied to the land, produced an effect upon the subsequent crop five times as great as the ordinary operation of manure. How absurd it must be to make strict calculations on the result of a given quantity of yard manure, without ever inquiring into the mode of application-whether, on the one hand, by spreading in large, unbroken lumps, carelessly and imperfectly plowed under, and in a condition wholly useless for plants, or even detrimental in case of drouth-or, on the other, by a thorough harrowing of the soil and manure together, before turning under and a repetition of the operation when 
necessary afterward for complete intermixture. We have known the most admirable results by this practice, where nothing but fresh, coarse manure could be obtained for succulent garden crops, and nearly a total failure under like circumstances without its performanes. Even the time of year that manure has been carted un the land, has sometimes had an injurious bearing on the surcesg of its application, simply by the packing and hardening resulting from traveling over its surface when in a wet and adhesive condition. It is a perfectly self-evident. truth, that a mix'c tre of unburned bricks and clods of manure, would afford immeasurably less sustenance to the fine and delicate fibers of growing plants, than the same mixture ground down together ir.t, a fine powder. Hence it may be reasonably believed that the general introduction and free use of pulverizers, as the most effective harrows, clod-crushers, and subsoilers, assisted by tile-draining, may be of greater benefit to the whole country than the importation of a million tons of guano."

\section{V.-COMPOSTS.}

Composts of various kinds have already been recommended and described; but a few words more:

Let nothing that is capable, when decomposed, of furnishing nutriment to your growing crops be permitted to go to waste about your premises. A compost heap should be at hand to receive all decomposed refuse. The best basis for this heap is well-dried swarp muck; but where this is not readily obtained, procure rich turf scraping from the roadside, leaves and - surface soil from the wood lands and the sides of fences, straw, chips, corncobs, weeds, etc., aiding the decay of the coarser materials by the addition of urine or the lime and salt mixture mentioned in a previous section. Let this be composted with any animal matter found about the premises, or in the vicinity : the carcasses of all dead animals, large or small, offal of every kind, woolen rags, bones, old boots, shoes, and waste leather of every description, the droppings of the hen-roost, soap-sud, salt, brine, all drainings from the sink spont, slops from tho 
chambers, and cleanings from the privy : let all go to the compost heap. And whatever will not decay there, with sufficient rapidity, without assistance, aid its decay by the addition of such substances as will facilitate the object. Bones, leather, etc., may be softened so as to pulverize readi' $y$, by being packed in ashes and kept moist a few months; and if the whole bo sufficiently covered with muck during the process, there will bo no loss of any element; or they may be parked in an old cask in a strong solution of potash, or may be prepared with sulphuric acid in the most scientific manner, and when thus prepared in either of these ways, will add greatly to the value of the compost heap. And if it still is not strong enough, add wood ashes to any extent, from one to ten or twelve bushels per cord.

When thus prepared, our compost heap should be carefully worked over, thoroughly mixing all the different ingredients. It may then be applied to the soil in the ame manner with that from the barn-cellar, or in any other way desirable.

In addition to the foregoing generai compost and the various special compounded manures already referred to, every farmer who has swamp muck or peat on his farm should compost it extensively with his stable manure; for it is believed, on the evidence of careful experiment, that two cords of compost prepared by mixing daily one cord of dry muck with the same quantity of the solid excrements of animals is fully equal, for all practical purposes, to two cords of the latter preserved and applied without the muck; and also that two cords of compost, prepared by using that quantity of dry muck, to absorb all the liquid voided by the same animals, during the time required to obtain one cord of solid excrement, to be equal in value to two cords of the former compost. Thus we have four cords of equal value by this process, to every one cord obtained where the manure is thrown out of doors and left exposed to sun, wind, and rain, and all the liquid allowed to run to waste.*

These are a few of the ways in which your stock of manures

* W. F. Wyman, in Country Gentlemam. 
may be greatly and cheaply increased. Your own experience, observation, and study will suggest others.

\section{VI.-IRRIGATION.}

Irrigation is manuring by means of water. "The manner of irrigating must depend on the situation of the surface and the supply of water. Sometimes, reservoirs are made for its reception from rains or inundations; and at others, they are collected at vast expense, from springs found by deep excavations, and led out by extensive subterraneous ditching. The usual source of supply, however, is from streams or rivulets, or copious springs, which discharge their water on elevated ground. The former are dammed up, to turn the water into ditches or aqueducts, through which it is condncted to the fields, where it is divided into smaller rills, till it finally disappears. When it is desirable to bring more water on to meadows than is required for saturating the ground, and its escape to fields below is to be avoided, other ditches should be made on the lower sides, to arrest and convey away the surplus water."

Irrigation contributes to the grow th of plants in several ways. 1. It causes the deposit on the surface of the soil of more or less fertilizing matter brought from a distance by the stream; 2. It brings the gases-oxygen, nitrogen, and carbonic acid, to the roots of plants in different proportions from those in which they exist in the air (but if the water be permitted to remain stagnant on the surface this effect ceases); 3 . It disposes the soil to those changes, both mechanical and chemical, which are essential to its greater fertility.

"The advantages of irrigation are so manifest that they should never be neglected, when the means for securing them aro within economical reach. To determine what economy in this case is, we have to estimate, from careful experiment, the equivalent needed in annual dressing with manures to produce the same amount of grass as would be gained by irrigation; and to offset the cost of the manure, we must reckon the interest on the permanent fixtures of the dam and sluices, etc. 
"The increase from the application of water is sometimes fourfold, when the soil, the season, and the water are all favorable, and it is seldom less than doubled. Many fields which, in their natural condition, scarcely yield a bite of grass for cattle, when thoroughly irrigated will give a good growth for years, and without the aid of any manures.

"Light, porous soils, and particularly gravels and sands, are the most benefited by irrigation. Tenácious and clay soils are bat slightly improved by it unless first made porous by underdraining. It is not only important that water be brought on to the ground, but it is almost equally important that it should pass off immediately after accomplishing the objects sought." 


\section{III.}

\section{ROTATION OF CROPS.}

If manning is the steam-englue which propols the vessel, rotation is the rudder whitch galses z in its progress, $-J, J$. Thomas.

\section{I.-THEORY OF ROTATION.}

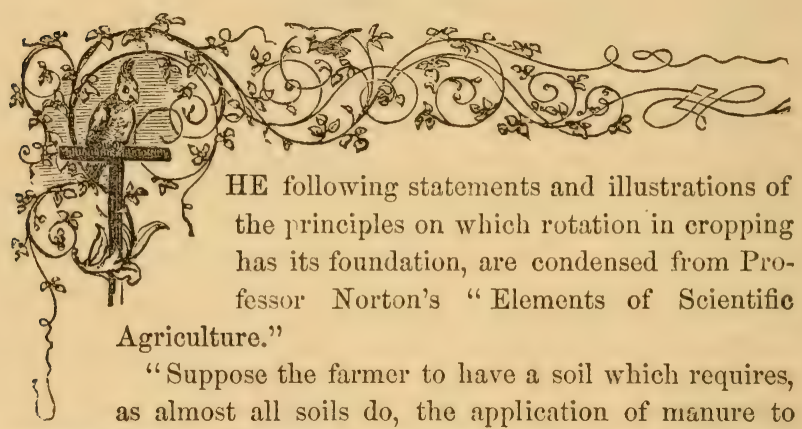
render it fertile. IIe adds a good coating of manure, and then takes off a crop of corn or wheat. This crop will carry away the largest part of the phosphates that were addod in the manure. In most cases, therefore, a second crop of the same kind would not be so good as the first; and the third would be still less. There yet remains, however, from the manure, considerable quantities of other substances, which tiue grain crops did not so particularly require, such as potash and soda. With this a good crop of potatoes, turnips, or beets may be obtained; and after this there is probably still enough lime, etc., left to produce an excellent crop of hay, if the ground be seeded down with another crop of grain of a lighter character than Indian corn or wheat. 


\section{Rotation of Crops.}

We perceive, then, that any good rotation must be founded upon the principle that different classes of crops require different proportions of the various substances which are present in soils, and in the numerous fertilizers which are applied for the purpose of enriching them. Thus the crops may be made to sncceed each other with the least possible injury to the soil, and with the greatest economy in the use of manures.

It would be useless to recommend here any particular system of rotation as best; for that must be determined by experience in each section of country, under the various circumstances of climate, location, and value of crops. Attention may, however, be again called to the fact that there are several distinct classes of crops, considered with reference to the sub.. stances which they take from the soil, and that these classes of crops should bear a part in every system of rotation. The principal of these are grain crops, root crops, and grass crops. See table and remarks in section 11 of the previous chapter.

\section{II.-BENEFITS OF ROTATION.}

J. J. Thomas, in speaking of rotation in cropping, says :

"There are other very important requisites in good farming, but they are all accomplished with an increase of expenditure and labor. Manuring, for example, is a most powerful means for improvement; but both manures and their application are expensive in proportion to the amount applied. Underdraining has wrought wonderful results, but the cost is always a large item, and the same may be said in some degree of deep plowing and subsoiling. But in the arrangement of a rotation, no additional expenditure or labor is necessary; it costs no more to cultivate crops which are made to succeed each other judiciously, than to cultivate those arranged in the worst manner possible. The former may bring triple the successful results of the latter-not by the expenditure of five hundred extra days in drawing manure, or five hundred dollar's' worth of ditching, but simply by making a proper use of one's brains.

"It seems surprising, under the circumstances, that so smail 
a number seize the golden prize thus completely placed within their reach-that there are so few, even of those reckoned good farmers, who pursue anything like a systematic succession, to say nothing of such a rotation that shall accomplish its peculiarly beneficial results, namely, preservation of the riches of the soil, destruction of weeds, destruction of insects, and the most advantageous consumption by each successive crop of all the means for its growth within reach. As a consequence of this neglect, we see land overcropped with wheat, the soil worn out for this particular grain, and those troublesome weeds, chess and red-root, taking its place. We see pastures, left unplowed for a long series of years, become filled with " buttercups" and ox-eye daisy. A disproportion of spring crops facilitates the spread of wild mustard, and among insects, grubs and wire worms increase according to the cultivation that favors their labors. It appears to be but little understood how great is the assistance to clean cultivation afforded by a good rotation. The best example of this sort we ever witnessed, where every field of the symmetrically laid-out farm, except a wet meadow, was brought under a regular, unvarying system, scarcely a weed was ever to be seen; and we ascertained that not one third of the labor usually expended was required for the hand dressing of hoed crops."

For something more on this topic, see chapter on "Farm Management." 


\section{Draining.}

\section{IV.}

\section{R A I N I N .}

If one of our railroxils should be known to pay thirty per cent. dividend annually, from its reg. zlar earnings, and the stock could be bought at par, what a furious rush would be made for it Yet there is a way that farmers may invest in stoclis at home, on their own lands, that will pay thirty to filty per cent. yearly. This is in systematic tile-draining. We have known many whc have tried it, and they generally say that it is paid for by the increased crops in two years. They are good farmers, however.-Annual hegister of Rural Affairs.

There is not one farm ont of every seventy-five in this state but needs draining-jes, much Araluing-to bring it into high cultivation,-Com. Report to N, Y. Rtale $\mathbf{A g}$. Sac.

\section{I.-EFFECTS OF DRAINING.}

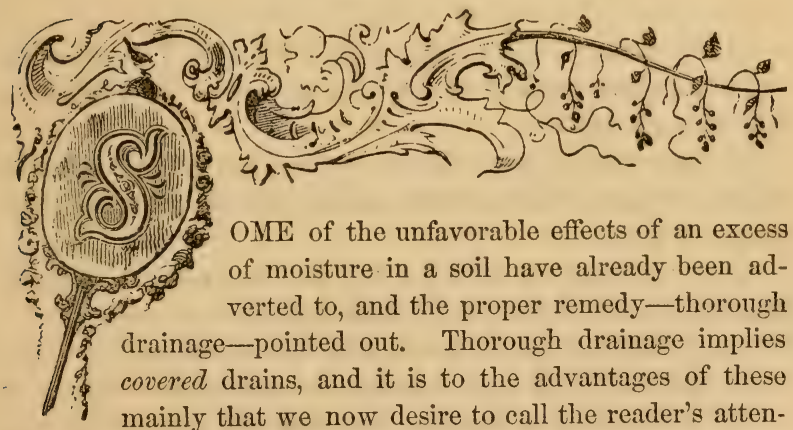
tion; although, as we have said in a previous chapter, open ditches and water-furrows are very useful in certain situations.

The rain which falls upon a piece of land prepared with properly constructed covered drains never remains to stagnate or to run over the surface, washing off the best of the soil, but sinks gradually down, yielding to the roots of plants any fertilizing matter which it may contain, and often washing out some hurtful substances. As itdescends, air and consequently warmth 
follow it. Under these new influences the proper decompo sitions and preparations of compounds fit for the sustenance of plants go on, the soil is warm and sufficiently dry, and plauts flour:sh which formerly would never grow on it in perfection, if at all. It is a curious fact, too, that such soils resist drouth better than ever before. The reason is, that the plants are able to send their roots much farther down in search of food without finding anything hurtful. Every part being penetrated by the air, and consequently dryer and lighter, these soils do not bake in summer, but remain mellow and porous. Such effects can not, in their full extent, be looked for in a stiff clay in a single season; the change must be gradual, but it is sure.*

The principal benefits of a system of covered drains are suc cinctly and clearly stated in the following-

\section{"TEN REASONS FOR UNDERDRAINING.}

"1. It prevents water which falls from resting on or near the surface, and renders the soil dry enough to be worked or plowed at all times.

"2. By rendering the soil porous or spongy, it takes in water without flooding in time of rain, and gives it off again gradually in time of drouth.

" 3 . By preventing adbesion and assisting pulverization, it allows the roots to pass freely through all parts of the soil.

"4. By facilitating the mixture of manure through the pulverized portions, it greatly increases its value and effect.

"5. It allows water falling on the surface to pass downward, carrying with it any fertilizing substances (as carbonic acid and ammonia), until they are arrested by the absorption of the soil.

"6. It abstracts in a similar manner the heat contained in falling rains, thus warming the soil, the water discharged by drain-mouths being many degrees colder than ordinary rains.

67. The increased porosity of the soil renders it a more por 
fect non-conductor of heat, and the roots of plants are less injured by freezing in winter.

"8. The same cause almits the entrance of air, facilitating the decomposition of enriching portions of the soil.

“9. By admitting early plowing, crops may be sown early, and an increased amount reaped in consequence.

"10. It economizes labor, by allowing the work to go on at all times without interruption from surplus water in spring, or from a hard-baked soil in summer."*

\section{II.-CONDITIONS REQUIRING DRAINAGE.}

The conditions from which arise the principal causes of mischief to undrained land are thus stated by Munn in "The Practical Land-Drainer :"

"1. Where water has accumulated beneath the surface and originated springs.

"2. Where, from the close nature of the substrata, it can not pass freely downward, but ac umulates and forms its level, or water-line, at a short distance below the surface; and

"3. Where, from the clayey or close texture of the soil, it lies on the surface and becomes stagnant."

Farmers are apt to consider land in which the second condition mentioned exists, to be too dry to need draining, yet it is cold and sour, late in spring, apt to bake hard in summer, and very liable to suffer from early frosts in autumn. There is no remedy but underdraining. The necessity of this operation in the other two cases named is obvious.

\section{III.-PRACTICAL DIRECTIONS.}

1. Preliminary.-The first thing to be done is to examine the field to be drained and determine the plan of drainage best adapted to effect the object in view, and the materials which may most economically be used in constructing the druins.

2. Draining Springy Soils.-Where the wetness to be remedied results from springs having their source in higher grounds 
above the field to be drained, the desired result is generally attained by making one or more drains across the declivity about where the low grounds of the valley begin to form, thus intercepting or cutting off the springs. These transverse drains must be connected with others, made for the purpose of conveying the water collected in them into some brook, ravine, or other outlet which may be near.

3. Direction of Drains.-In cases characterized by either of the other conditions specified in the previous section, parallel drains should be cut directly up and down the inclination of the field, and emptying into a main cross drain at the lower side.

4. Depth and Distance Apart.-In reference to depth and distance apart, differences of opinion and of practice prevail. Some cut their drains only about two and a half feet deep and from twelve to twenty feet apart, while others make them from three and a half to five feet deep and from thirty to fifty feet apart. The experience of scme of the most extensive drainers both in this country and in Europe seems to indicate, however, that for very heavy, clayey soils, from two and a half to three feet in depth and from twelve to thirty feet apart, generally produce the most satisfactory results. More porous and friable soils may be successfully drained at greater depth and distance.

5. Digging.-Having marked out your drains at the distance apart decided upon, and got your tiles or other materials ready for laying down the ducts, you may begin to dig, commencing at the lower end, cutting the main drain into which the others are to empty, and then working upward on the parallel drains. Their dimensions must depend mainly upon the material to be used for the ducts. Where they are to be filled with broken stone or brush, they are made wider than where the small, oval tile, tube, or pipe is to be laid. Where tiles of any kind are to be used, their size must determine the width of the bottom of the drain. The top must be wider for convenience of digging. A narrow spade and a peculiar hoe are necessary for digging and smoothing the bottom of the drain. There must 
be a gradual fall, of course, from end to end, of which the regular flow of water will be a test. For the purpose of keeping a uniform grade of descent in cutting drains, a common mason's level will answer; but the $\mathrm{A}$ or span level, represented by the accompanying cut, is better. Such a level may easily be constructed of wood. The span should be either sixteen feet six inches, or half that length. The two feet being placed on a perfectly level floor, the

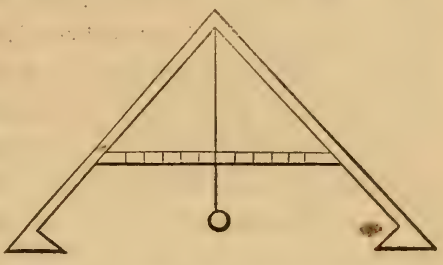
plumb-line will hang in the center, where a notch should be cut in the cross-bar. Then place a block of wood, exactly an inch thick, under one leg, and mark the place on the cross-bar that the plumb-line touches. Put a second block of one inch under the same leg, and mark the place of contact of the line with the bar as before, and so on so far as is necessary. Then mark the other side in the same way. When thus prepared, if the span of the level be sixteen feet and six inches, the plumb-line will indicate upon the bar, by the number of spaces at which it hangs from the center, the number of inches per rod of the descent. If its span be eight feet and three inches. it will, in the same way, indicate the number of inches of descent in half a rod.*

6. Materials and Construction.-The ditch thus excavated must now be furnished with a permanent duct through which water may at all times freely pass off. This may be constructed of various substances-brushwood, straw, turf, clinkers from furnaces, wood, brick, stone, and tiles of burned clay. Of these, stone and tiles in their various forms, when they can be procured, are the only materials which we can unconditionally recommend.

Erushoood Drains.-Where no better materials are avai-

* Munn. 
able these will be found, while they last, quite effective; and they are far more permanent than might be supposed. An instance is recorded where they have been found after twenty years in as good condition apparently as when constructed. They are formed by laying down branches or brushwood in the bottom of the drain to form the duct for the passage of the water. The brush are put into the cutting in a slanting direction with the descent of the ground, their root or large ends being toward the bottom. They should be trodden down and covered with inverted turf before filling in.

Stone Drains.-In reference to their mode of construction, stone drains are of various kinds. The simplest form is that in which the ditch or cutting is filled, to the depth of nine or ten inches, with small stones, covered with inverted turf, shav-

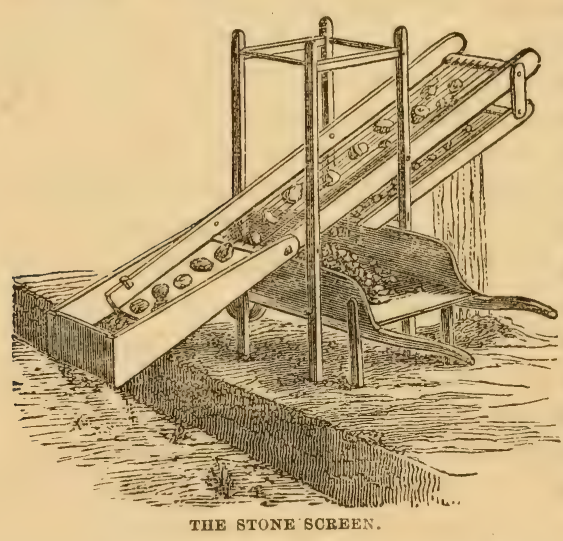
ings, or something of the kind. The stones should be about the size of a hen's egg. Where larger ones are used, the earth is apt to fall into the cavities, or mice or rats make their burrows there, and the drain becomes choked. Some, however, make use of larger stones, merely covering them with a layer of small stones or gravel, before putting on the sod. When the stones are procured. whether in a natural state or broken, it is desirable to screen them in order to get them assorted as to size. The accompanying cut represents an excellent portable harp or screen for that purpose. Having filled the ditch to the required depth, and covered the surface carefully with inverted sods, the earth 
should be thrown in and trampled hard upon them. The water

- should find its way into

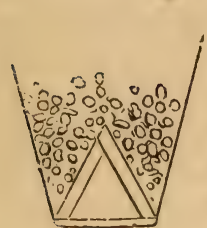

Fig. 1. the drain from the sides, and not from the top. The accompanying cuts represent other forms of stone drains, in which flat stones are used to form a regular and continuous duct. A drain

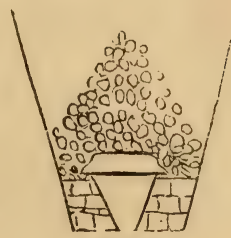

Fig 2.

well constructed in either of these forms may be considered

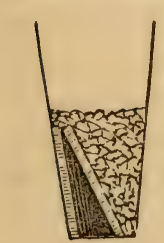

Fig. 3 permanent. Where the earth is hard and the quantity of water is not large, the form represented by Fig. 4 is the best and cheapest in which a stone drain can be constructed. In making stone drains in swampy or

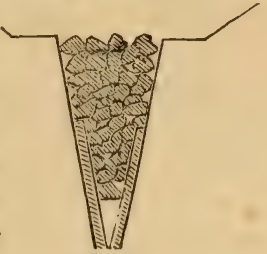

Fig. 4. very soft ground it is sometimes necessary to lay a plank or slab on the bottom, before putting in the stones, to prevent them from sinking before the soil shall become dry enough to be firm.

But in large portions of the country stones can not be procured, and where they can be had, and require to be broken and screened, the expense is considerable; and it is now found that, in many cases, tiles made of clay and burned are much cheaper. Tile Drains.-The first form of tile drain used was arched and marle to rest on a sole or flat tile laid under it; but the more modern tile pipes

Fig. 5. are to be preferred, as they are smaller, cheaper, and more easily laid. Those with an oval bore (fig.

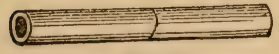

Fig. 6.

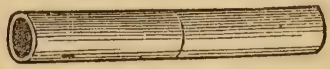

Fig. 7.

7) are considered better than those with a round one. The 
tiles are, of course, placed in the bottom of the ditch, which must be smooth and straight. They are simply placed end to end and wedged a little with small stones, if necessary, and the earth packed hard over them. The vater very readily finds its way in through the pores of the material and at the

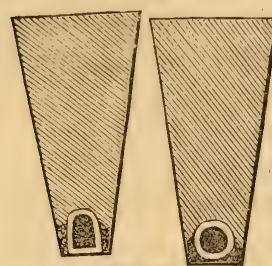

Fig. 8. joints. Collars or short outer tiles are sometimes used to go over the joints, to secure them against getting displaced. An inch pipe is sufficient for most situations. It may seem impossible for the water freely to reach a tile pipe with the earth packed close about it, especially where the soil is clayey; but practically no difficulty occurs. The portion of earth next the drain first dries; and as it shrinks on drying, little cracks begin to radiate in every direction, and to spread until they penetrate the whole mass of the soil within their influence, allowing the superfluous moisture to pass off, and rendering the ground, in the course of a season or two, light, mellow, and wholesome for plants.*

For main drains (where the parallel drains do not discharge directly into some open ditch, ravine, or brook, and the former are not constructed of stone or brick), two horse-shoe or arched tiles may be used, one inverted against the other.

The drains should be connected at the upper end of the field by a small drain running at right angles with them. It should be of the same depth as the other drains.

Where the ground is firm and the drain is made in the summer, and when the length is not great, begin at the upper end to lay the tiles or put in the stones; but where the ground is liable to fall down at the sides, the safest way is to build the conduit or duct immediately after the earth is taken out of the bottom.

IV.-WILL UNDERDRAINING PAY ?

The Genesee Farmer thus answers this question: This de- 
pends on circumstances. If good naturally underdrained land can be obtained in your neighborhood for from $\$ 15$ to $\$ 20$ per acre, it would not pay in all probability to expend $\$ 30$ per acre in underdraining low, wet, or springy land; but in all districts where land is worth $\$ 50$ per acre, nothing can pay better than to expend from $\$ 20$ to $\$ 30$ per acre in judicious underdraining. The labor of cultivation is much reduced, while the produce is generally increased one half, and is not unfrequently doubled; and it must be remembered that the increase is net profit. If we get $\$ 15$ worth of wheat from one acre and $\$ 20$ worth from the other, and the expense of cultivation is $\$ 10$ in both cases, the profit from the one is twice as much as from the other. That judicious underdraining will increase the crops one third, can not be doubted by any one who has witnessed its effects. If it should double the crops, as it often does, the profit would be four-fold."

It has been remarked, that "to apply manure to undrained land, is to throw money away," an illustration of which is furnished by a statement in the Transactions of the New York State Agricultural Society, where seven acres of low, wet land, manured annually at the rate of 25 loads to the acre, produced 31 bushels of oats per acre; but after being thoroughly underdrained at a cost of about $\$ 60$ for the whole, the first crop of oats without manure was $89 \frac{1}{2}$ bushels per acre.

Gov. Wright, in his address before the Wayne County Agricultural Society, estimates the amount of marshy lands in Indiana at three million acres. These were generally avoided by early settlers as being comparatively worthless, but when drained they become eminently fertile. He says: "I know a farm of 160 acres that was sold five years ago for $\$ 500$, that by the expenditure of less than $\$ 200$, in draining and ditching, the present owner refuses now $\$ 3,000 . "$

No estimates of the cost of draining that we could give would be of much practical value. The character of the soil, the cost of the materials, the price of labor, and other circumstances, must be taken into the account, and these vary so much 
in different localities that they can not be made the basis of any useful general estimates. The following table, showing the number of tiles, of the different lengths made, which are required for an acre, will be useful to those who may desire to purchase just enough for a particular piece of ground. We extract it from Munn's "Practical Land-Drainer :"

\begin{tabular}{|c|c|c|c|c|c|c|c|c|}
\hline \multicolumn{5}{|c|}{ DISTANCE APART. } & $\begin{array}{l}\text { 12-1nch } \\
\text { Tiles. }\end{array}$ & $\begin{array}{c}\text { 13-Inch } \\
\text { Tiles. }\end{array}$ & $\begin{array}{c}\text { 14-Inci } \\
\text { Tiles. }\end{array}$ & $\begin{array}{c}\text { 15-Inch } \\
\text { Tiles. }\end{array}$ \\
\hline \multicolumn{5}{|c|}{ Drains 12 feet apart require........ } & 3,630 & 3,351 & 3,111 & 2,94 \\
\hline & 15 & 66 & "6 & ......... & 2,904 & 2,681 & 2,489 & 2,323 \\
\hline "6 & 18 & 66 & 66 & & 2,420 & 2,234 & 2,174 & 1,936 \\
\hline "6 & 21 & "6 & " & …........ & 2,074 & 1,914 & 1,777 & 1,659 \\
\hline " & 24 & " & “ & …........ & 1,815 & 1,675 & 1,556 & 1,452 \\
\hline "6 & 27 & 6 & "6 & ......... & 1,613 & 1,480 & 1,383 & 1,291 \\
\hline 6 & 30 & "6 & " & …....... & 1,452 & 1,340 & 1,245 & 1,162 \\
\hline "6 & 33 & " & "6 & & 1,320 & 1,218 & 1,131 & 1,056 \\
\hline "6 & 36 & 66 & " & .......... & 1,210 & 1,117 & $\overrightarrow{1}, 08 \hat{7}$ & 968 \\
\hline
\end{tabular}

In reference to tile-pipe drains, it must be remembered that the ditch may be much narrower than when stones are used, thus making a considerable saving in the expense of digging. The upper part of the earth is taken out with a common spade, and the lower part with one made quite narrow for the purpose, being only about four inches wide at the point. 


\section{V.}

\section{FENCES.}

Have an eye upon your fences ! Farmer's Almanac.

\section{I.-REQUISITES OF A GOOD FENCE.}

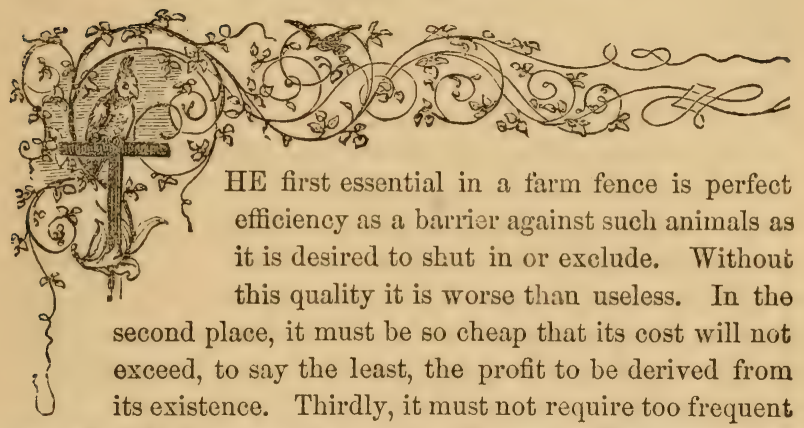
renewal. It is desirable, also, that it occupy little space, and that it do not present an unsightly appearance. The best fence, therefore, for any given place and time, is the one which combines most perfectly all these qualities. In one place this may be stone fence, in another one of posts and rails, in a third a live hedge, etc. In one period of a country's history it may be made of logs, in another ef rails, in a third of growing Osage orange or holly, and in a fourth of wire.

\section{II.-VARIOUS KINDS OF FENCE.}

1. Stone Fence.-Wherever there is plenty of stone, and especially where loose stones abound, and must be removed before the land can be properly cultivated, stone fences are tho 
best and most economical that can be constructed. When well built, broad, and high, they are perfectly efficient and very permanent. In an esthetic point of view they are far less offensive to the eye of taste than our wooden fences, even of the least objectionable form. After a few years, as we judge from the sober livery of moss with which she decks them, Nature adopts these structures as her own, and they become a legitimate portion of the landscape:

Where stone is not very abundant, a combination of stons and rail fence is often economically constructed. A substantial foundation of stones is laid, reaching two or two and a half feet above ground, in which posts are placed at proper distances, with two or three bar holes above the wall, for the insertion of an equal number of rails, which for convenience should bo put in when the posts are set.

2. The Zig-zag or Worm Fence.-In large portions of our country, where there is a superabundance of timber, and economy of space is of little importance, the common zig-zag or worm fence of the West and South is probably the most economical that can be erected. When well built, it is firm and durable, but unsightly and inconvenient, occupying a great deal of space, harboring vermin, and encouraging the growth of weeds and bushes.

3. Post-and-Rail Fences.-As timber becomes somewhat more valuable, it ceases to be economical to use it so lavishly as the worm fence requires, and the post-and-rail fence takes its place. This is, in many respects, the best of all the wooden farm fences.

"The posts," Allen says, "should be placed from two and a half to three feet below the surface, in the center of a large nole and surrounded by fine stone, which must be well pour ded dlown by a heavy, iron-shod rammer, as they are filled in. Tle post will not stand so firmly at first as if surrounded by uirt, out it will last much longer. The lower end should be pumied, which prevents its heaving with the frost. If the position of the post while in the tree be reversed, or the upper end of the 
split section of the trunk which is used for a post, be placed in the earth, it will be more durable. Charring or partially burn ing the part of the post which is buried, will add to its duration. So also will imbedding it in ashes, lime, charcoal, or clay; or it may be bored at the surface with a large auger, diagonally downward and nearly through, then filled with salt, and closely plugged.

"The best timber for posts, in the order of its durability, is red cedar, yellow locust, white oak and chestnut, for the Northern and Middle States. I recently saw red cedar posts in use for a porch which, I was assured, had been standing exposed to the weather previons to the Revolution, a period of over 70 years, and they were still perfectly sound. The avidity with which silicious sands and gravel act upon wood, renders a post fence expensive for such soils."

In some cases, boards may be economically substituted for rails, and firmly nailed to suitably prepared posts.

4. The Sunken Fence.-The sunken fence or wall consists of "a vertical excavation on one side, about five feet in depth, against which a wall is built to the surface of the ground. The opposite side is inclined at such an angle as will preserve the sod against sliding, from the effects of frost or rain, and is then turfed over. A farm thus divided presents no obstruction to the view, where it is everywhere properly walled in, besides affording good ditches for the drainage of water." Such a fence, properly constructed, might be considered absolutely permanent; and it would scarcely need repairing at all.

5. Iron Fences.-Wire and other forms of iron fence are coming into extensive use in some portions of the country. Where there is a deficiency of both timber and stone, the wire fence is probably the best and most economical that can be made. With the improvements lately introduced, especially those made by the New York Wire Railing Company, these fences are entirely efficient, and in every way satisfactory.

"The "American Farm Book." 
The fences are made with horizontal wires, tightened by means of an effective arrangement, so that the whole tension of the rod is obtained. The posts are furnished with contrivances of different patterns for security in the ground. The size of the rods varies in accordance with the uses for which the fence is designed. No ordinary domestic animal will break through fences of considerably less than $\frac{1}{4}$-inch wrought wire, while still larger sizes may be used with the same facility if required. The bright or hard wire is now generally used.*

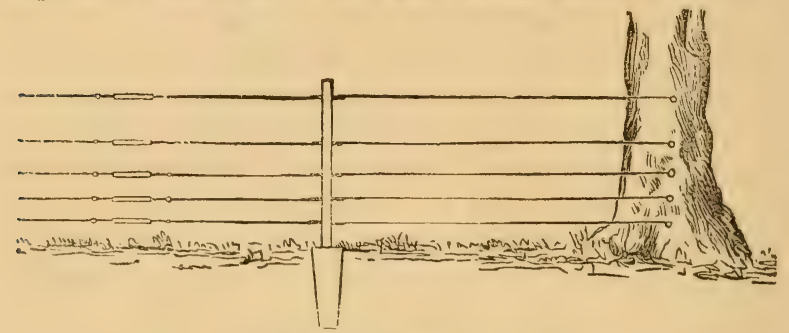

WIRE FENCE, WITI IRON POST8.

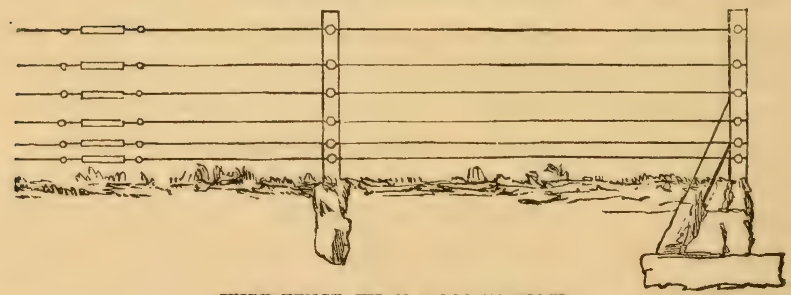

WIRE FENCE, WITIK WOODEN POSTS.

* We are indebted for the accompanying illustrations of wire fences to the Descriptive Catalogue of the New York Wire Railing Company. John B. Wickersham, Superintendent, 312 Broadway.

+ As it may be useful to some of our readers, we give the prices per rod at which this fence may be procured (packed anil shipped) at the warehouse of the New York Iron Railing Company, in New York.

For eattle and horses, $\$$ wires, with iron posts and screws...........\$1 66

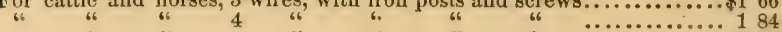

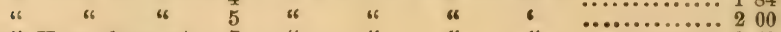

"Hogs, sheep, cte. 7 " " "

s6 Turkeys, geese, etc. 10 " " "

Each additional wire, 20 cents per rod. 
The accompanying cut exhibits the natural size of the wires most commonly used for farm fences, and shows the manner in

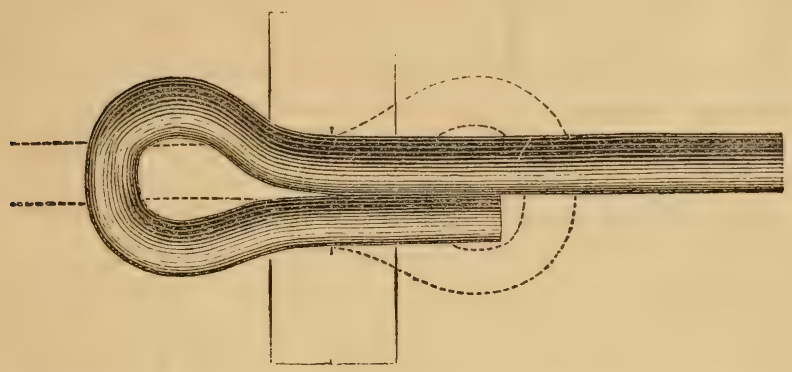

which they pass through and support the post and are supported by it. The following are the manufacturer's directions for putting up the fence:

"It is absolutely necessary that the straining pillar, or starting post, of wood or iron, at the extreme ends of the fence, should be perfectly firm, as the wires can not otherwise be made tight. Commencing from a tree is recommended, if possible. Plant the posts 12 feet apart, hook in the rails, and at the distance of 150 feet place a screw on each wire. Place the next set of screws at the distance of 300 feet, and so continue.'

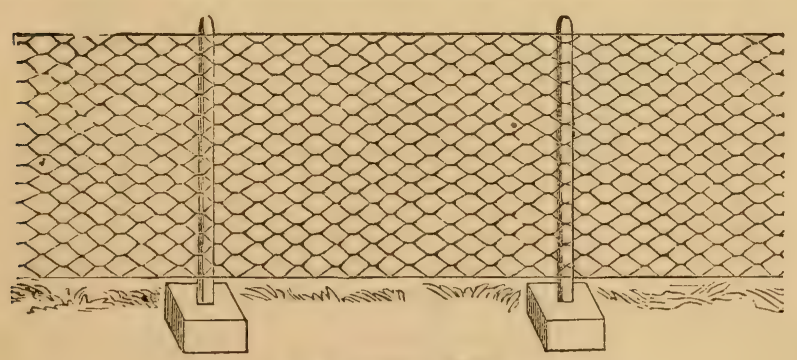

WIRF NETTING FENCE.

The wire netting fence furnishes an admirable barrier against small animals, poultry, etc. It costs from $\$ 150$ to $\$ 275$ per 
rod, according to the height and the size of the wire and meshes.

Another style of iron farm fence is called the "Corrugated Flat Rail Fence." It is in some respects preferable to the round rail or wire, being visible at a greater distance and less liable to sagging.

6. Hurdle Fence.-The hurdle, or light, movable fence is formed in short panels, and firmly set in the ground by sharpened stakes at the end of each panel, and these are fastened together. This is a convenient addition to farms where heavy green crops of clover, lucern, peas, or turnips are rtyuired to be fed off in successive lots, by sheep, swine, or cattle. It is variously constructed of wood or iron, and is much less expensive than might be supposed, "Wickersham's Corrugated Hurdle Fence" being furnished by the Wire Railing Company at from $\$ 250$ to $\$ 5$ per rod, according to weight and quality.

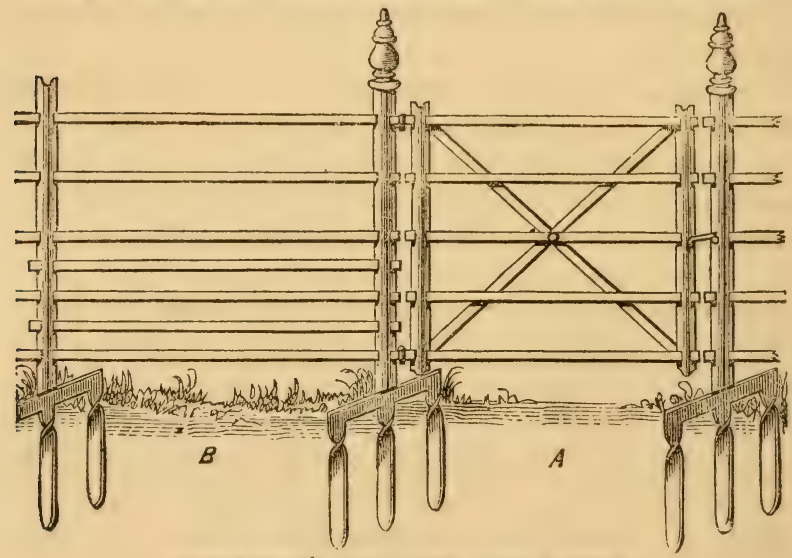

WIOKERSIAM'S CORRUGATED HURDLE FENCE.

7. Hedges.-The live fence, almost universal in England, is still an experiment here. There have been a few successes and many failures in the cultivation of hedges. The causes of failure have been various - a wrong choice of trees, the dryness 
of our climate, lack of experience in planting, neglect of proper after cultivation and pruning, etc. But the few examples of complete success which may be pointed ont prove conclusively that, under proper and easily attainable conditions, live fences are perfectly practicable in this country; and in some parts of it they are doubtless economical. When well kept, they are certainly very beautiful.

Among the plants employed in this country with more or less success for hedges are the buckthorn, the hawthorn, the barberry, the althea or rose of Sharon, the Osage orange, the American arbor vitæ, the American holly, the hemlock spruce, the white cedar, the evergreen thorn (Cratagus pyracantha), the Cherokee rose, and the white Macartney rose.

For the Middle, Western, and some of the Northern States, the Osage orange seems to be, on the whole, the best. It also succeeds at the South; but there the evergreen thorn, the Cherokee rose, and especially the single white Macartney rose, are preferable.

The soil for a hedge row must be deeply plowed or spaded, and, if poor, manured a little. The space thus prepared should be at least two feet wide, and with a soil from eighteen inches to two feet deep. The best way is to open a trench of the required width and depth, throw some well-rotted manure in the bottom, and then fill up with the surface earth. Along the middle of this filled trench stretch a line, and make holes under it in the soft earth every six or eight inches, with a "dibble" or pointed stick. Set your plants in the holes precisely as you would plant cabbages, pressing the earth around the roots, and leaving only one inch of the top visible above the surface. The plants may be either one or two years old, and the tops should be cut off within two inches of the root. The young hedge must be well cultivated for several years, and cut back once or twice a year till it shall be four feet high. The conical shape is best for a hedge, as it admits every shoot to the benefit of the air and light. Where vacancies occur, vigorous shoots may be "layered"-that is, fastened to the ground with hooked 
perss, when they will take root and send up sprouts to fill the open spaces.

The editor of the Country Gentleman very truly says: "Not one Gsage orange hedge in twenty succeeds, simply hecause it is expected to take care of itself after setting oui. Constant culture and cutting are as essential as air and food to animals."

Evergreens make the handsomest hedges; and although less stout, yet by shutting out sight are usually quite safe. The Norway fir is the fastest grower-the hemlock most beautiful, and the best of any for the shade of trees; the growth is, however, rather slow. It shears finely, and its intcrior is dense. The Norway fir also does well on these points.

At the South we should choose the single white Macartney rose for general cultivation; although the Cherokce rose, when properly treated, the evergreen thorn, the honey locust, the jujube, and the Spanish bayonet (Ircea gloriosa) all form efficient and beautiful hedges.

Mr. Redmond, one of the editors of the Southern Caltivator, gives the following directions for the cultivation of rose hedges; and no one is better qualified to speak on this point:

"As a general rule, both the Macartney and Cherokee roses are improperly planted. To succeed with them, it is necessary to open two parallel ditches or trenches about four feet apart, heaping the earth along the center in the form of a sloping bank. At the base of this bank, on each side, plant 12-inch cuttings in December or January, training the tops over the bank from each side. Having this bank as a foundation, they will constantly layer themselves and grow close at the bottom, and will interlace their thorny branches so intricately that no animal can pass through. The ditch on each side forms an additional obstruction to the passage of animals, and forms a definite boundary or limit to the hedge-to which limit only the ends of the branches must be allowed to extend. In trimming, a man passes rapidly along the bottom of the ditch, clipping off even with the inner side all the straggling ends of the plants. In order to explain this system of rose hedges 
Inore fully, we will unceavor to give a drawing hereafter. In the mean time, let it be remembered that the cuttings must alcays be planted at the bottom, never at the top of the bank -the latter situation being too dry to make them grow off vigorously."

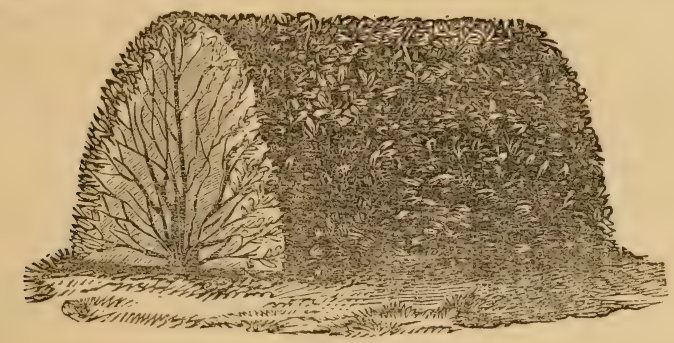

SECTION OF MODEL HEDGE.

A really good and perfect hedge should form a rounded pyramid, similar to the accompanying cut, branching out broadly and close to the ground, and tapering up either sharply or obtuse, as the taste of the cultivator may determine. This is a fundamental principle in all hedging, and unless it is secured at the outset by proper trimming, it can never be done afterward.

\section{III.-A HINT OR TWO.}

But let your fence be of what kind it may, it is necessary, in the words of our motto, to "keep an eye" upon it. Some accident may cause a breach in the best fence, and a fence that is not perfectly efficient is worse than none. A fence, to accomplish the purpose of a fence, must not only be able to "stand alone," but must bear a little jostling. Your cattle may very innocently rub themselves against it. If it tumble down, who can blame them if they walk into the adjoining field, or into the highway, as the case may be? And you underrate their sagacity if you suppose that they will not take a hint from the accident, and rub again for the express purpose of producing the result obtained before without a purpose. Rail bars are 
often slipped out in this way. Gates are much better. "When bars are used, they should be let down so near the ground that every animal can step over conveniently; nor should they be hurried over so fast as to induce any animal to jump. In driving a flock of sheep through them, the lower bars ought to be taken entirely out, or they be allowed to go over the bars in single file. Animals will seldom become jumpers, except through their owner's fault, or from some bad example set them by unruly associates; and unless the fences be perfectly secure, such ought to be stalled till they can be disposed of. The farmer will find that no animal will repay him the trouble and cost of expensive fences and ruined crops."

\section{IV.-ARE FENCES NECESSARY?}

The burden and expense of fence-making is so great that the question has very naturally been raised whether it would not be better, in an economical point of view, to dispense with them entirely. It is said that the greatest investment of capital in this country is in the common fences which divide the fields from the highway, and separate them from each other. De they pay?

In France, Belgium, Germany, Italy, and other parts of Eu rope, fences are seldom seen. When cattle or sheep are pas tured in these countries, they are placed under the care of a herdsman or shepherd, who, with the aid of his sagacious and well-trained dog, easily keeps a large herd or flock within prescribed limits, which are marked by a slight ditch, or in some other simple way. Does the labor of the herdsman and his dog cost more than the fences which would have been required without him? In those countries undoubtedly not. In reference to the United States we have not the necessary estimates or the exact data on which to base them; but, according to the figures given in the following extract from an article published in the Ohio Farmer, it appears that fences do not always pay, even here, where labor costs so much more than in Europe. After mentioning the fact that the ancients had no fences, and 
that there are none in France, and declaring them wholly unnecessary here, the writer goes on :

"The fences in our State cost more than its railroads. Now, this huge amount of capital is, to all intents and purposes, dead. More, it is a decaying capital; annually a large amount of its depreciated stock must be replaced. These repairs cost immense sums of timber, time, and hard work. But the evil does not stop here: timber is decreasing in quantity and quality ; for rails, posts, and stakes require a great deal, and that of the best kind, while our vast prairies have no timber at all hardly for fencing.

"And there are other evils connected with this expensive and stupid modern invention. Fences become the refuge of vermin and all manner of noxious weeds. Then, too, they act as natural and annual distributors of these weeds. The fence protects the weed till it is ripe, and then furnishes the seed to the first high winds of winter and spring.

"In addition to these objections to fences, we might mention that they occupy a great deal of ground.

"Now, what are their advantages? They keep cattle in their proper places, protecting the farmer against his own and other people's cattle. But what need is there for anybody's cattle to run at large? There are laws now prohibiting some kinds of animals from running abroad; why not extend it to all? It is our impression that it would be much more economical to hire help to attend them in the field and in the stable than to pay for fences, fencing, and waste lands occupied by fences.

"We will append a few figures, from our own experience, in order to present to the farming community the importance of looking at this matter. We claim no special accuracy for our statistics, but they are, in the main, correct; and if they will call out from one or more of our farmers and agricultural professors the facts in the case, as they exist in our State, we shall feel that our object has been accomplished.

"Taking our own observations as a guide, these are the figures: Chestnut rails are worth six dollars per hundred; oak 
stakes, about three dollars per hundred. It takes fourteen rails and four stakes per rod for a worm fence; in round numbers, it costs one dollar per rod. This would be three hundred and twenty dollars per mile, and there were seven miles of fence, making two thousand two hundred and forty dollars for the fencing material. Now, add to this first cost the price of hauling, of setting up, or keeping in repair, of decay, and of the waste of land occupied. If you pay for bringing these rails to their proper places and putting them up, the first cost of material will be three thousand dollars. First cost of material and work, three thousand dollars; interest at six per cent., one hundred and eighty dollars; annual decay, six per cent., one hundred and eighty dollars; annual repairs, three per cent., ninety dollars; loss of land, five per cent., one hundred and fifty dollars. Annual cost, five hundred dollars.

"Could not this sum be better used?"

We suspect that in reference to large portions of the West at least, the writer's closing question may be answered in the affirmative. 
Farm Impleanents and Tifeir Use. 73

\section{VI.}

\section{F ARII IIIPLE IIENTS AND TIIEIR USE.}

'Tis time to clear your plowshare in the glebe.-Graham.

\section{I.-THE PLOW.}

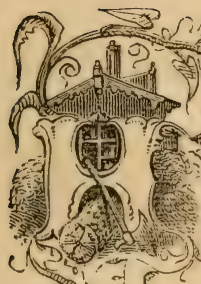

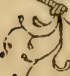

By consulting the sacred records (Deut. xxii. 10) we

ISTORY does not inform us when plows were first used; but there are traces of them in the earliest of all written authorities-the Bible. 9 find that in very early times they plowed with two oxen, $-J 6$ and that their plow had a coulter and plowshare (Sam. xiii. 20); and drawings of early Greek plows show that they were furnished with wheels. The plows of Rome were of the most simple form. "Nothing," J. J. Thomas says, "shows the improvements of modern agriculture more conspicuously than the difference between the old and new plows." The "old plow" is still used in many countries where farmers do not enjoy the benefit of agricultural periodicals. The accompanying cut represents the plow at present used in Morocco. It would hardly receive the premium of the State Agricultural Society, and has probably never been patented. It may, however, be made very cheaply, the point only being shod with iron. In the less civilized regions of Morocco the plow consists only of a crooked limb of a tree, with a projecting branch 
sharpened to a point for scratching up the ground. The Moors do not take the agricultural papers.*

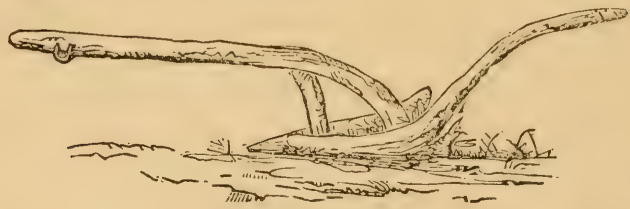

A MOORISH PLOW.

Compare the rude implement of the Moor with the improved Eagle Plow of Nourse, Mason \& Co., here represented. This

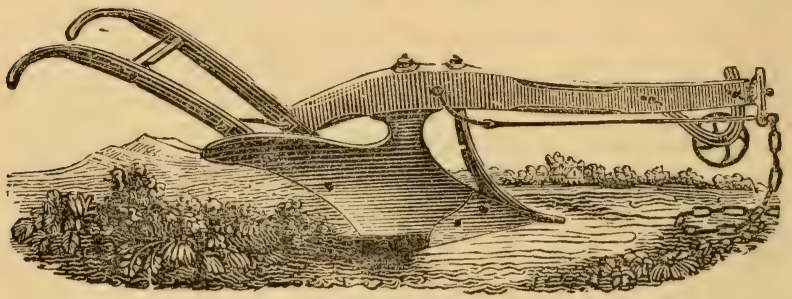

THE EAGLE PLOW.

is a No. 2, and is a medium-sized two-horse or cattle sod or stubble plow. It is adapted to turn sod furrows from four to seven inches deep by from twelve to fourteen inches wide, and will work somewhat deeper in stubble plowing. It is rigged with the lock coulter, wheel, draft-rod, and dial clevis, as represented by the cut, and with these fixtures is a very strong, and at the same time light plow for two cattle or horses, in plowing stony, stumpy, or rough, uneven land. Or it is rigged with wheel and cutter, for flat furrows in smooth land. There are other sizes, both larger and smaller than this, and for general use no plow has given better satisfaction.

An admirable plow for turning under sward deeply is the Double Michigan. "It has two mold-boards. The forward or small one skims the surface, taking off' a few inches of the top of the sod, and laying it in the bottom of the previous furrow;

* Annual Register of Rural Affairs. 
and the second or large mold-board turns up what is left, and completely buries the former. Three strong horses will draw this plow when of the smaller size, and will run a furrow eight or nine inches deep; but the larger sized plow requires nearly double this force, and will cut a furrow a foot deep.

"The Michigan plow prepares sod ground in the best manner for planting corn, the mellow soil which is thrown on the sod being docp enough to allow a coat of manure to be buried afterward a few inches by means of a gang-plow.

"Wen the subsoil is of such a nature as not to enrich the top soil when thrown up and mixed with it, or when it is desirable to loosen up a deep bed of mellow earth to serve as a reservoir for moisture, the subsoil plow serves a valuable purpose. It is also useful for loosening the soil to allow the trench or Michigan plow to enter more fully to a greater depth.

"The subsoil plow merely loosens the earth, but does not turn it up to the surface. It is made to follow in the furrow of a common plow. It runs much deeper than the trench plow, with the same force of team. Four horses attached to a strong plow, running in a furrow seven inches deep, will loosen the earth to a depth of fifteen to eighteen inches. The benefit of subsoiling depends essentially on keeping the ground well drained; for if the loosened earth is afterward allowed to become thoroughly soaked or flooded with water, it soon becomes rompacted together again, and the operation proves of no permanent advantage. This is one fruitful source of failure."*

The ridging or double moldboard plow is a very useful implement. It is used for opening drills to plant

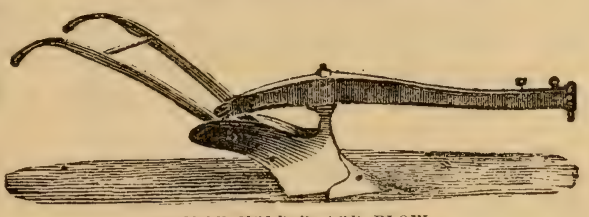
DUUBLE MOLD-BUARD PLOW. potatoes, corn, etc.; in plowing between narrow rows; in dig. 
ging potatoes, etc. No farmer should be without it. It is a light one-horse plow.

The side-hill or swivel-plow is so constructed that the moldboard is easily and instantly changed from one side to the other, which enables the plowman to perform the work horizontally upon hillsides, going back and forth on the same side, and turning all the furrow slices downward. This prevents the washing of the soil by heavy rains, to which all hillsides are more or less liable when plowed up and down the slope. Such a plow should be considered indispensable at the South.

\section{II.-THE HARROW.}

Next to the plow in the order of description, as well as of ase, comes the harrow. Like the plow, it was anciently a very

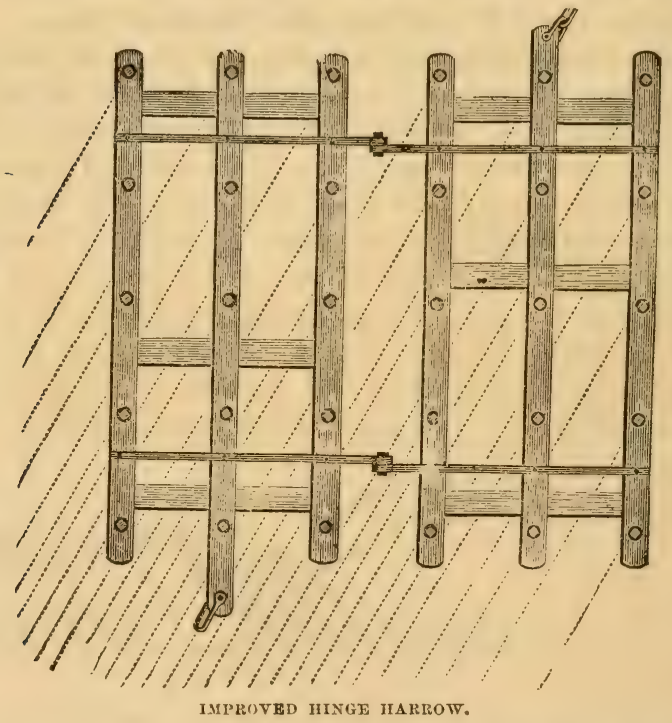

rude implement; and it is only quite recently that it has reached the high degree of efficiency and facility of action which chall- 


\section{Farm Implements and Their Use. 7 ?}

acterize the best implements of the present day. "He must have lived to little purpose who is content to use the clumsy, coarse harrow of former days."

One of the best of the improved harrows is the hinge harrow represented by the accompanying cut. This harrow may be folded double, or separated into two parts, for the convenience of transportation or other purpose. Either half may be lifted for any purpose while the implement is in motion; and the easy and independent play of the parts up and down upon the hinges enables the instrument to adapt itself to the surface of the ground in all places, so that whether going through hollows, or over knolls or ridges, it is always at work, and every tooth has an operation upon the soil.

The Geddes harrow and the Hanford harrow, triangular in shape, are also excellent implements; and for light grounds, free from stones and other obstructions, the Scotch or square harrow serves its purpose admirably.

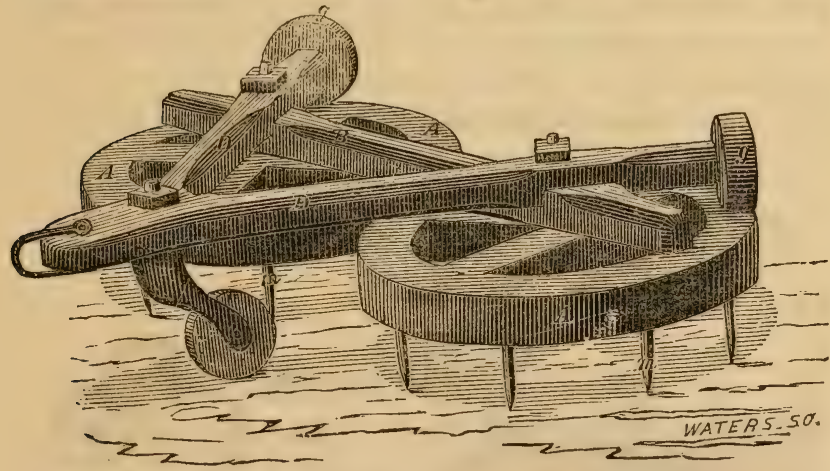

The accompanying engraving represents a harrow recently patented by Samuel J. Orange, of Grayville, Ill. It involves the rotary principle, the rotation being produced by the pressure of the rollers $g g$ upon the wheels $A A$. It has the important advantage, that while it secures the rotation of the wheels, it at the same time avoids side draft. 


\section{III.-THE CULTIVATOR}

This is a useful implement for stirring the soil and killing weeds. It is generally made to be drawn by one horse, and is mostly used between the rows of corn, potatoes, cotton, etc. It is made so as to expand or contract, according to the width of the rows. It saves a great deal of hard labor; but must not be allowed to usurp the place of the plow where deep cultivation is required.

\section{IV.-THE HORSE HOE.}

Allied to the cultivator is the horse hoe in its various forms. "Knox's patent has four teeth. The forward one is simply a coulter, to keep the implement steady and in a straightforward direction; the two side or middle teeth are miniature plows, which may be changed from one side to the other, so as to turn the earth from the rows at first weeding, when the plants are small and tender, or toward them in later cultivation-at the option of the operator; the broad rear tooth effectually disposes of grasses and weeds, cutting off or rooting up all that come in its way. It is a thorough pulverizer of the surface, sifting the earth

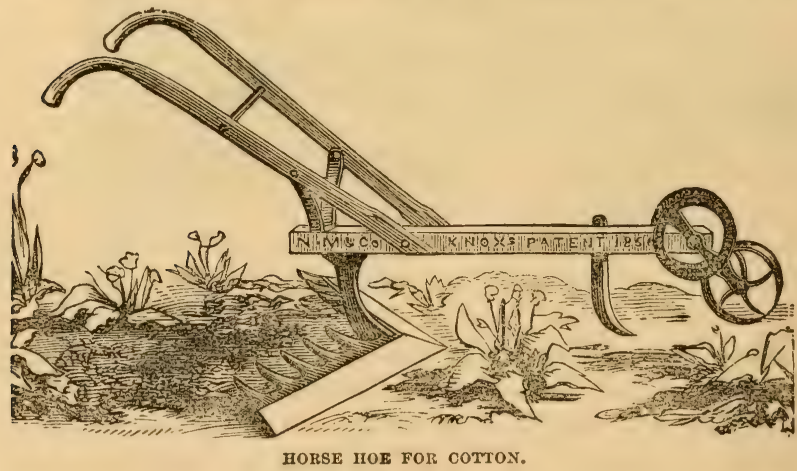

and weeds through its iron prongs or fingers in the rear, leaving the weeds on the surface to wilt and die, and the ground leves 


\section{Farm Implements and Their Use. 79}

and mellow. For hueing carrots, turnips, etc., where the rows are narrow, the side teeth are taken out, and the rear tooth, with the forward one as a director to guide the instrument, hoes and mellows the ground between the rows very perfectly." Our engraving represents a modification of Knox's hor'se hoe, adapting it particularly to the cultivation of cotton.

\section{V.-THE FIELD ROLLER.}

No good furmer will omit this useful implement from his list. It levels and sinooths the plowed land on sowing down to

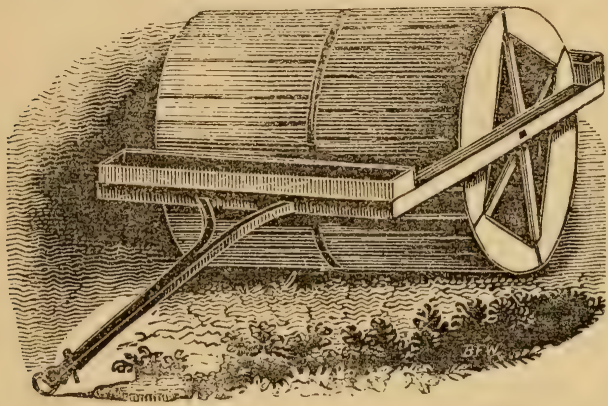

VOODEK FIEID ROLIE?.

grass, forcing sods and small stones into the soft ground, pulverizing all lumps of earth, pressing the light, loose soil of the surface around the seeds of grain, grass, ete., securing a suro and quick germination and growth of the seeds, and preparing a smooth, even surface for the reaper, seythe, and rake. By making the earth compact at the surface, insects are deprived of shelter; otherwise the sods, loose stones, and lumps of earth afford them convenient habitations. In spring there is frequently great advantage in rolling lands recently sowed to grain and grass, as the earth that has been raised by the fiost, exposing the roots of plants, is replaced by the operation, with bencfit to the growing crop. The roller is particularly beneficial on light lands, of soil too loose and porous to retain moisture and pro. 
tect the manure from the effects of drying winds and a scorch. ing sun, and too light too allow the roots of plants a firm hold in the earth; for on such lands its compressing effect, especially in dry seasons, very much increases the product of crop as well as preserves the manure from undue evaporation, thus saving a greater portion of its fertilizing properties for the benefit of the land and succeeding crops.

\section{VI.-SEED SOWERS.}

Every farmer or gardener needs a seed-sower of some sort; but one of the small-

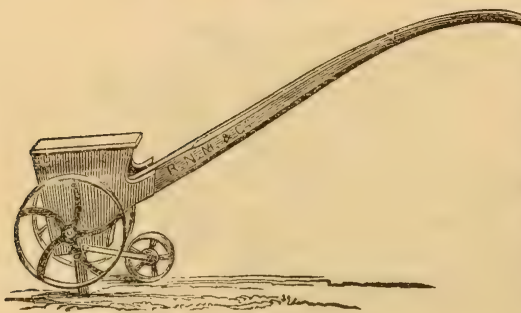

A BMALL IIAND-DRILL.

est and simplest of the many kinds manufactured will serve the purpose of the majority of agriculturists. The light hand-drill represented by the accompanying cut will be found entircly satisfactory where the work to be performed by such an implement is limited. The seed sower represented by the next engraving is larger, and rather more effective, but still light and cheap. With proper care, either of these little

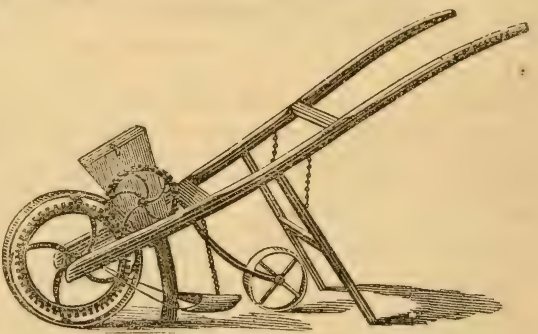

SEED-SOWER. implements will do the work required of them, in garden and field, for many years, without requiring renewal or repair.

$$
\text { VII.-THE HORSE RAKE. }
$$

The utility of this simple implement is not fully realized, wo 


\section{Farm Implements and Their Use. 81}

are sure, or it would be more generally employed. One man, with a horse and a boy (and with some of the implements the boy is not required), will, upon a favorable surface, perform the work of eight men with hand-rakes. A horse-rake is not an expensive implement, and every farmer should have one. The old revolver is perhaps the best for general use.

\section{VIII.-MOWERS, REAPERS, ETC.}

Of the expensive labor-saving agricultural implements, like the mower, the reaper, and the thrasher, it does not fall within our purpose to speak, further than to recommend our readers to avail themselves of the grand economies which they afford, whenever they can, by combinations with their neighbors for joint ownership of such machines, or by employing those kept for the purpose of being hired out. The small farmer can not afford to invest capital, of which he generally has too little, in these implements for himself alone. Those who are engaged in cultivation on a large scale, and have adequate capital, should, of course, own these labor-saving machines.*

For a complete list of farm implements, with an approximate estimate of their cost, see the next chapter.

* For most of the cuts used in illustrating this chapter, as well as for a portion of the descriptions given, we are indebted to the Descriptive and Illustrated Catalogue of Nourse, Mason \& Co., whose implements have won a deservedly high reputation in every part of the country. Their address is Quincy Hall, Boston, Mass. 


\section{VII.}

\section{FAR II II A A GE IIENT.}

A little farm well tilled ;

A little barn well flled;

A little wife well willed.

\section{I.-INTRODUCTORY.}

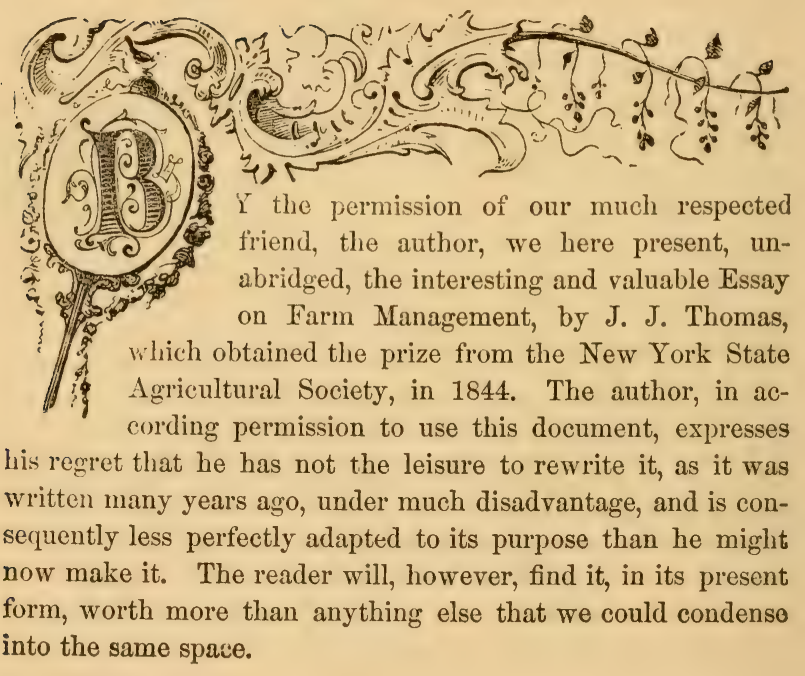

\section{II.-THE PRIZE ESSAY.}

ON FARM MANAGEMENT.

BY J. J. THOMAs.

The great importance of performing in the best manner the different operations of agriculture is obvious to every intelligent 
mind, for on this depends the success of farming. But a good performance of single operations merely does not constitute the best furming. The perfection of the art consists not only in doing everything well individually, but in a proper adjustment and systematic arrangement of all the parts, so that they shall be done not only in the best manner and at the right time, but with the most effective and economical expenditure of labor and money. Everything must move on with clock-work regularity, without interference, even at the most busy seasons of the year.

As this subject includes the whole routine of farming in a collected view as well as in its separate details, a treatise upon it might be made to fill volumes; but this being necessarily confined to a few pages, a general outline, with some remarks on its more essential parts, can only be given.

CAPITAL. - The first requisite in all undertakings of magnitude is to "count the cost." The man who commences a building, which to finish would cost ten thousand dollars, with a capital of only five thousand, is as certainly ruined as many farmers are who, without counting the cost, commence on a scale to which their limited means are wholly inadequate. One of the greatest mistakes which young farmers make in this country, in their anxious wish for large possessions, is, not only in purchasing more land than they can pay for, but in the actual expenditure of all their means, without leaving any even to begin the great work of farming. Hence, the farm continues for a long series of years poorly provided with stock, with implements, with manure, and with the necessary labor. From this heavy drawback on the profits of his land, the farmer is kept long in debt; the burden of which not only disheartens him, but prevents that enterprise and energy which are essential to success. This is one fruitful reason why American agriculture is in many places in so low a state. A close observer, in traveling through the country, is thus enabled often to decide from the appearances of the buildings and premises of each occupant, whether he is in or out of debt.

In England, where the enormous taxes of different kinds imperiously compel the cultivator to farm well or not farm at all, the indispensable necessity of a heavy capital to begin with is fully understood. The man who merely rents land there, must possess as much to stock it and commence operations as the muan who buy 
and pays for a farm of equal size in some of our best farming dis tricts. The result is, that he is enabled to do everything in the best manner; he is not compelled to bring his goods prenaturely to market to supply his pressing wants; and by having ready money always at command, he can perform every operation at the very best season for product and economy, and make purchases when necessary at the most advantageous rate. The English farmer is thus able to pay an amount of tax often more than the whole product of farms of equal extent in this country.

The importance of possessing the means of doing everything at exactly the right season can not be too highly appreciated. Ono or two illustrations may set this in a clearer light. Two farmers had each a crop of ruta-bagas of an acre each ; the first, by hoeing his crop early while the weeds were only an inch high, accomplished the task with two days' work, and the young plants then grew vigorously and yielded a heavy return. The second, being prevented by a deficiency of help, had to defer his hoeing one weck, and then three days more by rainy weather, making ten days in all ; during this time the weeds had sprung up six to ten inch as high ; so as to require, instead of two days, no less than six days to hoe them; and so much was the growth of the crop checked at this early stage that the owner had 150 bushels less in his acre than the farmer who took time by the forelock. Another instance occurred with an intelligent farmer of this State, who raised two fields of oats on land of similar quality. One field was sown very early, and well put in, and yielded a good profit. The other was delayed twelve days and then hurried; and although the crop was within two thirds of the amount of the former, yet that difference was just the clear profit of the first crop; so that with the latter the amount yielded only paid the expenses.

Admitting that the farm is already purchased and paid for, it becomes an object to know what else is neecled and at what cost, before cultivation is commenced. If the buildings and fences are what they should be, which is not often the case, little immediate untlity will be needed for them. But if not, then an estimate must be made of the intended improvements, and the necessary sum allotted for them. These being all in order, the following items requiring an expenditure of capital will be required on a good farm of 100 acres of improved land. 


\section{LIVESTOCK.}

The amount will vary with the fertility and products of the land, its quality, and situation with regard to market. The following will approximate the average on good farms taken at the spring of the year or commencement of work :*

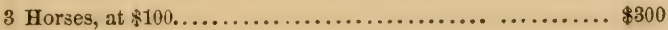

1 Yoke oxen................................... 150

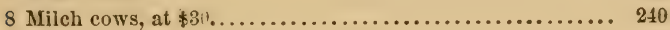

10 Steers, heifers, and calves....................... 100

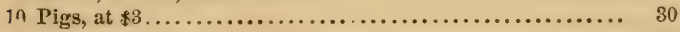

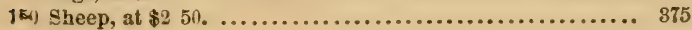

Poultry-say................................. 5

Total............................ $\overline{\$ 1,290}$

II. IMTPLEMENTS.

2 Plows fitted for work..........................\$20 00

1 Small plow, do. ............................. 600

1 Cultivator, best kind........................... 700

1 Drill-barrow................................. 50 00

1 Roller....................................... 500

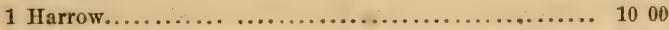

1 Fanning-mill ............................... 2000

i Straw-cutter................................. 1500

1 Root-slicer................................. 800

1 Farm-wagon, with hay-rack ete.................. 7000

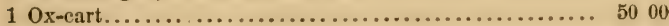

1 Double farm harness............................ 3000

1 Horse-cart..................................... 4500

1 Horse-cart harness............................. 1800

1 Root-steamer, or boiler.......................... 2000

1 Shovel and one spade......................... 250

3 Steel-plate hoes .............................. 150

2 Dung-forks.................................. 200

3 Hay-forks................................... 225

2 Hand-rakes.................................. 25

1 Revolving horse-rake.......................... 800

1 Grain-cradle................................ 400

2 Scythes.................................... 400

1 Wheelbarrow................................. 400

1 Pointed shovel............................. 125

1 Grain-shovel, or scoop-shovel.................... 125

1 Pick................................... 150

Carried forward....................... \$361 50

* We allow the figures to stand as in our first edition. If we add to each sum the premitim on gold, we shall approximate present prices. 
Brought forward $\$ 36150$

$1 \mathrm{Mall}$ and wedges............................ 250

2 Axes ...................................... 400

1 Hammer..................................... 50

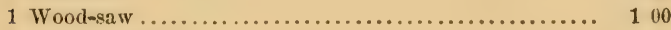

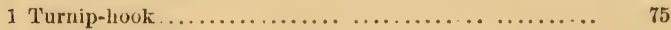

1 Hay-knife................................. 100

2 Apple-ladders (for gathering)................... 150

2 Large baskets.................................. 125

2 Hand-baskets............................... 50

1 Tape-line (for laying off land) $\ldots \ldots \ldots \ldots \ldots \ldots \ldots \ldots, 200$

2 Sheep-shears................................. 200

1 Grindstone.................................. 300

1 Steel-yard, large, and one small................... 200

1 Stable lantern................................. 50

1 Curry-comb, and one brush....................... 75

1 Half-bushel measure............................ 100

20 Grain-bags................................... 500

$10 x$-chain....................................... \$ 80

1. Crow-bar .................................... 200

1 sled and fixtures ............................. 3000

Total..................................\$125 75

Other articles might be included, as subsoil plow, sowing machine, threshing machine, etc. To the preceding amount ought to be added one-tenth the expense of fencing the farm, as fences need renewing at least once in ten years. Every furm should also be supplied with a small set of carpenter's tools, which would cost about $\$ 12$, for repairing implements in rainy weather and other useful purposes. This set should include saw, hammer, augers, planes, adze, mallet, chisel, square, breast-bits, etc., and by the convenience and economy afforded, would soon repay their cost.

III. SEEDS.

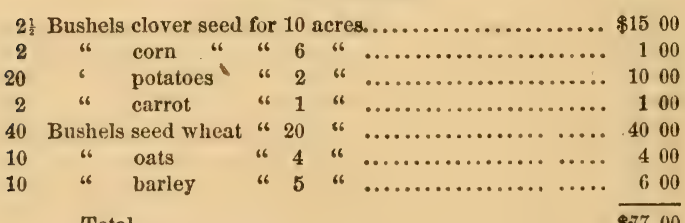

Total................................ \$7700

IV. LABOR.

Supposing the owner to labor with his own hands, as every owner should, so far as is consistent with a general superintend 
ence of all parts, which would probably amount to one half the time, he would need besides through the season two men and one boy, and in the winter one man; during haying and harvest he would require two additional hands. The men boarding themselves, could be had for twenty dollars per month in summer and sixteen in winter; if boarded, the cost of their meals would make up the deficiency in the wages to the same amount. The expenditure needed, then, would be,

2 Hired men, eight months, $\$ 21)$ per month........... $\$ 32000$

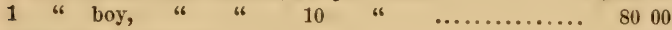

Day labor in harvest.......................... $\quad 3000$

Total................................. $\overline{\$ 43000}$

\section{MAINTENANCE OF ANIMALS.}

Cattle and sheep would need hay till fresh pasture, and horses hay, and also a good supply of oats till after harvest. All would be benefited by a liberal feeding of roots, including swine. The amount of all these supplies needed would be about,

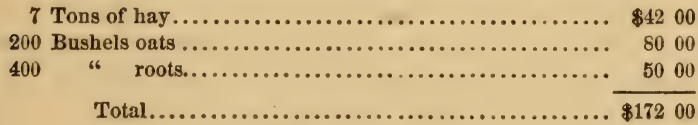

RECAPITULATION.

Livestock ................................. $\$ 1,20000$

Implements................................ 42575

Seeds ..................................... $\quad 7700$

Labor................................... $\quad 43000$

Maintenance of animals...................... 17200

Total

$\$ 2,31475$

- the amount of capital needed the first year, in stocking and conducting satisfactorily the operations of one hundred acres of improved land, several items being doubtless omitted.

If this is a larger sum than the young farmer can command, let him purchase only fifty acres, and reserve the rest of the purchase money which would be needed for the one hundred acres, to commence with on a smaller farm, and he will scarcely fail to make more than on a larger, with every part subjected to ar imperfect, hurrying, and irregular management. He may calculate, perhaps, on the return of his crops in autumn, at least to pay his 
hands. But he must remember that the first year of farming is attended with many expenses which do not usually occur afterward, which his crops may not repay, besides supporting his family and paying his mechanics' and merchants' bills. The first year must always be regarded with uncertainty ; and it is better to come out at the end on a moderately sized farm, wull tilled and in fine order, with money in pocket, than on a larger one, in debt, and hired hands - a class of men not to be disappointed, and who ought not to be-waiting for their pay. There are a far greater number of farmers embarrassed and crippled by placing their estimate of expenses too low, than of those who swing clear and float freely by a full previous counting of cost.

Size of Farms. - After what has just been said, the cultivator will perceive in part the advantages of moderately sized farms for men in moderate circumstances. The great disadvantage of a superficial, skimming culture is obvious with a moment's attention. Take the corn crop as an illustration. There are a great many farmers, to my certain knowledge, whose yearly product per acre does not exceed an average of twenty-five bushels. There are other farmers, whom I also well know, who obtain generally not less than sixty bushels per acre, and often eighty to ninety-five. Now observe the difference in the profits of each. The first gets 250 bushels from ten acres. In doing this, he has to plow ten acres, harrow ten acres, mark out ten acres, find seed for ten acres, plant, cultivate, hoe, and cut up ten acres, besides paying the interest on ten acres, worth from three to five hundred dollars. The other farmer gets 250 bushels from four acres at the farthest; and he only plows, plants, cultivates, and hoes, to obtain the same amount, four acres, which from their fine tilth, and freedom from grass and weeds, is much easier done, even for an equal surface. The same reasoning applies throughout the farm. Be sure, then, to cultivate no more than can be done in the best manner, whether it be ten, fifty, or five hundred acres. A friend who owned a four-hundred-acre farm told me that he made less than his next neighbor, who had only seventy-five. Let the man who applies a certain amount of labor every year to his farm reduce its dimensions until that labor accomplishes everything in the very best manner. $\mathrm{H}_{0}$ will doubtless find that the amount of land will thus become much smaller than he supposed, more so than most would be willing to 
reduce it; but, on the other hand, the net proceeds from it will augment to a greater degree than perhaps could possibly be believed.

But let me not be misunderstood. Large farms are by no means to be objected to, provided the owner has capital enough to perform all the work as well as it is now done on the best farms of small size.

As an example of what may be obtained from a small piece of land, the following products of fifty acres are given, and are not more than I have known repeatedly to be taken from good land by several thorough farmers :

\begin{tabular}{|c|c|c|c|c|c|}
\hline \multicolumn{2}{|c|}{10 Acres wheat, } & \multicolumn{3}{|c|}{35 bushels per acre, at $\$ 100 \ldots$} & \multirow{2}{*}{$\begin{array}{r}\$ 35000 \\
15000\end{array}$} \\
\hline 56 & corn, & $90 \quad 6$ & " & $40 \ldots$ & \\
\hline $2 \quad 6$ & potatees, & 300 & 66 & $20 \ldots$ & 12000 \\
\hline 1 Acre & ruta-bagas, & 800 & " & $10 \ldots$ & 8900 \\
\hline 6 Acre: & winter apples, & 250 & - & $25 \ldots$ & 37500 \\
\hline 66 & hay, & $2 \frac{1}{2}$ tons & 6 & $600 \ldots$ & 9000 \\
\hline 10 & pasture, worth & a............ & ...... & ....... & 6000 \\
\hline "6 & barley, & 40 bushel & acre & $40 \ldots$ & 8000 \\
\hline 66 & oats, & $50 \quad 66$ & 6 & $20 \ldots$ & 5000 \\
\hline
\end{tabular}

This aggregate yield is not greater than that obtained by some who might be named, from a similar quantity of land. Good land in most localities could be brought to that state of fertility very easily, at a total cost of one hundred dollars per acre, and then it would be incomparably cheaper than many large good farms at nothing; for, while the fifty acres could be tilled for three hundred and eighty-five dollars, leaving one thousand dollars net profits, large poor farms hardly pay the work spent upon them. One proprietor of such a farm declared, "It requires me and my hired man all summer hard at work to get enough to pay him only."

LAYING OUT FARMrS.-This department is very much neglected. The proper disposition of the different fields, for the salke of economy in fencing, for convenience of access, and for a full command of pasture and protection of crops at all times, has received comparatively little attention from our agricultural writers and from farmers.

Many suppose that this business is very quickly disposed of ; that a very few minutes, or hours at mosc, will enable a man to plan 
the arrangement of his fields about right. But this is a great error. Even when a farm is of the simplest form, on a flat, uniform piece of ground, many things are to be borne in mind in laying it out.

In the first place we all know that the fencing of a moderately sized farm costs many hundred dollars. It is very desiralle to do it well, and use at the same time as little material as possible. To do this much will depend on the shape of the fields. A certain length of fence will inclose more land in the form of a square than in any other practictl shape. Hence fields should approach this form as nearly as possible. Again, the disposition of lanes is a matter of consequence, so as to avoid unnecessary length and fencing and occupy the least quantity of ground.

But these rules may be materially affected by other considerations. For instance, it is very desirable that land of a similar quality may be in the same inclosure. Some may be naturally too wet for anything but meadow or pasture: some may be much lighter, and susceptible of plowing, while others are not: some may be naturally sterile, and need unusual manuring with green crops. All these should, as far as practicable, be included each in its own separate boundary. The situation of surface drains, forming the boundaries of fields, may influence their shape ; facilities for irri gation may have an essential bearing: convenience for watering cattle is not to be forgotten. Where, in addition to all these considerations, the land is hilly, still more care and thought are required in the subdivision, which may possibly require years of experience; but where fixed fences are once made, it is hard to remove them; hence a previous thorough examination should be made. A farm road, much used for heavy loads, should be made hard and firm, and can not easily be altered ; it consequently should be exactly in the right place, and be dry, level, and short; the shape of adjoining fields even conforming with these requisitions ; but a road little used should not interfere with the outlines of fields.

$$
\%
$$$$
\text { " }
$$$$
\text { * }
$$$$
\text { : }
$$$$
\text { : }
$$$$
\text { औ }
$$

In laying out a farm with a very uneven surface or irregular shape, it would be best to draw, first, a plan adapted to sinooth ground, and then vary the size and shape of the fields, the distance of the lane from the center, its straightness, etc., accurd. ing to the circumstances of the case. 
Fences." - The kind of fence used, and the materials used for its construction, must depend on circumstances and localities. A good fence is always to be preferred to an imperfect one; though it will cost more, it will more than save that cost, and three times the amount in vexation besides, by keeping cattle, colts, and pigs out of fields of grain. A thriving farmer whose whole land, except a small part with stone wall, is inclosed by common rail fence, with upright cedar stakes, and connecting caps to the tops, finds that it needs renewing once in six years. He accordingly divides his whole amount of fences into six parts, one of which is built new every year. All is thus kept systematically in good repair. Stone walls, if set a foot below the surface to prevent tumbling by frost, are the most durable fence. Hedges have not been sufficiently tried. The English hawthorn is not well adisted to our hotter and drier climate, and though sometimes doing well for a time, is not to be depended on.

Gates.-Every field on the farm should be entered by a good self-shutting and self-fastening gate. A proper inclination in hanging will secure the former requisite, and a good latch, properly constructed, the latter. Each field should be numbered, and the number painted on the gate-post. Let the farmer who has bars instead of gates, make a trial of their comparative convenience, by taking them out and replacing them without stopping as often as he does in one year on his farm, say about six hundred times, and he can not fail to be satisfied which is the cheapest for use.

Buildings. - These should be as near the center of the farm as other considerations will admit. All the hay, grain, and straw being conveyed from the fields to the barn, and most of it back again in manure, the distance of drawing should be as short as possible. This will also save much traveling of men and cattle to and from the different parts of the farm. The buildings should

* Strange as it may seem, the greatest investment in this country, the most costly production of human industry, is the common fences which divide the fields from the highway, and separate them from each other. No man dreams that when compared with the outlay of these unpretending monuments of art, our cities and our towns, with all their wealth, are left far behind. You will scarce believe me when I say that the fences of :his country have cost more than twenty times the specie there is in it. In many of the counties of the Northern States the fences have cost more than the farms and fonces are worth -Burnap. 
not, however, be too remote from the public road, and a good, dry, healthy spot should be chosen. The dwelling should be comfortable, but not large; or it should rather be adapted to the extent of the lands. A large, costly house with a small farm and other buildings, is an indication of bad management. 'The censure of the old Roman should be avoided, who, having a small piece of land, built his house so large that he had less occasion to plow than to sweep.

The barn and out-buildings should be of ample extent. The barn should have space for hay, grain, and straw. It is a matter of great convenience to have the straw for littering stables housed and close at land, and not out of doors, under a foot of snow. There should be plenty of stables and sheds for all domestic animals. This provision will not only save one third of the fodder, but stock will thrive much better. Cows will give much more milk, sheep will yield more and better wool, and all will pass through the winter more safely. The wood-house, near or attached to the dwelling, should never be forgotten, so long as cumfort in building fires and economy in the use of fuel are of any importance.

A small, cheap, movable horse-power should belong to every establishment, to be used in churning, sawing wood, driving washing machine, turning grindstone, cutting straw, and slicing roots.

There should be a large ront-cellar under the barn, into which the cart may be dumped from the outside. One great objection to the culture of roots, in this country-the difficulty of winter keeping-would then vanish.

Both barns and house cellars should be well coated, on the bottom and sides, with water-lime mortar, which is a very ciseap and effectual way to exclude both water and rats.

Choice of Implements. - Of those which are much used, the very best only should be procured. This will be attended with a gain in every way. The work will be easier done and it will be better done. A laborer who, by the use of a good hoe for one month, can do one quarter more each day, saves, in the whole time, an entire week's labor.

Chorce of Anmars. - The best of all kinds should be selected, even if costing something more than others. Not "funcy" ari mals, but those good for use and profit. Cows should be product. 
ive of milk, and of a form adapted for beef ; oxen hardy, and fastworking; sheep, kept fine by never selling the best; swine, not the largest merely, but those fattening best on least food. A Berkshire at 200 pounds, fattened on 10 bushels of corn, is better than a "land pike" of 300 , fattened on 50 bushels.

Having now taken some notice of the necessary items for commencing farming, it remains to glance a little at

Soils, and their Management. - Soils are of various kinds, as heavy and light, wet and dry, fertile and sterile. They all require different management in a greater or less degree.

Heavy soils are often stronger and more productive than light ; but they require more labor for pulverization and tillage. They can not be plowed when very wet, nor so well when very dry. Although containing greater or less portions of clay, they may be distinguished, as a class, from lighter soils, by the cloddy surface the fields present after plowing in dry weather, by their cracking in drouth, and by their adhesiveness after rains.

Sandy and gravelly loams also contain clays, but in smaller quantity ; so that they do not present the cloddiness and adhesiveness of heavy soils. Though possessing, generally, less strength than clay soils, they are far more easily tilled, and may be worked without difficulty in wet weather. They do not crack or break in drouth. Indian corn, ruta-bagas, and some other crops, succeed best upon them. Sandy soils are very easily tilled, but are generally not strong enough. When made rich, they are fine for some succulent crops. Peaty soils are generally light and free, containing large quantities of decayed vegetable matter. They are made by draining low and swampy grounds. They are fine for Indian corn, broom corn, barley, potatoes, and turnips. They are great absorbers, and great radiators of heat; hence they become warm in sunshine and cold in clear nights. For this reason they are peculiarly liable to frosts. Crops planted upon them must, consequently, be put in late, after spring frosts are over. Corn should be of early varieties, that it may not only be planted late, but ripen early.

Each of these kinds of soil may be variously improved. Heavy soils are much improved by draining; open drains to carry off the surface-water, and covered drains, that which settles beneath. An acquaintance covered a low, wet, clayey field with under-drains, 
and from a production of almost nothing but grass, it yielded the first year forty bushels of wheat per acre, enough to pay the expense, and admitted of much easier tillage afterward. Heavy soils are also made lighter and freer by manuring; by plowing under coat. ings of straw, rotten chips, and swamp muck; and, in some rare cases, by carting on sand, though this is usually too expensive for practice. Subsoil plowing is very beneficial both in wet seasons and in drouth; the deep loose bed of earth it makes, receiving the water in heavy rains, and throwing it off to the soil above, when needed; but a frequent repetition of the operation is needed, as the subsoil gradually settles again.

Sandy soils are improved by manuring, by the application of lime, and by frequently plowing in green crops. Leached ashes have been found highly beneficial in many places. Where the subsoil is clayey, which is often the case, and especially if marly clay, great advantage is derived from shoveling it up and spreading it on the surface. A neighbor had twenty bushels of wheat per acre on land thus treated, while the rest of the field yielded only five.

ManUres.-These are among the first of requisites in successful farm management. They are the strong-moving power in agricultural operations. They are as the great steam-engine which drives the vessel onward. Good and cle:n cultivation is, indeed, all important; but it will avail little without a fertile soil; and this fertility must be created or kept up. by a copious application of manures ; for these contribute directly or assist indirectly to the supply of nearly all the nourishment which plants receive. It is these which, produced chiefly from the decay of dead vegetable and animal matter, combine most powerfully to give new life and vigor; and thus the apparently putrid mass is the very material which is converted into the most beautiful forms of nature, and plants and brilliant flowers spring up from the decay of old forms; and thus a continued succession of destruction and renovation is carried on through an unlimited series of ages.

Manures possess different degrees of power, partly from their inherent richness, and partly from the rapiaity with which they throw off their fertilizing ingredients, in assisting the growth of plants. These are given off by solution in water, and in the form of gas; the one as a liquid manure, which, running down, ia 
alssorbed by the roots ; and the other, as air, escaping mostly into the atmosphere, and lost.

The great art, then, of saving and manufacturing manure consists in retaining and applying, to the best advantage, those soluble and gaseous portions. Probably more than one half of all the materials which exist in the country are lost, totally lost, by not attending to the drainage of stables and farmyards. This could be retained by a copious application of straw; by littering with sawdust, when saw-mills are near; and, more especially, by the frequent coating of yards and stables with dried peat and swamp muck, of which many parts of our States furnish inexhaustible supplies. I say dried peat or muck, because, if it is already saturated with water, of which it will often take in five sixths of its own weight, it can not absorb the liquid portions of the manure. But if it will alssorb five sixths in water, it will, when dried, absorb five sixths in liquid manure, and, both together, form a very enriching material. The practice of many farmers shows how little they are aware of the hundreds they are losing, every yea1, by suffering this most valuable of their farm products to escape. Indeed, there are not a few who carefully, and very ingeniously, as they suppose, place their barns and cattle-yards in such a manner, on the sides of hills, that all the drainage from them may pass off out of the way into the neighboring streams; and some one mentions a farmer who, with pre-eminent shrewdness, built his hogpen directly across a stream, that he might, at once, get the cleanings washed away, and prevent their accumulation. He, of course, suceeded in his wish ; but he might, with almost equal propriety, have built his granary across the stream, so as to shovel the wheat into the water when it increased on his hands.

The loss of manure, by the escape of gas, is often very great. T'be proof of this was finely exhibited by Humphrey Davy, in an experiment performed by filling a large retort from a heap of fermenting manure, and placing the beak among the roots of some grass. Nothing but vapor left the vessel, yet in a few days the grass exhibited greater luxuriance around the beak of the retort than any of the surrounding portions. Hence the superiority of unfermented manures; the rich portions are not yet lost. And hence, too, the importance of preventing this loss by an immediato application, and plo ving into the soil, or by mixing it in composts 
with muck, peat, swamp mud, and even common earth, in a dry state-and of preventing its escape, from stables and yards, by a daily strewing with dried peat, lime, or plaster.

Fresh manure is generally in a state not readily mixed with soils. It is thrown into large lumps over the surface, some of which are plowed in, others not; but none of them prove of immediate use to the crops. But, on the other hand, fermented manure, from its rearly pulverization, admits of an easy admixture. But let fresh manure be thoroughly ground down and worked into the soil by repeated harrowings and two or three plowings, and its influence will be like magic.

Swamp muck has often been spoken of as manure; but those who expect great and striking results from its application will be disappointed. Even with ashes, it is much less powerful than stable manure, not only because it possesses less inherent richness, but because it has less soluble parts, and, consequently, imparts its strength more slowly to growing plants. But this quality only makes it the more enduring. By decoction in water, vegetable mold loses a small portion of its weight by solution; but if the remaining insoluble part is exposed to the air and moisture a few months, another part may be again dissolved. Thus, peat, muck, and all decayed vegetable fiber, become a slow but lasting source of nourishment to plants.

But it is when shoveled out and dried, to be mixed with farmyard manure, as a recipient for its evanescent parts, that peat or muck becomes pre-eminently valuable. Some parts of the State abound with inexhaustible supplies in almost every neighborhood; many land-owners have from twenty to a hundred thousand cubic yards on their farms, lying untouched, while half-starved crops are growing in the adjacent fields. There are whole counties so well supplied with, it that, if judiciously applied, it would, doubtiess, double their aggregate products.

All neat farming. all profitable farming, and all satisfactory farming must be attended with a careful saving of manures. The people of Flanders have long been distinguished for the neatness and excellence of their farms, which they have studied to make like gardens. The care with which they collect all refuse materials which may be converted into manures, and increase their composts, is one of the chief reasons of the cleanliness of their towns and 
residences; and were this subject fully appreciated and attended with a corresponding practice generally, it would, doubtless, soon increase, by millions, the agricultural products of the State.

But there is another subject of scarcely less magnitude. This is a systematic

Rotation of Crops.-If manuring is the steam-engine which propels the vessel, rotation is the rudder which guides it in its progress. Unlike manuring, rotation does not increase the labor of culture : it only directs the labor in the most effective manner by the exercise of judgment and thought.

The limits of this paper do not admit of many remarks on the principles of rotation. The following courses, however, have been found among some of the best adapted to our State :

I. 1st year-Corn and roots, well manured.

$2 d$ year-Wheat, sown with clover-seed; $15 \mathrm{lbs}$. an acre.

3d year-Clover, one or more years, according to fertility and amount of manure at hand.

II. 1st year-Corn and roots, with all the manure.

$2 \mathrm{~d}$ year-Barley and peas.

3d year-Wheat, sown with clover.

4 th year-Clover, one or more years.

III. 1st year-Corn and roots, with all the manure.

$2 d$ year-Barley.

3d year-Wheat, sown with clover.

4th year-Pasture.

5th year-Meadow.

6th year-Fallow.

7th year-Wheat.

- 8th year-Oats, sown with clover.

9th year-Pasture or meadow.

The number of the fields must correspond with the number of the changes in each course ; the first needing three fields to carry it out, the second four, the third nine. As each field contains a crop each, in the several successive stages of the course, the whole number of fields collectively comprise the entire series of crops every year. Thus, in the list above given, there are two fields of wheat growing at once, three of meadow and pasture, one of corn and roots, one of barley, one of oats, and one in summer fallow.

Operations in the Order of Trme. - The vital consequence of doing every thing in the right season is known to every good farmer.

To prevent confusion and embarrassment, and keep all things 
clearly and plainly before the farmer at the right time, he should have a small book to carry in his pocket, having every item of work for each week or each half month laid before his eyes. This can be done to the best advantage, to suit every particular locality and difference of climate, by marking every successive week in the season at the top of its respective page. Then as each operation severally occurs, let him place it under its proper heading; or if out of season, let him place it back at the right time. Any proposed improvement can be noted down on the right page. Interesting experiments are often suggested in the course of reading or observation, but forgotten when the time comes to try them. By iecording them in such a book, under the right week, they are brought at once before the mind. Such an arrangement as this will prevent a great deal of the confusion and vexation too often attendant on multifarious cares, and assist very essentially in conducting all the farm work with clock-work regularity and satisfaction.

In reviewing the various items which are most immediately essential to good farm management, some of the most obvious will be-capital enough to buy the farm and to stock it well ; to select a size compatible with these requisites; to lay it out in the best manner ; to provide it well with fences, gates, and buildinge ; to select the best animals, and the best implements to be had reasonably; to bring the soil into good condition, by draining, manuring, and good culture; to have every part under a good rotation of crops; and every operation arranged so as all to be conducted systematically, without clashing or confusion. An attention to all these points would place agriculture on a very different footing from its present condition in many places, and with most farmers. The business, then, instead of being repulsive, as it so frequently is to our young men, would be attended with real enjoyment and pleasure.

But in all improvements, in all enterprises, the great truth must not be forgotten, that success is not to be expected without diligence and industry. We must sow in spring and cultivate weil in summer, if we would reap an abundant harvest in autumn. When we see young farmers commence in life without a strict attention to business, which they neglect for mere pleasure, well may we in imagination see future crops lōst by careless tillage- 
broken fences, unhinged gates, and fields filled with weeds-tools destroyed by heedlessuess, property wasted by recklessness, and disorder and confusion triumphant; and unpaid debts, duns, and executions already hanging over the premises. But, on the other hand, to see cheerful-faced, ready-handed industry, directed by reason and intelligence, and order, energy, and economy, guiding the operations of the farm-with smooth, clean fields, and neat, trim fences-rich, verdant pastures, and fine cattle enjoying them ; and broad, waving meadows and golden harvests, and waste and extravagance driven into exile, we need not fear the success of such a farmer; debts can not stare him in the face, nor duns enter his threshold.

It is such enterprise as this that must place our country on a substantial basis. Agriculture, in a highly improved state, must be the means which, next to the righteousness which truly exalts a nation, will contribute to its enduring prosperity. All trades and commerce depend on this great art as their foundation. The cultivation of the soil and of plants was the earliest occupation of man. It has, in all ages, been his chief means of subsistence ; it still continues to furnish employment to the great majority of the human race. It is truly the great art of peace, as during wars and commotions it has languished and declined, but risen again, in strength and vigor, when men have lived at peace with each other; it has then flourished and spread, converted the wilderness into life and beauty, and refreshed and adorned nature with embellished culture. For its calm and tranquil pleasures-for its peaceful and healthful labors-away from the fretful and feverish life of crowded cities, "in the free air and beneath the bright sun of heaven" -many who have spent the morning and noon of their lives in the anxious cares of commercial life, have long sighed for a scene of peace and of quietude for the evening of their days. 


\section{VIII. \\ FAR II CROPS.}

Let it raln potatoes. - Shakspeare.

\section{I. - THE EDIBLE GRAIN.}

1. Indian Corn-Zea Mays.

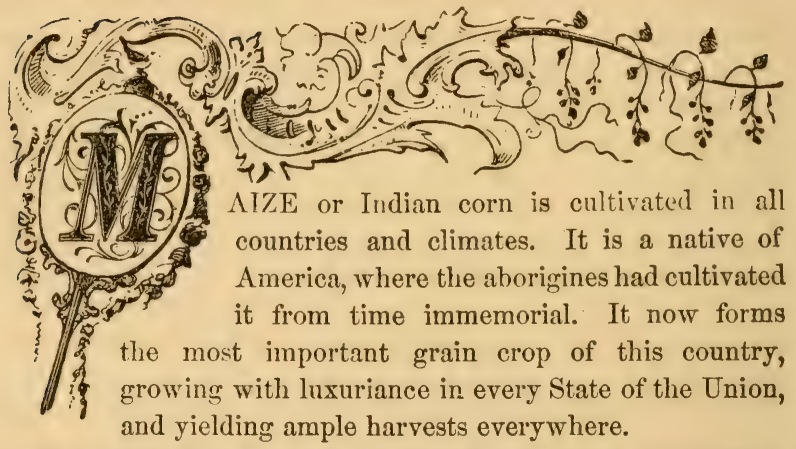

The varieties of maize in cultivation are almost numberless, and new sorts are constantly being produced. No plant, perhaps, is equally susceptible of modification by hybridizing, cultivation, soil, and climate. At the North it is dwarf in its habit, and requires but three or four months to bring it to maturity, while at the South it reaches a magnificent height, and is much longer in maturing. A kind of corn cultivated in Oregon has a separate sheath or envelop for every distinct kernel; but in the climate of New York it soon loses this characteristic, and assumes the more comprehensive husk. So the low growing, early Northern corn, if cultivated for a few years 


\section{FARM Crops.}

at the South, becomes taller, larger, and later; thus approximating to the Southern varieties.

The principal varieties of Indian corn in extensive use for field culture in the United States are the Big White, Big Yellow, Little White, Little Yellow, and Virginia Gourd Seed (yellow and white). Of each of these there are many sub-varieties. The King Philip or Brown Corn, a very early and small-growing, but productive variety, is much approved in the more Northern States; and Peabody's Prolific or Tillering Corn, said to be a wonderfully productive sort, is adapted to the Southern and Middle States; but it has not yet been extensively tested. In the selection of varieties, choose for general planting those that have been proved in your own vicinity, as the best sort of one locality may prove inferior in another. For trial, get new sorts from a more northern latitude, especially where earliness is particularly desirable.

The best soil for corn is a rich loam, but good crops are produced, with proper manuring, on light, sandy land. A strong clay, or a poor, wet soil, will not produce a good crop. Corn is a gross feeder, and, except on very light, sandy soils, fresh, unfermented manure is best for it. Ashes may be added, or applied as a top-dressing, with great advantage; also the salt and lime mixture.

Indian corn should always be planted in hills, and in straight rows, both ways, for convenience of cultivation. The distance apart of the hills should be from three to five feet, varying with the sort of corn and the quality of the land. From three to five stalks in a hill is better than a larger number. Soak the seed one or two days in a solution of common salt, or, better still, of saltpeter, after which apply a coat of tar and plaster, according to the directions given in Chapter II. This will not only accelerate the growth of the plant, but also afford an efficient protection against both worms and birds. As to the proper depth for covering the seed, much difference of opinion exists. We think a depth of one inch, in soil of medium consistency and humidity, and of two or two and a half inches in 
a dry, sandy soil is sufficient. Plant so soon as the ground is sufficiently warm and dry, without respect to the day of the month. The blossoming or leafing of certain trees may be taken as a guide. Our time is when the flower-buds on the apple-trees begin to burst open.

The after-culture of Indian corn may mostly be performed with a light plow and a good cultivator. It should be commenced soon after the plants show themselves above ground; but deep culture of every kind should be discontinued after the roots have spread through the soil, as they can not be disturbed without great injury. Hilling or heaping the earth about the plants is an absurd and injurious process, which, instead of helping to support them, as many suppose, greatly weakens the stalks, by destroying or covering up the prop-roots with which Nature has supplied them. This compels them to partially exhaust themselves by putting forth others, which after all can not efficiently perform their office. Indian corn requires very little, if any, earthing.

In reference to harvesting Indian corn, a variety of opinions prevail. Some advocate topping it soon after the kernels have become glazed or checked, believing that such a course hastens the ripening of the grain, and that the fodder thus cut is much more valuable than when left till the corn is fully ripened. In these opinions the advocates of topping are undoubtedly correct; but, on the other hand, experiments seem to prove that the weight of the grain and the number of bushels per acre is considerably lessened by thus cutting the stalks. The more common practice at present, except at the South, is to let the crop stand till the kernels are principally glazed, and then cutting all near the surface of the ground, and shocking in the field, to remain till dry enough to husk. The grain loses a little in weight, no doubt, by this process, but the fodder is more valuable than when it stands till fully ripened, and the crop thus treated is placed beyond injury from frost. This, for tho Northern and Middle States, we consider the best way to harvest Indian corn; although a somewhat greater bulk and weight 
of grain may be obtained, if the frosts be long enough deferred, by allowing nature to take its course.

Corn should be perfectly dried in the field, husked, and stored in an airy loft, or in a properly constructed granary or crib.

The proper selection and saving of seed is of great importance. It should be selected in the field from the earliest and largest ears of the most prolific stalks. In this way astonishing improvements in a variety may be gradually made. Thomas N. Baden, Esq., of Prince George County, Md., by carefully selecting the best seerl in his field for a long series of years, having special reference to those stalks which produced the greatest number of ears, ultimately ovtained a variety which yields from four to ten ears to the single stalk.

In husking seed corn, leave a few of the husks upon the ears, with which to braid several of them together, for convenience in hanging them up. They should be hung in a dry, airy loft. In shelling, reject both extremities of the ear where the kernels are imperfect or misshapen.

The expense per acre of cultivating corn varies greatly in different parts of the country, being influenced by soil, climate, cost of manure, price of labor, etc. For New York, Judge Buel estimates as follows:

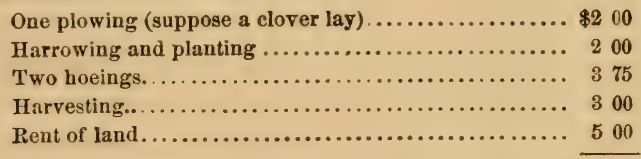

Total................................ $\$$

This estimate does not include manure, which is generally essential, and would add from five to ten dollars to the expense. In New England the whole expense varies from twenty-five to fifty dollars. A farmer near Philadelphia estimates it at twenty-three dollars in his neighborhood; another, at Ripley, Ohio, gives the following:

"I subjoin my account with a corn-field of eighteen acres. The ground and the corn have been measured-there is no guess work about it. 
"Timber-originally walnut, ash, sugar maple, and beechhas been under cultivation twenty years-last year was in wheat, and the year before in corn. The soil dark-ten inches deep, with a clay bottom-was broken up eight inches deep with a span of horses:

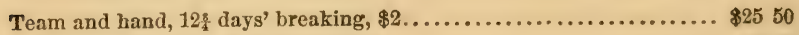

Cost of seed, laying off, and planting...................... 1805

$30 \frac{s}{4}$ days' work, harrowing, plowing, hoeing, etc., $87 \frac{1}{2}$ cents......... 2090

Use of team, equal to $26 \frac{8}{4}$ days single, 52 cents................. 1391

Repairing tools....................................... 100

Entire cost, board, labor, and all ..................... $\$ 8036$

"The yield is 1,350 bushels, costing before gathering not quite six cents per bushel."*

Here no manure is used, we presume, and the soil requires less cultivation than at the East, in order to produce good crops. The expense per acre, exclusive of harvesting, according to

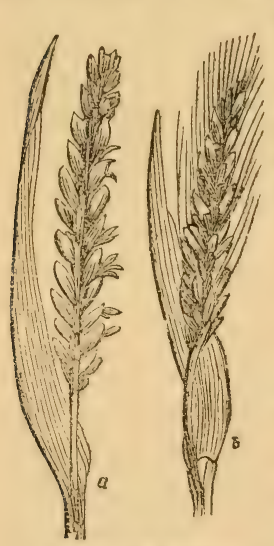

HEADS OF WHEAT. this estimate, is less than $\$ 450$.

But, leaving these estimates out of the account, the fact that corn is generally one of the most profitable crops that a farmer can cultivate, may be set down as an established fact.

\section{Wheat-Triticum of species.}

The origin of wheat is unknown; but it is certain that it was cultivated upward of a thousand years before the Christian era, and that more than one sort was known at that time, for it is stated in the book of Ezekiel (xxvii. 7) that "Judah traded in wheat of Minnith." Columella, who wrote about the time of Christ, observes that, "The chief and the most profitable corns for men are common wheat and bearded wheat."

Botanists describe about thirty species of wheat, and some 
hundreds of varieties. The species mainly cultivated in the United States are the Winter Wheat and the Spring Wheat, in their numerous varieties.

In your choice of varieties it is best to be governed, as in the case of Indian corn, by the experience either of yourself or others. From the ever-varying character of the various kinds of seed, their superiority at one time and locality, and their inferiority at other times and in other situations, it would be worse than useless for us to recommend any particular variety. Depend upon known and tried sorts till, by experiments on a small scale, you are satisfied that you have obtained something better.

Wheat thrives best on a strong, clayey loam, but many light and all calcareous soils, if in a proper condition, will give a good yield. A glance at the table on page 28 will show that potash, lime, and phosphoric acid enter largely into the composition of the grain, and that both lime and silica abound in the straw ; for this reason, rich vegetable soils generally, being deficient in these elements, are not well adapted to wheat. On such soils there is always a tendency to rapid growth, large but weak straw, and light grain ; and a liability both to lodge and to rust. A remedy, however, may be found in the application of ashes, lime, bone-dust, etc. The soil should be deep and well pulverized with the plow and the harrow. Underdraining and subsoil plowing add greatly to the amount of the crop.

Select seed that is free from the seeds of weeds and from smut, if this be possible; but, in any event, it is well, previous to sowing, to wash it in a strong brine made of salt and water, taking care to skim off all light and foreign seeds. If the grain be smutty, repeat the washing in another clean brine, when it may be taken out and intimately mixed with about one twelfth of its brilk of pulverized quicklime.

The time for sowing in the Northern States is from tle tenth to the twentieth of September, but it is often successfully sown both earlier and later. Sow broadcast, at the rate of from 
three to nive pecks to the acre, and harrow thoroughly. Rolling is beneficial, especially on light soils.

"Wheat is subject to the attack of the Hessian fly, if sown soo early in the fall, and again the ensuing spring, there being two annual swarms of the fly, early in May and September. When thus invaded, harrowing or rolling, by which the maggots or flies are displaced or driven off, is the only remedy of much avail. Occasionally, other flies, and sometimes wheat worms, commit great depredation. There is no effectual remedy known against any of these marauders, beyond rolling, brushing, and harrowing."

Smut is a parasitic fungus, of a brown or blackish color, which grows upon the head and destroys the grain. We have indicated the only remedy with which we are acquainted, in speaking of the preparation of the seed.

"The grain should be cut immediately after the lowest part of the stalk becomes yellow, while the grain is yet in thes dough state, and easily compressible between the thumb and finger. Repeated experiments have demonstrated that wheat cut at this time will yield more in measure, of heavier weight, and a larger quantity of sweet, white flour. If early cut, a longer time is required for curing before storing or threshing."

Spring wheat should be sown so early as the ground will admit. The best crops are raised on land that has been plowed the previous fall, and sown without additional plowing, but harrowed-in thoroughly.

Propagation may be extended with incredible rapidity by dividing the plant. The English Philosophical Transactions give the result of a trial, made by planting a single grain on the $2 d$ of June. "On the 8th of August it was taken up and separated into eighteen parts, and each planted by itself. These were subdivided and planted, between 15 th of September and 15th of October, and again the following spring. From this careful attention, in a fertile soil, 500 plants were obtained, some containing 100 stalks hearing heads of a large size; and the 


\section{Farm Crops.}

total produce within the year was 386,840 grains from the single one planted."

\section{RYE-Secale Cereale.}

This plant is supposed to be a native of the Caspian Caucasian desert. It is more hardy than wheat, and will flourish on soils too poor or too destitute of lime for wheat. It has taken the place of wheat in many portions of the

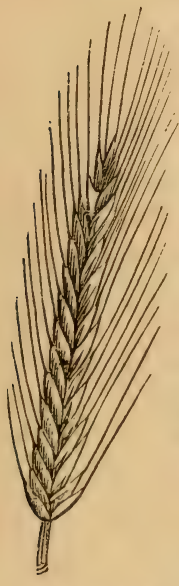

RAB OF BYE. country, where repeated crops of the latter have exhausted the soil of some of the requisite elements for its growth. The best soil for it is a rich, sandy loam, but it grows freely on the lightest sandy and gravelly soils that are capable of sustaining any kind of vegetation. The directions for the preparation of soil and seed, and for cultivation, harvesting, etc., are the same as for wheat; but it is sometimes sown among standing corn and hoed in, the ground being left as level as possible. So soon as the corn is matured, it is cut up by the roots and removed to the sides of the field, when the ground is thoroughly rolled.

Winter rye and spring rye are varieties of the same species, and may readily be transformed into each other. Sow from five pecks to two bushels to the acre, according to the quality of the soil, the richest lands demanding most. Winter rye may be sown from the 20th of August to the 20th of September, and spring rye so soon as the state of the soil will permit in the spring.

Rye, when ground and unbolted, is much used in New England to mix with Indian corn meal, for bread-making. The corn meal is scalded, and the loaves baked for a long time. The product is known as "rye-and-Indian bread," and is much esteemed and very wholesome. There is a peculiar aroma and flavor connected with the husk of the grain, which is lost in the bolted flour. Dr. Thaer, the distinguished German physician and agricultural writer, says that "this substance has a 
singularly strengthening, refreshing, and beneficial effec' on the animal frame."

\section{The OAT-Avena Sativa.}

This grain will grow on any soil and in almost any climate. It is affected less by disease, and has fewer insect enemies than most of the cereals. The wire worm, however, occasionally proves destructive to it, when sown on fresh sod. The remedy in this case is to turn over the sod late in the fall, just before the severe winter frosts.

There are many varieties and subvaricties of the oat. Loudon describes the following:

"The White or Common Oat is in most general cultivation in England and Scotland, and is known by its white husk and kernel.

"The Black Oat, known by its black

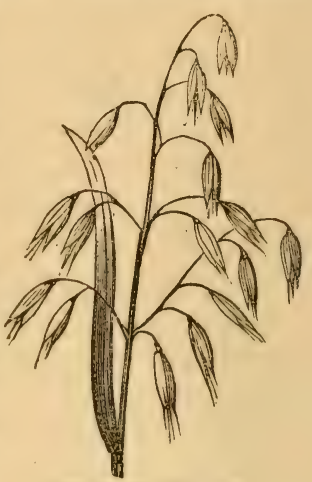

IIEAD OF THE OAT, husk, and cultivated on poor soils in the north of England and Scotland.

"The Red Oat, known by its brownish-red husk, thinner and more flexible stem, and firmly-attached grains. It is early, suffers little from winds, meals well, and suits windy situations and a late climate.

"The Poland Oat, known by its thick, white husk, awnless chaff, solitary grains, short, white kernel, and short, stiff straw. It requires a dry, warm soil, but is very prolific.

"The Black Poland Oat is one of the best varieties; it sometimes weighs $50 \mathrm{lbs}$. to the bushel.

"The Friesland or Dutch oat has plump, thin-skinned, white grains, mostly double, and the large ones sometimes awned. It has longer straw than the Poland, but in other respects resembles it.

"The Potate Oat has large, plump, rather thick-skinned. 
white grains, double and treble, with longer straw than either of the two last. It is now almost the only kind raised in the north of England and south of Scotland, and brings a higher price in London than any other variety.

"The Georgian Oat is a large-grained, remarkably profitable variety, and on rich soil, in good tilth, has produced more than any other variety.

"The Siberian or Tartarian is by some conceded a distinct species. The grains are black or brown, thin and small, and turned mostly to one side of the panicle, and the straw is coarse and reedy. It is little cultivated in England, but is found very suitable for poor soils and exposed situations.

"The Winter" Oat is sown at the rate of two bushels per acre in October, the plants are luxuriant and tiller well, and afford good winter and spring pasture for ewes and lambs, and when these are shut out, it affords an ample crop of grain in August."

The heaviest oat cultivated in the United States is the Imperial; and it is preferred by many to all others. It is bright and plump, and yields a large proportion of nutritive matter. It has proved very productive in the Northern and Middle States. But the variety most cultivated is the conmon White Oat, which is hardy and a good bearer.

The only oat that will mature with certainty in the Southerm States is the Egyptian. It is sound, hardy, and moderately productive. It is sown in autumn.

At the North, oats may be sown from the first of March till the last of May; but the earliest sown usually yield the best crops. From two to four bushels to the acre are sown in this country; but in England they sow from four to six. The land should be prepared by plowing and harrowing, after which the seed should be sown broadcast, and harrowed in. On most soils rolling is beneficial.

Oats may be mowed or cat with the cradle or the sickle. They are fit to harvest when they begin to turn yellow.

As an article of diet, the oat is not properly apprecinted in this cointry, oatmeal being little eaten except by for eigners. 
In Ireland and Scotland it is a common article of diet. It would be well for us if it were so here. It is wholesome and strengthening. It is prepared by grinding the kiln-dried seerls, which have been previously deprived of their husks and outer skin.

\section{BARLEY-Hordeum of species.}

In Europe this grain ranks next to wheat in importance; but it is much less extensively cultivated in the United States.

Professor Lowe enumerates six species of barley, but two only are in general cultivationthe 'Two-Rowed and the Six-Rowed. In England, the latter is preferred for its superior hardiness and productiveness; but the former is more generally cultivated in this country, the Six-Rowed being,
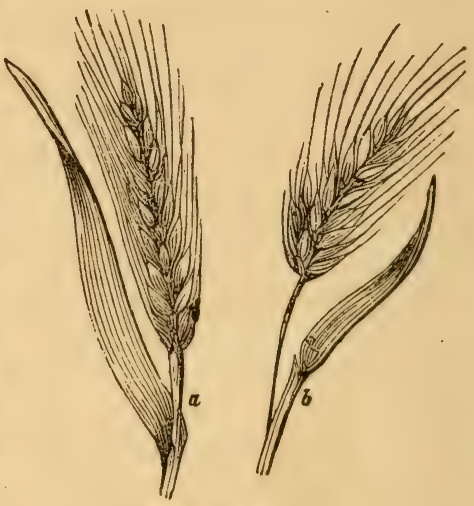

HEADS OF BARLEY. with us, more subject to the smut.

Like rye, it may be made either a winter or a spring grain; but in this country it is almost universally sowed in the spring. Sow so soon as the ground is sufficiently dry, on land plowed the previous fall. If sown on sod, it may be lightly plowed in, and afterward harrowed or rolled. Sow about two bushels to the acre, on soil of medium richness. If sown very early, a smaller quantity of seed will suffice. A loam of medium consistency, between light and heavy, is best for it. Barn-yard manures must never be applied directly to this grain. Steeping the seed twenty-four hours in a weak solution of saltpeter is beneficial. The roller is sometimes applied to the field, when the plants are two or three inches high, with great benefit.

It is of great importance to harvest barley at the proper time. 
If cut too early, the kernels shrink very much, and if suffered to stand too long, the grain wastes at the slightest touch, the heads breaking off and falling to the ground. It is known to be ripe by the disappearance of the reddish cast from the ear, the drooping of the heads, and the yellowish color of the stalks. It may be stacked like wheat.

Barley is very useful as an article of human food, but, like oats, is too much neglected in the United States, being used principally for malting and brewing. In the form of peari barley, which is the small, round part of the kernel that remains after the skin and a part of the seed are ground off, it is excellent when cooked in the same way as rice-either simply boiled or in puddings.

\section{Rioe-Oryza Sativa.}

Rice probably affords food for more human beings than any

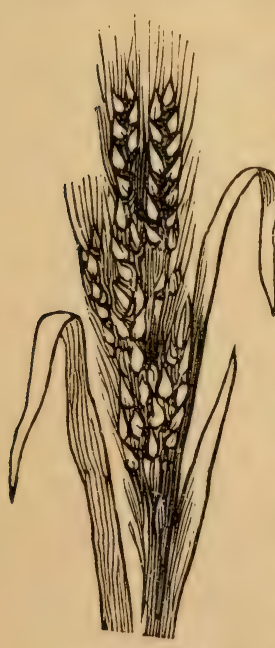

HEAD OF RION. other plant. In China, and nearly the whole length of the southern part of Asia; throughout the innumerable and densely populated islands of the Pacific and Indian oceans; in the southern part of Europe, and a large extent of Africa; and through no inconsiderable portion of North and South America and the West Indies, it is extensively grown, and forms the staple food of the inhabitants.

The varieties of rice most grown in South Carolina and Georgia, which have hitherto been the greatest rice-producing States of the Union, are the Gold-seed rice, the Guinea, the Common White, and the White-bearded. There are several other varieties, but generally inferior to the foregoing. The best are produced by careful cultivation on soils suited to this grain, and by a careful selection of seed. 
The method of cultivation pursued on the rice lands of the lower Mississippi, as detailed by Dr. Cartwright, a practical planter, is as follows:

"The seed is sown broadcast about as thick as wheat, and harrowerl-in with a light harrow, having many teeth; the ground being first well plowed and prepared by ditches and embankments for inundation. It is generally sown in March, and immediately after sowing, the water is let on, so as barely to overflow the ground. The water is withdrawn on the second, third, or fourth day, or as soon as the grain begins to 'swell. The rice very soon after comes up and grows finely. When it has attained about three inches in height, the water is again let on, the top leaves being left a little above the water. Complete immersion would kill the plant. A fortnight previous to harvest the water is drawn off to give the stalks strength, and to dry the ground for the convenience of the reapers.

"The same measure of ground will yield three times as much rice as wheat. The only labor after sowing is to see that the rice is properly irrigated; except in some localities, where aquatic plants prove troublesome, the water effectually destroying all others. The rice grounds of the lower Mississippi produce about seventy-five dollars' worth of rice per acre. The variety called the Creole white rice is considered to be the best." *

Upland rice is cultivated entirely with the plow and harrow, and grows well on the pine barrens. A kind of shovel plow, drawn by one horse, is driven through the unbroken pine forest, not a tree being cut or belted, and no grubbing being necessary, as there is little or no undergrowth. The plow makes a shallow furrow about an inch or two deep, the furrows about three feet apart. The rice is dropped into them and covered with a harrow. The middles, or spaces between the furrows, are not broken up until the rice attains several inches in height. One or two plowings suffice in the piney woods for its cultiv 
tion-weeds and grass, owing to the nature of the soil, not being troublesome.

Rice prepared according to the following recipe makes a dish which we prefer to the richest rice pudding, and which is certainly far more wholesome:

Slowly simmer the rice in milk three or four hours, or til the grains burst and absorb the milk; add a little sugar; put the whole into a wide dish, and bake till slightly brown. Eat with milk or butter.

\section{BбoKWHeat-Polygonum Fagopyrum.}

Buckwheat is extensively cultivated in the United States; as

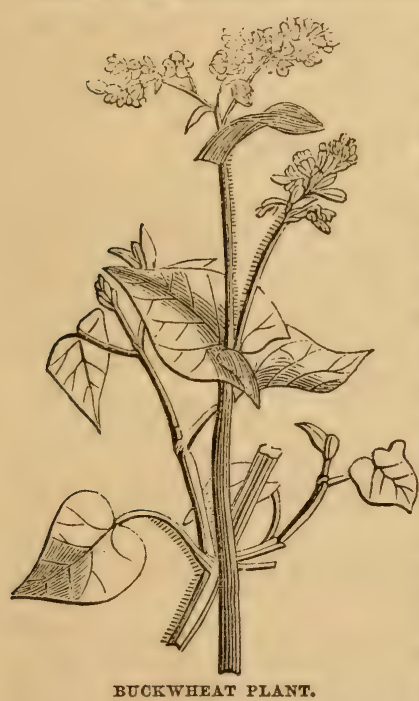
it affords a flour which is much esteemed as an article of food. It will grow with considerable luxuriance on the poorest land. It comes to maturity so quickly that it is frequently sowed upon ground from which wheat or some other crop has been taken. When intended for seed it should be sown suffciently early to allow the kernel to become perfectly ripe-say from the middle of June to the first of July. In New York it is often sown in August with winter wheat, affording a ripe crop in the fall, without injury to the wheat, except so far as it may exhaust the soil. It is sown broadcast, at the rate of from a bushel to a bushel and a half per acre. In harvesting it is usually mowed with a scythe, and made into small stacks.

Buckwheat is often used for plowing under as a green manura 
This can be done where the land is too poor to produce clover for that purpose. When in flower, it should be first rolled, and then plowed in.

\section{Millet-Panicum of species.}

The species generally cultivated for the seed is the P. milliaceum. As a forage crop, the German millet ( $P$. Germanicum) is preferable, and is coming into extensive use, especially at the West. The common species is sown, either broadcast or in drills, from the first of May to the first of July. If for hay, it is best sown broadeast about five pecks to the acre. In drills, which is the best way when cultivated for the grain, eight quarts will suffice.

Of the German millet or Hungarian grass we shall have more to say, under the head of the grasses.

\section{II.-HOW TO SHOCK GRAIN.}

Many a valuable harvest may be preserved from ruin by taking heed to the following hints from a practical farmer. They are from that excellent paper, the Ohio Farmer. The readers of this little manual shall have no excuse for the too common awkward and inefficient modes of shocking grain. Here are our sensible farmer's rules:

"1. Grain should be firmly bound in smaller sheaves than it is almost universally found. Loosely bound sheaves can not be well shocked. They also admit more rain than tightly bound ones.

"2. Two men can shock better and more advantageously than one.

"3. Let the shocker always take two sheaves at a time, holding them with his elbow against his side, bringing the heads together with hands well spread upon them. Lift them as high as possible, bringing them with force, in as nearly a perpendicular position as can be, to the ground. Never make the second thrust, if the sheaves stand erect, for every one after the first, by breaking the butts, makes the matter worse. 
"4. Then let two persons bring down two sheaves each at the same time, as before described, being extremely careful to keep them perpendicular. The form of shock at this * * * period may be represented thus: $\quad * * *$

"5. As lastly stated, two more each, thus: * * The reader will perceive we now have ten sheaves, $*_{*} *^{*}$ forming a circle as nearly as can be.

"6. While one man presses the head of the **** shock firmly together, let the other break, not bend, the twoo cap sheaves, and place them on, well spreading heads and butts.

"The main points are, to have grain well bound, sheaves made to stand in an erect position, and then to put cap sheaves on firmly, and every gust of wind will not demolish your work.

"Grain is usually shocked in this manner: One sheaf is made to stand alone, another is leaned against it, and another, sometimes at an angle of forty-five degrees, 'to make them stand up,' until a sufficient number is thought to be leaned up.

"Now the probability is, that there is but one sheaf in the whole shock that has its center of gravity within its base; as a matter of course, each depends on some other to hold it up Consequently they twist; and if the shock does not fall down before the hands get the next one up, it most certainly will during the first rain, just when the perpendicular position is most necessary."

\section{III.-THE LEGUMES.}

\section{The Kidney Bean-Phaseolus Vulgaris.}

The bush or dwarf kidney bean is frequently cultivated as a field crop. There are many sorts that may be profitably used for this purpose, but the Small White is generally preferred, as it is very prolific, quite hardy, will grow in light, poor soil, and is more delicately flavored than the colored varieties. The Long White garden bean is also good. See "The Garden" for a list of the best varieties for horticultural purposes.

The bean succeeds best on a light, warm, and moderately fertile soil. A strong soil, or too much manure, induces a 
tendency to run to vine, without a corresponding quantity of fruit.

Plant either in hills or in drills. If you have a sower, or drill for putting them in, the latter is the best mode. The drills may be from two to three feet apart, the hills from eighteen inches to two feet each way. From five to eight plants are enough for a hill. They must be kept clear from weeds by the use of the hoe or cultivator; but should be earthed up very slightly, if at all. The first of June is sufficiently early to plant them. They are sometimes planted with corn, putting three or four beans in each hill. This may be done either at the time of planting the corn, or at the first hoeing.

The best mode of harvesting beans with which we are acquainted is thus described by a correspondent of the Country Gentleman:

"Place a small pole or stick a foot in the ground, and five or six above ground; around this stick lay some stones, say from four to six inches high, and from twenty to thirty inches in diameter; then place your beans, with the stems against the pole, allowing the roots to be on the opposite side; your next handful you lay with the top on those last laid roots, and the roots of this on the pod and leaves, and so on to the top, forming, as you proceed, a sugar-loaf, keeping it round, or as you would build a stack, tying the top with a straw band. Thus you throw the water all to the outside, the beans being so compact as not to admit water. You can by this means ailow thern to remain in the field until you are ready to thresh them in November or December, the stones at bottom keeping them dry. In carting to the barn I loosen the pole by slaking, nd take hold bottom and top, and throw pole and beans into the wagon; by doing so you do not shell the beans."

As an article of food, the bean has been undervalned. It is, when properly cooked, very palatable and exceedingly nutritious. It abounds in legumin, which is analogous to casein, the snimal principle in milk, and is essentially the same as the fibrin of lean meat. 
Sheep are very fond of beans, and the straw or haulm inakes an excellent fodder for them. No other animal, we believe, will eat beans raw ; but cattle, hogs, and poultry thrive on them when cooked.

\section{The PeA-Pisum Sativum.}

The Marrow fat and Small Yellow peas are the sorts generally used for field culture. The Marrowfat is the richer and better pea, and is to be preferred for good soils. The Small Yellow thrives on poorer soils, and is therefore, in some cases, more profitably cultivated. In some parts of the South a very prolific bush pea is cultivated and much esteemed for the table, both green and dry.

Prepare the ground as for any other spring crop, by plowing and harrowing, and sow broadcast, at the rate of two or two and a half bushels to the acre. Cover them with the harrow or the cultivator, the latter implement being preferable, and smooth the ground by the use of the roller.

In harvesting the pea, some farmers hook them up with a scythe, and some rake them up by hand with the common rake; but the most expeditious and best way, by far, is to use the horse-rake in gathering this crop.

Peas are easily threshed and prepared for market, and may be made a very profitable crop; from thirty to forty bushels per acre being not an uncommon yield. As an article of food, they are excellent "both for man and beast."

The great enemy of the pea is the pea-weevil or pea-bug, which is too well known to require description. It deposits its egg in the growing pea, by piercing the tender pod. As a remedy, some recommend keeping the seed in tight vessels over one year. This plan, if universally adopted, would probably lead to the total extermination of this destructive insect; but as this is not likely to be the case, the only practicable way to avoid its ravages is by late sowing. It has been ascertained that it is limited to a certain period for depositing its eggs; peas, therefore, which are planted sufficiently late in the season 
to postpone their seeding beyond this period, are not injured. The time for planting to avoid the bug ranges, in different latitudes where experiments have been made, from May 20 th to June 10tl .

The Chinese Prolific pea and the Japan pea are new sorts, which seem to promise valuable additions to our leguminous crops.

The plant called Cow-pea or Indian pea, and sometimes Stock pea, is extensively cultivated in some of the Southern States, both as a forage crop and a fertilizer. It is sown broadcast, in drills, or hoed in among Indian corn, when the latter is laid by for the season. When intended for cattle, it is harvested before the seed is fully ripe. It may be harvested in the same way as the common pea.

\section{The Pea-Not-Arachis Hypogca.}

This is a legume bearing its pods under the surface of the ground. It was originally brought from Africa.

A North Carolina planter thus describes the mode of cultivation: "So soon as the frost is out of the ground, the land is broken up, and about the middle of April laid off with the plow thirty-three inches each way; two or three peas are then dropped in the crosses thus made. The plants are kept clean with hoes and plows until the vines cover the ground; but no dirt is put on the vines. In October they are dug with a rake or plow. Hogs are then turned into the field, and they soon fatten upon the peas left upon the ground. When the vines are left upon the land for the hogs to feed upon, there is no crop that improves the land so much.

\section{IV.-ESCULENT ROOTS.}

\section{Tre Potato-Solanum Tuberosum.}

This most valuable of all the esculent roots is a native of the American continent, and is now found in a wild state in parts of South America. It was probably introduced into southern 
Europe by the Spanish adventurers, and into Enyland by Sir Walter Raleigh. In this country it has been cultivated from the first settlement; but until a comparatively recent period only to a limited extent.

In reference to the choice of varieties for planting, the best advice we can give will be simply a repetition of our recommendations in respect to several other plants: Choose such as have been well tested by yourself or others, and found adapted to the soil and purposes for which they are to be cultivated. Try your experiments with new sorts, on a small scale, and with close observation of the results. Experiment also, if leisure serve, in the production of new varieties from the seeds found in the balls. See directions in "The Garden."

A fair crop of potatoes may be produced on almost any soil, properly manured and prepared and well eultivated, but a rich loam, of medium humidity, is best. If fresh or unfermented manures be used, they should be spread on the land, and plowed under, and not seattered in the drills or hills, as they are apt to injure the flavor of the potatoes. Lime, crushed bones, gypsum, salt, and ashes are excellent special manures for the potato. The soil should be made loose and mellow before planting.

In reference to seed, planting, and cultivation, opinions and practices differ widely. We have not room to discuss the various points in controversy between different scientific and practical agriculturists. All that our plan will permit is to give our own mode of cultivation, leaving our readers to try it in connection with other methods, and adopt the best.

We choose for seed good, well ripened, medium-sized potatoes, such as we would select for the table. These we should prefer to plant whole, but, seed being scarce and dear, we think it economical to cut each into two or four pieces, according to the size. We cut them three or four days, at least, before they are wanted for planting, roll them in plaster of Paris, and spread them on the floor in an airy loft to dry.

We plant in drills from two and a half to three and a half feet apart, according to the strength of the soil and the sort of 
potatoes planted, some varieties producing much larger tops than others. On some soils we should plant in hills, for conve. nience of cultivation with the plow and cultivator, but on light and loamy soils tolerably free from weeds and unobstructed by stones, we prefer the drills. We drop our sets from six to nine inches apart in the drills, and cover to a depth of three or four inches.

When the shoots have fairly made their appearance above ground, we run a plow between the rows, throwing the earth well to the plants, and following with a hoe, if necessary. This plowing, or plowing and hoeing, are repeated once or twice before the blossoms appear, but not afterward.

The harvesting is commenced so soon as the tops are mostly dead. We allow only sufficient exposure to the sun to dry the tubers, and then store them at once in bins or barrels, where they will be secure against frost, covering them with straw or dry sand, to prevent the circulation of air.

For an early crop we plant only the seed ends, but for the earliest possible crop we should proceed as follows:

Select inedium-sized or large tubers early in February, and prepare them by carefully cutting out all the eyes, except the crow-eye or eyes (for there are sometimes two of them), and then place them in a layer, on some dry sand, in a shallow box, and cover them with sand, chaff, or straw, and keep them in a warm room, where light can be freely admitted. When the shoots appear, they must be exposed to the light as much as possible, by partially removing the covering during the day, but keeping them carefully covered at night, when there is any danger from cold. The leaves soon become green and tolerably hardy. Early in March they may be planted out in a warm southern exposure, covering them so as to just expose the leaves above ground. Give them a covering of straw or litter at night, whenever there is danger from frost. By this means you may have potatoes fit for the table two or three weeks earlier than by planting in the ordinary way. A modification of this plan is to forward the sets prepared, as before, on a heap of fer- 
menting manure, in some warm exposure in the open air, covering them well at night when the weather is cold.

In "The Garden" (page 76) we have given a description of the method pursued by Mr. Peabody, of Georgia, for raising potatoes under straw. We are convinced that his plan is a good one for the South, and late experiments seem to prove that it works well at the North also. A correspondent of the Ohio Valley Farmer, for instance, says:

"Having a ciuantity of wheat straw near a piece of ground I was planting with potatoes, I concluded to try the straw-covering process. The soil, if I may so call it, was hard yellow clay. On the surface, and without any preparation of the ground, I distributed my potatoes, covering them some six or eight inches with straw, and did nothing more to them. They grew finely, and in the fall I took hold of the tops and "drawed" my crop. I found the tubers of a good size, and nice, bright, and clean enough for the boiler! and the yield much greater than of those planted in sod ground in the usual way."

Another correspondent of the same paper makes the following strong statement:

"We have the three last years planted our potatoes under straw, and have got more than double the quantity, on the same ground, with less work in planting and gathering. Our plan is to prepare the ground as thoroughly as possible, then mark it out with the plow, as close as we can; drop the potatoes six inches apart in same, cover as lightly as possible with the soil, then take the wagon containing the straw, and spread lightly to cover the ground. In this manner the work is done till harvest-time. We then take the potato-hook, and rake the straw into winrows, and our crop is nearly all in sight, ready to be gathered."

We have not ourself sufficiently tested this mode of planting, to speak with confidence from our own experience. Let our thousands of readers try it, and report through the papers!

"Of the potato disease or rot," as we have remarked in "The Garden," "little can profitably be here said. Its cause and 
remedy have yet to be made known. As preventives, a dry, or an underdrained soil; the use of lime, salt, and ashes; the absence of fresh stable manure; early planting; and new, healthy varieties, may be confidently recommended." Thorough underdraining alone is, we believe, generally effective in preventing the disease.

\section{The Sweet Potato-Convolvulus Batatas.}

This is the potato of the South, and is much cultivated in the Middle and Western States. In its perfection, as it grows in South Carolina and the other extreme Southern States, it is the best of all the esculent roots.

The varieties most cultivated are the Small Spanish, long, purplish color, grows in clusters, very productive, and of good quality ; Brimstone, sulphur-colored, long, large, and excellent; Red Bermuda, the best early potato; Common Yam, root oblong and large, the best keeper, and very productive.

A dry, loamy soil, inclining to sand, is best for the sweet potato. The manure should be plowed in, and the ground well pulverized. A top-dressing of wood ashes is very beneficial.

The Spanish varieties are generally planted where they are to remain, either whole or cut up into sets. But these may, and the yams must be, propagated by slips, as they grow larger and yield more abundantly.

To raise slips, select a sunny spot, sheltered by fences or buildings, and lay it off in beds four feet wide, with alleys of the same width between them. Slope the beds a little toward the sun, and add plenty of well-rotted manure, if the soil be not already rich. Do this in February or early in March. Choose large, smooth, healthy-looking potatoes, and lay them regularly over the bed, an inch or two apart, and cover them with three or four inches of soil from the alleys. It requires ten bushels of potatoes, thus bedded, for an acre of ground.

Lay off your ground in low, horizontal ridges or beds, the crowns of which should be three feet apart, and about six inches high, on which, when the slips are ready, which will bo 
about the middle of April, plant them out eighteen inches apart; one plant in a place, choosing a wet or cloudy day for the operation. Draw the slips when from three to four inches high, by placing the left hand on the bed, near the sprout, to steady the root and prevent it from being pulled up with the sprout. This is loosened with the right hand from the parent; tuber, which will continue, if undisturbed, to produce a succession of sli] s till the first of July. Stir the soil frequently, keeping the weeds well subdued. Be careful not to cover the vines, but if they become attached to the soil, loosen them from it, so that the whole vigor of the plant may go to the formation of tubers. Make the hills large and flat. When they have been laid by, it is a good plan to fill up the spaces between the rows with litter, when the ground is wet, to retain the moisture.

So soon as the tops are dead or touched by the frost, the srop should be gathered.

Sweet potatoes are difficult to keep. The following is $\mathrm{Mr}$. Peabody's plan:

"Let the small heaps dry during the day. In handling them, take care not to bruise or injure the skin, as the least bruise produces rapid decay. Put them up in hills containing thirty or forty bushels each. Make a circular trench as large as the hill you wish to make. Elevate the earth surrounded by it six inches, or at least sufficiently to prevent the access of moisture. Cover this with straw, and heap the potatoes upon it in a regular cone. If the weather be good, cover them only with pine or other straw for two or three days, that the potatoes may be well dried before earthing up. The covering of straw should be three or four inches thick. Cover this with strips of pine bark, commencing at the base, and covering as in shingling, leaving a small aperture at the top for the escape of the heat and moisture generated within. Cover this, except the aperture, with earth, to the thickness of four or five inches. Some cover the opening in the top with a piece of pine bark, to keep out the rain, but a board shelter for the whole heap is preferable. In the spring take up the potatoes, rub off the 
sprouts, and keep them on a dry floor. If put up with care, they will keep till July."**

Baked, or roasted in hot ashes, the sweet potato is one of the most delicious and nutritive of all vegetables. They are also used for pies and puddings, and sweet-potato rolls are excellent.

\section{The Turnip-Brassica Repa.}

In England the turnip crop is one of the most extensive and important in the whole compass of agricultural production. Fields of hundreds of acres are sometimes seen, and inclosures of fifteen or twenty are common. Here they are cultivated to a more limited extent, differences of opinion existing in reference to the profit of their cultivation as a crop for feeding stock.

"In the corn-growing regions of the fertile West, from the facility with which Indian corn can be grown, and the low price of it in many sections of the country, and its nutritive value over that of roots is such, that it is doubtless more profitable growing corn than roots for feeding purposes. But in the Northern States, where corn is usually worth from 80 cents to $\$ 1$ per bushel, we believe farmers would generally find it for their interest to grow a certain amount of roots, proportioned to the number of cattle and other stock they winter. Aside from the actual amount of nutritive food that roots afford, we think there can be no doubt that the winter condition of our farm stock would be greatly improved by a daily feed of succulent food, even if it were but four quarts per day to each animal, with their dry hav and straw ; but with a larger allowance of roots, cattle can be kept in good condition through our long winters on hay of poor quality, or on straw, and so they can in freely feeding Indian meal or oil cake; but in sections of the country where corn is worth one dollar per bushel, and oil cake in a similar ratio, it is presumed roots would be found the cheapest."'

The varieties of the turnip are numerous. The flat English 
turnip has been longest in cultivation, and still holds its place among most farmers as a field crop. It thrives best on new land and freshly turned sod, but will grow wherever Indian corn can be raised.

The English turnip may be sown from the middle of June to the first of August, either broadcast or in drills. If sown broadcast, about two pounds of seed per acre will be required. The seed should be lightly harrowed or bushed in. Drilling it in with the seed sower and cultivating with the cultivator or hoe is the better way. The crop will be materially assisted by a top-dressing of lime, ashes, and plaster, at the rate of fifteen or twenty bushels of the first two, and from one and a half to three of the last.

English turnips are often sowed among Indian corn at the last hoeing, producing, in many cases, a fair crop.

The Ruta Baga or Swedes turnip is a far more valuable root than the English, but requires a little more attention in cultivation. It will grow on a heavier soil, yield as good a crop, furnish a more nutritive root, and keep longer.

"The Swedes turnip is generally sown in drills about two feet apart, and on heavy lands these should be slightly ridged. The plants must be successively thinned, to prevent interfering with such as are intended to mature, but enough should remain to provide for casualties. Where there is a deficiency, they may be supplied by transplanting during showery weather. They should be left six or eight inches apart in the drills. The Swede turnip is a gross feeder, and requires either a rich soil or heavy manuring; though the use of fresh manures has been supposed to facilitate the multiplication of enemies. Bones, ground and drilled in with the seed, or a dressing of lime, ashes, gypsum, and salt, are the best applications that can be made. The Swede should be sown from the 20th May to the 15th June, and earlier than the English turnip, as it takes longer to mature; and two or three weeks more of growth firequently adds largely to the product. An early sowing, also, gives time to plant for another crop, in case of failure of the first. 
"The turnip is exposed to numerous depredators, of which the turnip flea-beetle is the most inveterate. It attacks the plant so soon as the first leaves expand, and often destroys two or three successive sowings. When the fly or bug is discovered, the application of lime, ashes, or soot, or all combined, should be made upon the leaves, while the dew or a slight moisture is on them."*

Harvesting should be deferred till the approach of severe frosts, and at the South the crop may remain in the ground till wanted in the winter.

The Purple-Topped Swede, Skirving's Swede, and Ashcroft's Swede are approved varieties.

\section{KoHL RABI-Brassica Oleracea.}

In England and Ireland, where the turnip has, in some places, shown signs of degeneracy, the Kohl Rabi has been proposed as a substitute, and has already come into somewhat extensive cultivation. It seems to possess all the good qualities of the turnip, with the addition of some excellences pcculiar to itself. It has been proved to be perfectly hardy, to stand severe frosts better, and to keep in store for a longer period than the Swedish turnip. It also resists the attacks of the fly and grub. Its feeding qualities have been fully tested, and all kinds of stock are exceedingly fond of it. When fed to milch cows it does not impart that turnip taste to the milk and butter, as is frequently the case when cows are freely fed with turnips.

The average weight per statute acre has been from $\$ 7$ to 31 tons, of tops and bulbs.

The seeds of the Green and Purple-Topped varieties have been extensively distributed through the agency of the Patent Office, during the past two or three years. So far as we have learned, they have fallen short of the Swedes in productiveness or weight per acre. But in all cases that have come to our knowledge, the seed of the Kohl were sown at the time of 
sowing the turnips. This is too late for sowing Rabi seed. The Irish Farmer's Gazette says: "The seed is sown in a wellprepared seed-bed; about the end of February, in drills about a foot apart; and in May they are transplanted in the field (when the plants are six or eight inches high), in rows about two feet asunder, and eighteen inches apart in the rows."

\section{The Carrot-Daucus Carota.}

The carrot is looked upon with much favor as a field crop in some parts of the United States. It is preferred by many farmers to every other vegetable for feeding cattle, horses, and swine. A bushel of carrots cut and mixed with an equal quantity of oats is thought to be equivalent to two bushels of oats; and five or six hundred bushels may easily be raised on an acre of good land. Rev. Mr. Coleman, of Massachusetts, says that he has raised them at the rate of more than a thousand bushels to the acre.

The varieties mostly used for field cnlture are the Altringham, the Orange, and the White Belgian. The last-named is very productive, and, growing high out of ground, is more easily harvested than the other sorts; but, on the other hand, it is considered below the others in nutritive value.

"It is very important to have both the soil and the manure for carrots free from the seeds of weeds and grasses; the plants in the early stages of their growth are small and feeble, which makes it a slow and expensive process to eradicate the weeds, if abundant. Well manured sandy, or light, loamy soils are best adapted to the carrot crop. The ground should be deeply worked, and brought to a fine tilth before sowing the seed. For field crops, the drills should be eighteen inches distant; the plants in the rows should be thinned to six or eight inches apart. This 'thinning out' is a matter too frequently neglected. We have frequently seen carrots growing so thickly that they would average a dozen or more plants to the foot; when left to grow in this crowded manner, the roots must necessarily bo small, and the expense of harvesting greatly increased." 


\section{The Parsnep-Pastinaca Sativa.}

This root is nearly equal to the carrot in value, and large crops may be obtained on deep, rich, well-pulverized soil. The best variety for field culture is the Isle of Jersey. The cultivation is similar to that of the carrot. The harvesting should be deferred till spring, unless the roots may be wanted for winter's use, as they keep best in the ground.

The parsnep is one of the best of all our table vegetables, and is also excellent for cattle, sheep, and swine. The leaves of both parsneps and carrots are good for cattle, either green or dried.

\section{The BeET-Beta Vulgaris.}

The varieties most in use for field culture are the Sugar beet and the Mangold-Wurzel, of both of which there are several sub-varieties.

Beets do well in any soil of sufficient depth and fertility, but they are perhaps most partial to a strong loam. If well tilled, they will produce large crops on a tenacious clay. We have raised at the rate of 800 bushels per acre, on a stiff clay, which had been well supplied with unfermented manure. The soil can not be made too rich; and for such as are adhesive, fresh or unfermented manures are much the best.

The beet should be planted in drills from twenty to twentyfour inches apart, at the rate of six pounds of seed to the acre. Cover about an inch deep. The seed should be early planted, or as soon as vegetation will proceed rapidly ; but it must first be soaked by pouring soft, scalding water on it, allowing it to cool to blood-heat, and remain for three or four days, then roll in plaster and drill it in. The culture is similar to that of carrots and parsneps.

As an article of human food, the beet is a universal farorite. Domestie animals are very fond of it, and swine prefer it to any other root-except the parsnep; and on no vegetable can they be kept in a better condition. 


\section{Chinése YaM-Dioscorea Batatas.}

This root was introduced into France seven or eight years ago, and seems to have won a considerable degree of public estimation there. It has not had so long a period of trial here, but has been experimented with more or less in all parts of the United States, generally with ill or indifferent success. We can speak of it only as an object of experiment.

The mode of culture required by the Chinese yam is not yet well determined. It evidently needs a deeply spaded or trenched soil, and probably should be cut into sets and planted in rows three or four feet apart, and one foot apart in the row, and treated like the sweet potato, except that it requires no earthing up. The plants may be forwarded in a hot bed or in a cold frame under glass.

\section{V.-THE GRASSES.}

The grasses cultivated for the food of animals are too $\mathrm{nu}$ merous to admit of a description in such a work as this. It is said that no less than two hundred varieties are cultivated in England. In this country we make use of fewer sorts for cultivation; but the number and excellence of our natural grasses are probably unsurpassed in any quarter of the globe.

We will speak briefly of a few of the leading species cultivated among us, noting some of their peculiar excellences and adaptations.

\section{Tпмотну-Phleum Pratense.}

Allen says: "For cultivation in the northern portion of the United States, I am inclined to place the Timothy first in the list of the grasses. It is indigneous to this country, and flourishes in all soils except such as are wet, too light, dry, or sandy; and it is found in perfection on the rich clays and clay loams which lie between $38^{\circ}$ and $44^{\circ}$ north latitude. It is a perennial, easy of cultivation, hardy and of luxuriant growth, and on its favorite soil yields from one and a half to two tons of hay per acre at one cutting."

It may be sown either in August or September with the $6^{*}$ 
winter grains, or in the spring. "Twelve quarts of seed per acre on a fine mellow tilth are sufficient; and twice this quantity on a stiff clay." This is the Herds grass of New England.

\section{The Smootm-Stalked Meadow Grass-Poa Pratensis.}

This is one of the best of grasses, both for hay and for pasture. It is a native species, and is found almost everywhere, but does not grow in its greatest perfection north of the valley of the Ohio. It is seen in all its glory on the fertile soils of Kentucky and Tennessee. Every animal that eats grass is fond of it. "The seed ripens in June, and is self-sown upon the ground where the succeeding rains give it vitality and it pushes out its long slender leaves two feet in length, which in autumn fall over in thick winrows, matting the whole surface with a luscious herbage."

The Roughish Meadow grass ( $P$. trivialis) has the appearance of the smooth variety, but is rough to the touch, and prefers moist situations and clayey soils. This, also, is an excel.ent grass.

\section{RED Top-Agrostis Vulgaris.}

A hardy and luxuriant species, much relished by cattle, but possessing only a moderate nutritive value. It is much cultivated in some portions of New England and elsewhere; but where better grasses will grow, this should be rejected. It is sometimes called Foul Meadow and Bent Grass.

\section{Tall Oat Grass-Avena Elatior.}

An early and luxuriant grass, flourishing in a loamy or clayey soil, and making good hay. It grows to the height of four or five feet on good soils. It is well suited to pasture.

\section{The Fesoue Grasses-Festuca of species.}

The Tall Fescue grass ( $F$. elatior), according to some experiments made in England, yields more nutritive matter per acre, when cut in flower, than any other grass cut either in flower or 
seed. It is an American grass, but has found less favor at home than abroad.

The Meadow Fescue (F.pratensis); the Spiked Fescue ( $F$. loleacea); the Purple Fescue (F. rubra); and the Floating Fescue ( $F$. fuitans), are all indigenous grasses of fine qualities and great value.

\section{Orohard Grass-Dactylis Glomerata.}

The Orchard or Cock's Foot grass is excellent for shaded situations. It should be cut before it is ripe, and will furnish three or four crops a year. Twenty or thirty pounds of the seed should be sown per acre. It will grow in almost any climate, being found in this country from the extreme north to the extreme south.

\section{The Egyptian Grass-Sorghum Halpense.}

A cane-like grass which grows in profusion in some of the Southern States. It is a superior stock-sustaining plant; but as it is difficult to remove when once embedded in the soil, its introduction into cultivated fields is considered a great evil.

\section{German Millet-Panicum Germanicum.}

This plant, known at the West as Hungarian grass, seems to have been introduced into Iowa by a Hungarian immigrant, and to have spread thence to other parts of the country. It had, however, been previously cultivated in small quantities under its proper name of German Millet. As a forage crop, for the West, at least, its value seems to be well proved. It has been less extensively tested at the East.

An Iowa farmer thus describes the mode of cultivation pursued in his vicinity:

"We prepare the ground the same as for oats, and sow about eleven quarts to the acre when we want grass; but if sced is the object, eight quarts to the acre. Good seed will weigh fifty pounds to the bushel. I will say in general terms that wherever a crop of Indian corn will grow, the II 
grass will succeed. It loves warm weather, but it requires but about six weeks to mature. If cut green, it will put out an excellent second growth, making the richest kind of pasturage. I have seen, this season, one plant that stood rather isolated produce seventy shoots, and each shoot produce a head. It is a great thing to stool, or send out suckers; so if you sow thin or thick, you are sure of a crop. It usually grows from three to four and a half feet high with us. The best time for sowing is about the 20th of May, or when the ground gets warm, on clean ground, harrowed both ways.

"The usual yield of this grass with us is from four to six tons to the acre, according to the pains taken in its cultivation; but the premium crop of this county, as returned to our last fall's fair, was eight tons and some two hundred pounds to the measured acre of good, dry hay, suitable to put in stack, duly sworn to by disinterested parties, to the satisfaction of the committee, in order to receive the premium."

\section{The Clovers-Trifolium of species.}

According to botanical arrangement, the clovers belong among the lcgumes, and not among the grasses; but we find it more convenient to speak of them in connection with the other common forage plants.

The Common Red clover (T. pratense) is a hardy and easily cultivated species, of which there are several varieties. It grows luxuriantly on every well-drained soil of sufficient strength to afford it nutriment.

It may be sown broadcast either in August or September, or early in the spring; with most of the grains. Sow from ten to twelve pounds per acre on well-prepared loams, and from twelve to sixteen on clayey lands. It should be very slightly covered. A top-dressing of plaster, at the rate of three or four bushels to the acre, has a most beneficial and striking effect upon this plant.

Clover should be cut after having fully blossomed and assumed a brownish hue. 


\section{Farm Crops.}

Southern Clover (T. medium) is a smaller species than the common Red, and matures earlier. It succeeds better on a light soil than the latter, and should be sown more thickly.

The White or Creeping clover (T. repens), of which there are several varieties, is a self-propagating plant, and adds greatly to the richness of many of our pastures, especially on clayey soils. It is very nutritious, and cattle, sheep, and horses are all fond of it.

\section{Other Grasses.}

The Muskeet Grass, found growing on the plains of Mexico and Texas, is considered one of the best of the indigenous grasses. We have seen it growing on the plantations of Louisiana, where it has been successfully transplanted.

Winter Grass is known on the low, moist fertile soils of $\mathrm{N}_{\mathrm{W}} \mathrm{s}-$ sissippi and adjoining States. It springs up in the autumn, grows all winter, and seeds in the spring. It fattens all animals that feed upon it.

Grama (La Grama, or the grass of grasses) is held in the highest estimation by the Mexicans. It attains a medium height, and is deemed the most nutritious of the natural grasses in our southwestern frontier prairies, in California, and parts of Mexico. It grows on dry, hard, gravelly soils, on side hills, and on the swells of the prairies.

The Prairie Grasses abound in the Western prairies, and are of great variety, according to the latitude and circumstances under which they are found. They afford large supplies of nutritive food, both as pasturage and hay. They possess different merits for stock, but as a general rule they are coarse when they have reached maturity, and are easily injured by the early frosts of autumn. Some of the leguminose or wild pea vines, which are frequently found among them, yicld the richest herbage. We are not aware that any of these grasses have been cultivated with success.

Dr. Darlington, of Pennsylvania, gives the following as the 
species of grasses most valuable in our meadows and pastures, naming them in the order of their excellence:

1. Meadow or green grass (Poa pratensis). 2. Timothy (Phleum pratense). 3. Orchard grass (Dactylis glomerata). 4. Meadow Fescue (Festuca pratensis). 5. Blue grass (Poa compressa). 6. Ray grass (Lolium perenne). 7. Red top (Agrostis vulgaris). 8. Sweet-scented vernal grass (1nthoxanthum odoratum).*

\section{VI.-MISCELLANEOUS OBJECTS OF CULTIVATION.}

1. СоттоN-Gossypium of species.

As cotton is generally cultivated on large plantations, and does not strictly come under the head of farm crops, we shall content ourself with a few words only upon this grand object of culture and commerce.

Cotton can not be profitably cultivated north of Tennessee. It requires a dry, rich loam to produce the largest and most profitable crops.

"During the winter, the land intended for planting should be thrown up in beds by turning several furrows together. These beds may be four feet from center to center for a moderate quality of upland soil, and five feet for the lowlands. But these distances should be increased with the increasing strength of the soil, to seven and eight feet, and in some instances even to a greater distance for the strongest lands. These may lie until the time of planting, from 20th of March to 20th of April, when no further danger from frost is apprehended ; then harrow, and with a light plow mark the center of the beds, and sow at the rate of two to five bushels per acre. A drilling-machine might be made to answer this purpose better, and save much time. An excess of seed is necessary, to provide for the enemies of the plant and other contingencies. If all the seed germinates, there will be a large surplus of plants, which must be removed by thinning. There is an advantage 
in mixing the seed, before it is sown, with moistened ashes or gypsum, as it facilitates sowing and germination. It should be buried about an inch deep, and the earth pressed closely over it,"

Harvesting is commenced when the bolls have begun to expand and the cotton is protruded, and is continued as the bolls successively ripen and burst their capsules.

\section{The Stgar-C $\mathrm{C}_{A \mathrm{NE}}-$ Saccharum Officinarum.}

This is another plantation crop, and lies beyond the scope of this little book. It is indigenous both in the Old and the New World, but is restricted in its cultivation to a belt or zone extending from $35^{\circ}$ to $40^{\circ}$ on each side of the equator. In the United States the cultivation can not be profitably carried on advantageously higher than about $32 \circ$.

\section{Chinese Sugar-Cane-Sorghum Saccharatum.}

Although the value of this plant as an object of general cultivation is not universally conceded, we think it may be safely set down as worthy the farmer's attention, both as a forage crop and for making syrup. Its habits and mode of cultivation are similar to those of Indian corn. It may be planted at the same time as corn, about three feet apart each way, and two or three plants in a hill; or in drills three feet apart, and the plants, one in a place, two feet apart in the row. When the plants are from six inches to a foot high, turn over the earth on each side of the row with a plow and afterward keep the weeds down with the hoe. On good soil it will grow from six to twelve or fourteen feet high, furnishing a very heavy and nutritious crop of fodder; and one hundred and seventy-five gallons of syrup, equal to the best molasses, and worth at least one dollar per gallon, have been made from an acre of the cane, and that with very imperfect apparatus. A correspondent of one of the agricultural journals, in closing a narrative of his experiments, says:

"The result, thereforc, of my experiments lead me to the con- 
clusion that the accounts heretofore published, as to the value of the Chinese Sugar-Cane, are not exaggerated; that it may be grown upon almost any ordinary soil, requiring no more attention than is profitably bestowed upon a crop of Indian corn ; that as a soiling erop it is far superior both in quantity and quality to Indian corn, producing as a first crop more than can be obtained from any other plant in cultivation; and after once cut, again producing a valuable crop; and that a superior article of syrup can be produced at little cost or trouble."

An African sorgho, called Imphee, has been experimented with both in Europe and America, in connection with the Chinese. It has the advantage of maturing earlier, but in reference to its value as a sugar-producing plant, in comparison with the other, opinions, founded probably on imperfect experiments, differ widely. M. Velmarin, of Paris, who has experimented largely with the various saccharine plants, pronounces it greatly inferior. It has hardly had a fair trial yet in this country.

\section{Broom Cons-Sorghum Saccharatum.}

Broom corn requires similar soil to Indian corn. A green sward turned over late in the fall is best. Well-rotted horse or sheep manure and wood ashes may be liberally scattered in the drills or hills. A situation not subject to early or late frosts should be chosen. Clayey lands are not suitable.

Plant so soon as danger from frosts will permit, in drills three feet apart; or in hills from two to two and a half feet apart each way, from twelve to fifteen seeds in a hill, thinning out to ten plants at the first hoeing. The after-culture consists in frequent stirring of the soil with a light plow or cultivator, and keeping the crop clear of weeds with the hoe.

"Break the tops before fully ripe, or when the seed is a little past the milk; or if frost appears, then immediately after it. This is done by bending down the tops of two rows toward each other for the convenience of cutting afterward. They should be broken some fourteen inches below the brush, and 
allowed to hang till fully ripe, when they may be cut and carried under cover, and spread till entirely dry."

\section{Flax-Linum Usitatissimum.}

A deep, rich loam or alluvial soil is best for flax. The proper fertility should be secured by a surplus of manure applied to a previous crop, as fresh manures are injurious to it. It is sown broadcast, on well-prepared soil, at the rate of from sixteen to thirty quarts when wanted for seed, and two bushels when cultivated for the fiber.

\section{Hemp-Cannabis Sativa.}

This is a plant of the nettle tribe, and came originally from India. The Russians are at present its chief cultivators; but in our Western States, and especially in Kentucky, it is beginning to be widely raised.

A rich loam or a vegetable mold suits the hemp plant. The ground should be carefully prepared by plowing and harrowing till it is perfectly pulverized, smooth, and even. The seeds are sown broadcast at the rate of a bushel and a half to the acre, and plowed or harrowed in. Plowing is best on ground liable to bake. In Kentucky they sow any time from the first of $A$ pril to the tenth of May. It is desirable to sow just before a rain.

For a full description of the mode of cultivation, harvesting, and preparing hemp, as practiced in Kentucky, see the "American Farmer's Encyclopedia ;" article "Hemp."

\section{THE Hор-Humulus Lupulus.}

The hop is found growing spontaneously on the banks of rivers and brooks in various parts of this country.

The best soil for the cultivation of hops is a sandy loam, rather low and moist; but they will grow on soils very different from this. New lands are to be preferred.

The following is the mode of cultivation recommended by Allen in the "American Farm Book:" 
"If the land has been long in use, it should be dressed with a compost of alkaline manures; or, what is nearly equivalent, with fresh barn-yard manures, on a previously well-hoed crop, and made perfectly free from all weeds, and deeply plowed and harrowed. Then mark out the ground at intervals of six feet each way and plant in the intersection of the furrows, and unless the ground be already rich enough, place three or four shovels of compost in each hill. The planting is done with the new roots taken from the old hills, which are laid bare by the plow. Each root should be six or eight inches long, and must contain two or more eyes, one to form the root, and the other the vine. Six plants are put in a hill, all of which should be within the compass of about a foot, and covered to a depth of five inches, leaving the ground level when planted. The first season the intermediate spaces between the hills may be planted with corn or potatoes, and the ground carefully cleared of weeds, and frequently stirred. No poles are necessary the first year, as the product will not repay the cost. The ground should receive a dressing of compost the following spring, and the plants be kept well hoed and clean.

"Poles may be prepared at the rate of two or three to each hill, twenty to twenty-four feet long, and selected from a straight, smooth undergrowth of tough and durable wood, from four to seren inches diameter at the batt end. These aro sharpened and firmly set with an iron bar, or socket bar with a wooden handle in such a position as will allow the fullest effect of the sun upon the hills or roots. When the plants have run to the length of three or four feet in the spring, train them around the poles, winding in the direction of the sun's course. and fasten below the second or third set of leaves, where there is suffieient strength of vine to sustain themselves. They may be confined with rushes, tough grass, or more easily with woolen yarn. This operation is needed again in a few days, to secure such as may hare got loose by the winds or other causes, and to train up the new shoots.

"The gathering of hops takes place when they have acquired 
a strong scent, at which time the seed becomes firm and brown, and the lowest leaves begin to change color. This precedes the frosts in September. The vines must first be cut at the surface of the ground, and the poles pulled up and laid in convenient piles, when they may be stripped of the hops, which are thrown into large, light baskets; or the poles may be laid on long, slender boxes with handles at each end (to admit of being carried by two persons), and as the hops are stripped they fall into the box. Be careful to select them free from leaves, stems, and dirt.

"After gathering in the fall, the hops should be hilled or covered with compost, and all the vines removed. The following spring, when the ground is dry, the surface is scraped from the hill, and additional compost is added, when a plow is run on four sides, as near as possible without injury to the plants. All the running roots are laid bare and cut with a sharp knife within two or three inches of the main root, and the latter are trimmed, if spreading too far. It is well to break or twist down the first shoots and allow those which succeed to run, as they are likely to be stronger and more productive. Cutting should be avoided, unless in a sunny day, as the profuse bleeding injures them. The poles will keep much longer, if laid away under cover till again wanted the following spring. Drying may be done by spreading the hops thinly in the shade and stirring them often enough to prevent heating; but when there is a large quantity, they can be safely cured only in a kiln." 


\section{IX.}

\section{T II E 0 R C II A R D.}

There hang the red-cheeked apples, blushing in the gun.-Fonus.

I.-"THE GARDEN."

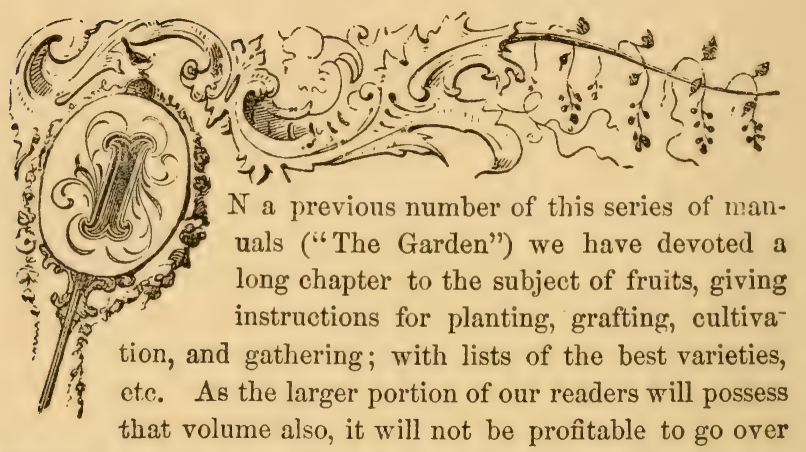

the same ground again here; but some additional hirts on several points not sufficiently dwelt upon in the work referred to will be useful in this.

\section{II.-LAYING OUT ORCHARDS.}

We copy from Tucker's "Annual Register of Rural Affairs," for 1857 , the following useful directions for laying out orchards:

We have often observed a good deal of inconvenience and perplexity in measuring off and laying out orchards, from a want of accuracy at the commencement. If the rows are begun crooked, stake after stake may be altered, without being able to form straight lines, and with only an increase of the confusion. If the first tree, in a row of fifty, be placed only sis 
inclies out of the way, and be followed as a guide for the rest, the last one will deviate fifty times six inches, or twenty-five feet from a right line, even if the first error is not repeated. We have seen large apple orchards with rows nearly as crooked as this. To say nothing of the deformed appearance to the eye, they proved exceedingly inconvenient every time the crooked space between the rows was plowed, and every time the ground was planted and cultivated with crops in rows.

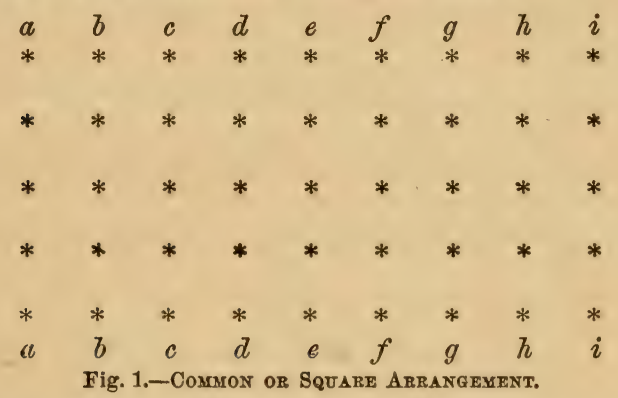

The most simple and convenient arrangements for orchards in all orlinary cases is in squares, as shown in fig. 1. But planters are often puzzled to know how to lay out such orchards, with trees at equal distances throughout, and in perfectly straight rows. The easiest and most successful mode is first to measure off one side along the boundary, with a chain or tapeline (a chain is best), and drive in a stake perpendicularly at equal distances (say two rods or 33 feet), in a straight line, and at a proper distance from the fence for the first row of trees. Then ineasure off each end in the same way; and between the last two stakes in these end rows, form another line of stakes like the first, which will be parallel and opposite to it. The more accurately the measuring is done, the less labor will be required in rectifying small errors-no stake should stand half an inch out of a straight line. These rows are represented by the letter's $a, b, c, d, e, f, g, h, i$. Then measure off the distance between $a$ and $a$, driving in a small stake or peg at each dis. 
tance of two rods, and then in the same waj between $3, e \cdot$ etc. If accurately done, these will all form perfectly airaight. rows. The holes may then be dug without the least, difficulty or embarrassment, and the trees set out. But a difficult arises, as the stakes must be removed in digging the holes; this is at once obviated by the plan here proposed, by placing the tree in a line with the row of stakes on one side, and with the newly-set trees on the other, as the holes are successively dug and the trees set.

These directions may seem quite simple, but from want of being generally understood, a great many crooked lines of trees are seen through the country.

The second mode of arranging trees is in the old quincunx form (fig 2), which is nothing more than a series of squares laic off diagonally, and has no special advantage to recommend $i$ except novelty.

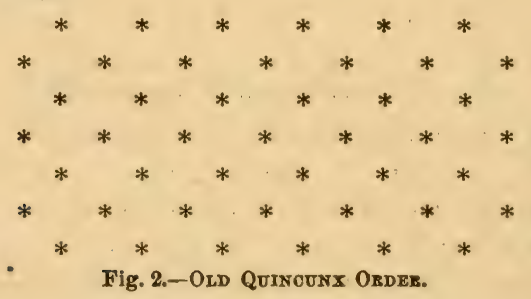

The hexagonal or modern quincunx (fig. 3) possesses two important advantages. One is its more picturesque appearance,

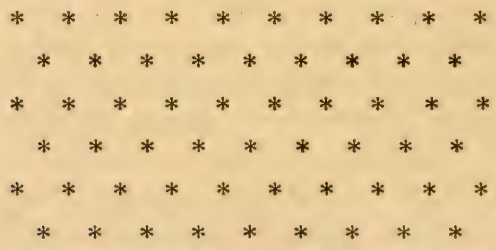

Fig. 3.-Hexagonal ot Modern Quinounx.

and its consequent fitness for proximity to ornamental plantations; and the other is its greater economy of space, as the 
trees are more evenly distributed over the gronnd. This is shown in fig. 4, where each tree stands in the center of a circle, surrounded at equal distances by six other trees, and each single circle leaves but little vacant space beyond it. If cultivated with horses, the furrows may be drawn in three different directions, instead of only two, as in the square arrangement.

One principal reason why the hexagonal mode is so little adopted, is the supposed difficulty in laying out the ground. But like many other apparent difficulties, it becomes very simple and easy when once understood.

To lay off a piece of ground for this purpose, measure off one side of the field at equal distances, as already described for squares, as at $a, b, c, d, e$, fig. 4 . These distances must be the distance apart at which the trees are to stand, because they form the sides of the equilateral triangles into which the whole

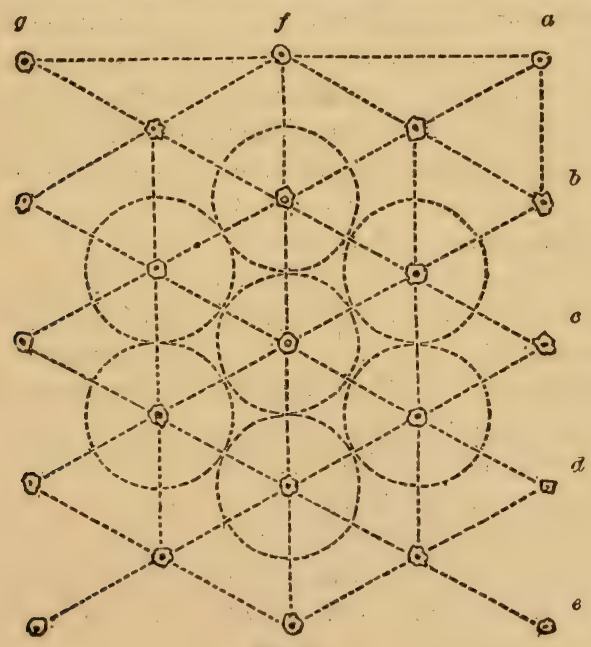

Fig. 4.

ground becomes divided. The next thing is to find the distances, $a, f, g$, for the line of trees at right angles to the first- 
mentioned row. An arithmetician will easily determine this, for the triangle, $b a f$, being a right one, the square of $b$ a (which is 33 feet) subtracted from the square of $b f$ (which is 66 feet) will leave the square of $a f$, the root of which extracted will give the distances of $f, f, g$, etc., which is 57 feet and half an inch. Divide this and the opposite side of the field, therefore, into distances of 57 feet and half an inch, and the side opposite the first, at 33 feet distances, and proceed to stake off all intermediate intersections, as described for squares. If the distances are less than 33 feet, as they would be for any other kind of fruit-trees, a corresponding proportion is of course to be taken, and which is easily determined as above.

\section{III.-SOIL AND SITUATION.}

Downing says that strong loams, by which is meant loams with only just sufficient sand to render them friable and easily worked, are, on the whole, by far the best for fruit in this country. The trees do not come into bearing so soon as on a light, sandy soil, but they bear larger crops, are less liable to disease, and are much longer lived. Clayey loams, when well drained, are good, and trees growing on them are generally free from insects.

It is difficult to give any precise rules in reference to aspect. Good orchards may be found in all aspects; but a gentle slope to the southwest is generally to be preferred to any other. Where fruit is very liable to be killed by late spring frosts, and the season is long and warm enough to ripen it in any exposure, planting on the north sides of hills is practiced with advantage. Deep valleys with small streams of water should be avoided, as the cold air settles down in such places, and frosts are apt to prove fatal; but the borders of large rivers and lakes are favorable for orchards, as the climate is rendered milder by the presence of large bodies of water. 


\section{IV.-PLANTING AND CULTIVATING AN ORCHARD.}

At the risk of repeating in part what has already been published in "The Garden," we will add a hint or two under this head.

The first thing is to prepare the ground by underdraining (if it require it, as most land does), subsoiling, or trench plowing, harrowing, manuring, etc.

Choose sound, healthy trees for planting, and set them ont carefully, as directed in "The Garden." Apple-trees should bo thirty feet apart in orchard culture. Set the same kind in rows together. This will facilitate the gathering of the fruit, and improve the anpearance of the orchard.

"It is an indispensable requisite in all young orchards to keep the ground mellow and loose by cultivation; at least for the first few years, until the trees are well established. Indeed, of two adjoining orchards, one planted and kept in grass, and the other plowed for the first five years, there will be an incredible difference in favor of the latter. Not only will these trees show a rich, dark, luxuriant foliage, and clean, smooth stems, while those neglected will have a sickly look, but tho size of the trees in the cultivated orchard will be treble that of the others at the end of this time, and a tree in one will be ready to bear an abundant crop before the other has commenced yielding a peck of good fruit. Fallow crops are best for orchards-potatoes, beets, carrots, bush beans, and the like; but whatever crops may be grown, it should be constantly borne in mind that the roots of the tree require the sole occupancy of the ground, so far as they extend, and therefore that an area of more than the diamete of the head of the tree should be kept clean of crops, weeds, and grass." *

To keep your trees in a healthy, bearing state, regular manuring is requisite. They exhaust the soil, like any other crop.

\section{* Downing.}


Top-dressings of marl, or mild lime, may alternate with barn. yard manure, muck composts, etc.

To prevent the attacks of the apple-borer, place abont the trunks early in the spring a small mound of ashes or lime. Nursery trees may be protected by washing the stems in May, quite down to the ground, with a solution of two pounds of potash in eight quarts of water.

\section{V.-THE PROFITS OF APPLE CULTURE.}

"There is no question of the propriety and necessity of the farmer planting apples enough to supply abundantly his own table with the best of this fruit through the whole year; but further than this, we require to know whether a large extent of land may be usefully applied to raising apples for sale; and abont what returns may he expected from such orchards, with good manargement; and what 'good management' is.

"There are some varieties, which, although possessing superior qualities for home use, and therefore necessary in the family orchard, are not salable, and, of course, worthless for marketing. A fruit for sale must at least be fair and good looking; it ought, also, to be of fine quality, to bring the best price; it must also be a sure and good bearer, and one that keops long enough to insure carriage to market, and a reasonable period for selling. We find among all the sorts which are known te our nurserymen and orchardists, that there are few that have all these qualifications to such an extent that they can safely be recommended. A close inquiry will show that, in all mixed orchards, the profit has been derived from a very few sorts. Other kinds are found to yicld some superior speeimens, and to be well worth raising for one's own satisfuction, but, so far as money is concerned, the soil would be more profitably employed if planted with other crops.

"Soil and sitnation fit for an apple orchard must always be valuable for other purposes; and as none but the best of lands can be depended upon, the value of such lands is consequently high. We are safe in assuming that land tit for such use, in 
Western New York, is worth, on an average, one hundred dollars per acre, the annual rent of which should be at least ten dollars per acre.

"This is more than would generally be realized net profit from the crops for some years after the planting of an orchard upon it; and at the end of ten years (at which time we might presume the trees to be in a bearing state), there wonld be a balance due from the orchard to the planter. After this time, the crops from the orchard should not be reckoned worth much, as the trees will occupy the whole soil with their roots, and the sun and air with their branches.

"Ten years from planting, Baldwin and Rhode Island Greening apple-trees can be relied upon to bear about three barrels per tree, each bearing year, which occurs each alternate year with the Baldwin, and gemerally so with the Greening. This gives us sixty barrels of fine winter apples per year, from trees planted two rods apart, or forty trees per acre. The whole annual expense of cultivation, and the gathering and barreling, will scarcely amount to twenty-five dollars, leaving the net proceeds, if sold at one dollar per barrel, about thirty-five dollars per acre. This sum per acre will soon repay any balance due the planter, and the rapidly increasing produce of the trees, for many years, will satisfy any reasonable man of the expediency of planting large orchards, where the conditions of success are observed; but it will readily be seen that an orchard of any but the best varieties will not pay interest and care.

"It is important that the fruit-grower should base his expectations entirely upon the results to be derived from a series of years, and not from any less period of time; otherwise he will be found wide from the truth." * 



\section{A P P E N D I X.}

A.

\section{MEASURING LAND.}

Fammers often desire to lay off small portions of land for the purpose of experimenting with manures, crops, etc. ; but sometimes find difficulty in doing it correctly, for the lack of a few simple rules. The following table and accompanying explanation, which we eopy from the New England Farmer earefully studied, will make the whole matter perfectly clear.

ONE ACRE CONTAINS

160 square rods ; 4,840 square yards ; 43,560 square feet.

ONE ROD CONTAINS

80.25 square yards; 272.25 square feet.

One square yard contains nine square feet.

THE SIDE OF A SQUARE TO CONTAIN
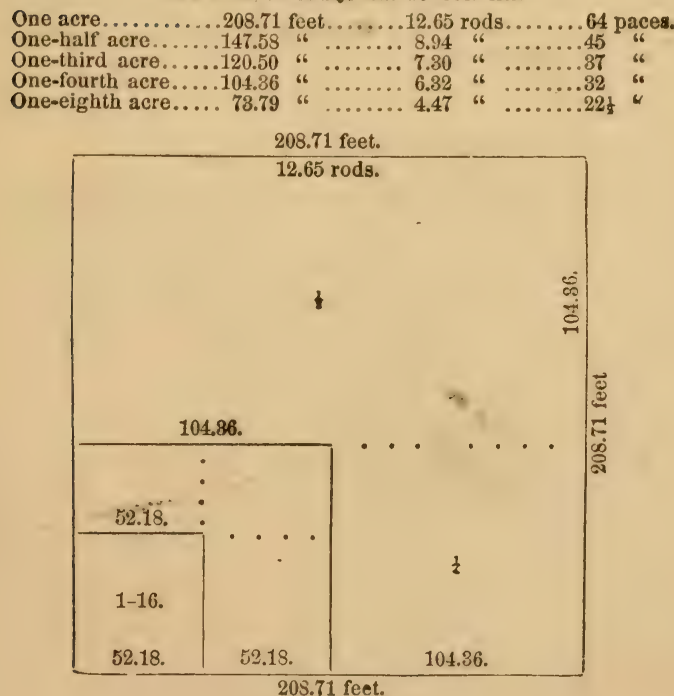

208.71 feet. 
It will be seen by reference to the plan that a practice sometimes followed by farmers is very erroneous; if the side of a square containing one acre measures 203.71 feet, one half that length will not make a square containing one half an acre, but only one fourth an acre, and one third the length of line will inclose a square of one ninth an acre, and one fourth the line, squared, will contain one sixteenth an acre, and so on.

B.

\section{HOW TO ESTIMATE CROPS PER ACRE.}

A friend communicates the following method of making an estimate of the yield per acre of a growing crop, of wheat, rye, oats, or barley, which he says has been found correct in England. As it seems easy of application, and approximately correct, we give the plan, and hope it will be tried at the next harvest-time.

Frame together four light sticks, measuring exactly a foot square inside, and, with this in hand, walk into the field and select a spot of fair average yield, and lower the frame square over as many heads as it will inclose, and shell out the heads thus inclosed carefully, and weigh the grain. It is fair to presume that the product will be the 43,560 th part of an acre's produce. To prove it, go through the field, and make ten or twenty similar calculations, and estimate by the mean of the whole number of results. It will certainly enable a farmer to make a closer calculation of what a field will produce, than he can do by guessing.-New York Tribune.

O.

NOMBER OF PLANTS PER ACRE.

NUMBER OF PLANTS OR TREES THAT CAN BE PLANTED ON AN AORE OF GROUND, AT THE FOLLOWING DISTANOES APART, IN FEET.

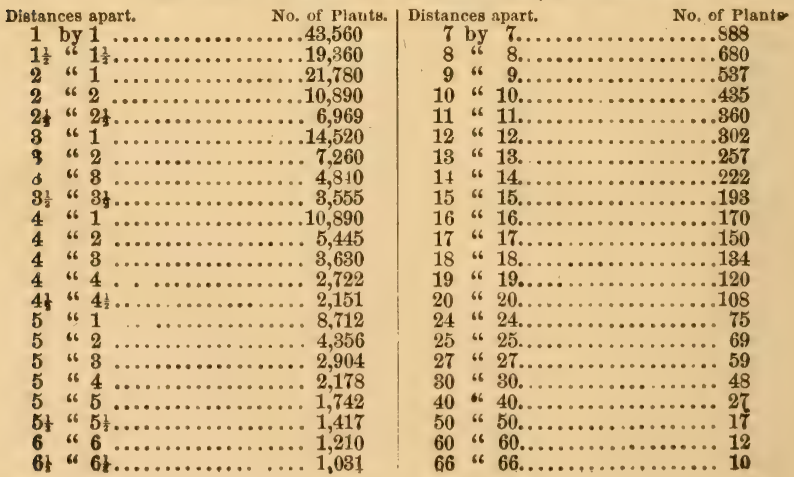


Multiply the distances into each other, and divide it by the square feet in an acre, or 43,560 , and the quotient is the number of plants.

D.

WEIGHTS AND MEASURES.

WEIGHT OF GRAIN, ETO.

\begin{tabular}{|c|c|c|c|c|c|c|c|c|c|c|c|c|c|c|c|c|}
\hline ARTICLES。 & 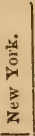 & $\stackrel{\circ}{\Xi}$ & 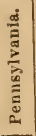 & 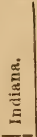 & 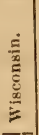 & $\stackrel{\tilde{E}}{E}$ & 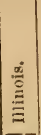 & 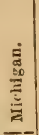 & 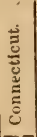 & 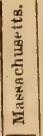 & 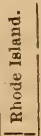 & 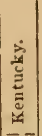 & 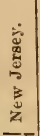 & 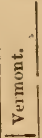 & 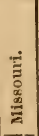 & 忍 \\
\hline & 60 & 60 & 60 & 60 & 611 & 60 & 60 & 60 & 56 & 60 & .. & 611 & 60 & 6!) & 60 & 60 \\
\hline & 56 & 56 & 56 & 56 & 56 & 56 & 54 & 56 & 56 & 56 & .. & 56 & 56 & 56 & 56 & 56 \\
\hline & 58 & 56 & 56 & 56 & 56 & 56 & 56 & 56 & 56 & 56 & . & 56 & 56 & $5 b^{\circ}$ & 52 & 56 \\
\hline & 32 & 32 & 32 & 32 & 32 & 35 & 32 & 32 & 25 & 30 & . & 33 & ว่0 & 32 & $\mathrm{~m}$ & 34 \\
\hline & 48 & 48 & 47 & 18 & 48 & 48 & 44 & 48 & & 46 & . & 45 & $4 S$ & 46 & $\mathrm{~m}$ & 4 \\
\hline B & 48 & 20 & 48 & 50 & 42 & 52 & 40 & 42 & 45 & 46 & .. & 52 & 50 & 46 & $\mathrm{~m}$ & 4 \\
\hline & 60 & 64 & .. & 60 & $6 ! 1$ & 60 & .. & 60 & $\cdots$ & . & . & 60) & 64 & .. & $\mathrm{m}$ & 60 \\
\hline l.. & 44 & $4: 2$ & .. & 45 & $\ldots$ & 45 & . & $\mathbf{m}$ & .. & m & - & 45 & & . & m & 45 \\
\hline & 55 & 56 & .. & 56 & . & 56 & . & $\mathbf{m}$ & .. & $\mathbf{m}$ & . & 56 & 53 & . & m & 56 \\
\hline & 44 & .. & .. & 44 & . & 44 & . & . & .. & . & . & . & . & . & . & . \\
\hline ed. & 14 & & . & 14 & & 14 & . & $\ddot{0}$ & .. & .. & .. & .. & . & . & . & $\ddot{\theta}$ \\
\hline & 22 & 25 & . & .. & $2 y$ & 24 & . & 28 & .. & - & .. & $\cdots$ & - & . & . & 2 \\
\hline , dried. & 32 & 33 & & & 28 & 33 & .. & 25 & .. & $\ddot{70}$ & .. & $\ddot{\text { ii }}$ & -. & .. & $\ddot{\circ}$ & \\
\hline ? & 56 & 50 & 85 & $5 !)$ & .. & 50 & .. & .. & . & 70 & . & 511 & . & .. & 50 & 56 \\
\hline & 56 & 511 & 62 & 50 & . & 50 & . & . & $\ddot{\theta}$ & 70 & .. & 50 & - & $\ddot{6}$ & 50 & 56 \\
\hline & 60 & $\cdots$ & .. & 60 & .. & 60 & .. & .. & 60 & 60) & 60 & $\cdots$ & * & 61 & $\cdots$ & \\
\hline & 60 & & . & & . & & . & & $\cdots$ & 60 & . & $\ddot{6}$ & $\cdots$ & $\cdots$ & $\cdots$ & \\
\hline & 62 & 56 & . & 60 & . & 60 & . & $\cdots$ & $\cdots$ & 60 & $\cdots$ & 60 & & & $\cdots$ & \\
\hline & 46 & .. & . & 46 & .. & 46 & . & $\cdots$ & $\cdots$ & 51) & & $\cdots$ & $\cdots$ & $\cdots$ & . & - \\
\hline & 57 & . & . & 57 & . & 57 & & $\cdots$ & $\cdots$ & 50 & & $\cdots$ & $\cdots$ & $\cdots$ & & . \\
\hline & $\cdots$ & .. & .. & 50 & . & . & & $\cdots$ & $\cdots$ & . & 50 & 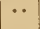 & $\cdots$ & $\cdots$ & $\cdots$ & $\cdots$ \\
\hline 20 & & $\cdots$ & & 71) & & & . & . & & $\cdots$ & . & $\cdots$ & $\cdots$ & .. & . & \\
\hline
\end{tabular}

A law of New York, in force at the present time, adopts the United States bustuel of measure, viz. : 2150.42 cubic inches per bushel, 1075.21 half bushel; and the wine gallon, 281 cubic inches.

To reduce cubic feet to bushels, struck measure, divide the cubic feet by 56 . and multiply by 45 .

\section{BOX MEASURES.}

Farmers and market gardeners will find a series of box measures very useful; and they can readily be made by any one who understands the two-foot rule, and can handle the saw and the hammer. The following measurements, it will be seen, vary slightly from the United States bushel adopted by some of the States, but are sufficiently accurate for all ordinary purposes:

A box 16 by $16 \frac{1}{8}$ inches square, and 8 inches deep, will contain a bushel, 2150.4 cubic inches, each inch in depth holding one gallon.

A box 24 by 11.2 inches square, and $S$ inches deep, will also contain a bushel or 215.4 cubic inches, each in depth holding one gallon. A box 12 by 11.2 inches square, an $1 \mathrm{~S}$ inches deep, will contain half a bushel, or 1075.2 cubio inches, each inch in depth holding half a gallon. 
A box $S$ by $S .4$ inches square, and 8 inches deep, will contain half a peck, or 298.5 cubic inches. Tle gallon, dry measure.

A box 4 by 4 inches square, and 4.2 inches deep, will cortain one quart, or 67.2 cubic inches.

WEIGITT PER CUBIC FOOT.

Weights of a Cutic Foot of various Sutstances, from which the Bulk of a Load of one Ton may be easily culculated.

Cast iron ...................450 lbs. Common soil, compact, about. 124 "

Water......................62 "6

White pine, seasoned, about.. 30 " Clay with stones, about........160 "

White oak, " " . 52 " Brick, about...............125 "

Loose earth, about........... 95 “

Bulk of a Ton of different Substances.

23 cubic feet of sand, 18 cubic feet of earth, or 17 cubic feet of clay, make a ton. 18 cubic feet of gravel or earth, before digging, make 27 cubic feet when dug; or the bulk is inereased as three to two. Therefore, in filling a drain two feet deep above the tile or stones, the earth should be heaped up a foot above the surface, to settle even with it, when the earth is shoveled loosely in.

E.

\section{UNPROFITABLE FARMING.}

Manure is a necessary application, in order to bring an impoverished soil Into a productive state. Nothing is more certain, all agree. And yet how much of the unprofitable firming of the country results from the attempt to grow erops on worn-out soils without manure! Plant corn on such land-the crop is a meager one, both from want of strength in the soil to grow it, and length of the season to mature it. A rich or well-manured soil will ripen this crop weeks earlier than a poor one. An acre of land, rich, deeply tilled, planted in good season, and thoroughly and cleanly cultivated, will produce more corn than five acres poor, shallow-plowed, late-planted, and half-cultivated, and at perhaps one half the expense of the latter.

Stagnant water, either in or upon the soil, is another cause of unprofitable farming. A soil which has no escape or outlet for the water which falls upon it save evaporation, can not be made to produce a paying crop. In a dry season it is baked and hard-in a wet one it is often flooded with stagnant water, and is never in a condition very favorable to the growth of cultivated crops, however well suited it may be to the production of wild grass, flag, and rushes. And partially drained land of this character is little better. Flooded in spring, the water passes off but slowly; nothing can be done upon it until the "subsiding of the waters," which, as they must in great part go cloudward, is a tedious process.

Poor manure-made so by exposure and leaching while yet in the yard-is another sc uree of loss to the farmer. The contents of the barn-yard are generally dignified with the name of manure; even if they consist of little moro than a leached mass of straw and excrement, the real strength of which has long ago passed off into some stream, or floated down the roudside ditch, and 
into some provident neighbor's fleld, it is still "manure," and is carted to the fleld and offered to the crop, with the expectation that it will find therein nutriment, and the material for large productiveness. One thought will show how futile this expectation. How does manure benefit a plant? By its soluble constituents-they receive only liquid food. This leached manure has lost the greater share of the soluble elements of fertility, and acts in great part only mechanically upon the soil.

Attempting too much is another great eause of loss to the farmer. "Much labor on little land" is the secret of sucess-enough labor, at least, to do every thing in the best manner. Look at it-is it good policy to expend the labor of putting in a crop over six acres, when. at the same cost, a like result may bo realized from three or four? Will you be content with thirty bushels of corn per acre, at an expense of, say $\$ 12$, when, by adding $\$ 3$ in manure and better culture, you may realize sixty or one hundred bushels? Will you grow inferior stock with the same amount of food, when by a larger outlay at first you may have the best--those always salable at good prices--while the unimproved scarcely find purchasers at any price? Is it not best, either to cencentrato your labor on less land, or increase your expenditure so as to embrace the whole farm in a thorough system of cultivation?

The acknowledged causes of unprontable farming are not exhausted, and it is a proper subject for the examination of the farmer. Let him look into the matter, and see where and why he has failed.-Country Gentleman.

F.

\section{FACTS ABOUT WEEDS.}

Dr. Lindley estimates as a low average the following number of seeds from each of these four plants :

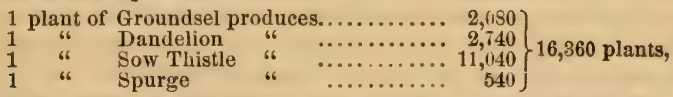

or enough seed from these four plants to cover three acres and a half, at three feet apart. To hoe this land, he says, will cost 6s. (sterling) per acre, and hence a man throws away 5 s. $3 \mathrm{~d}$. a time, as often as he neglects to bend his back to pull up a young weed before it begins to fulfill the first law of nature. He recommends every farmer, whose vertebral column will not bend, to count the number of dandelions, sow thistles, ete., on the first square rod he can measure off.

This operation may be repeated in this country by applying all the above estimates to pig-weed, burdock, fox-tail, chick-weed, and purslane.

\section{G.}

\section{SUCCESSFUL FARMING.}

James Gowen, of Mount Airy, near Philadelphia, raised, in 1845, a ten-acre field of corn, which averaged 95 bushels of shelled corn per acre. It had been in grass without manure, five years; it was plowed, and the fleld manured 
with a ton of guano, costing $\$ 40$. The rows were 31 feet apart, and the plants 12 inches. (This distance would be too great for small Northern corn.) Judicious harrowing, in preparation, cleared the ground thoroughly of grass and weeds, and it was kept perfectly clean afterward at little cost. There were 7 acres of winter wheat, and one of spring wheat, the whole computed to average over $4^{\prime \prime}$ bushels per acre. The spring wheat was after an acre of carrots, of 900 bushels, and was followed by an acre of turnips of 1,10 , bushcls; the whole worth over 554 -from one acre in two years. The carrot erop the same year was 1,00 bushels per acre; sugar-parsnep, $s_{0}$ bushels; ruta-baga, over 600 bushels; potatoes, 3 acres, over 200 bushels each. These were only part of the crops. Besides, there were more than 100 tons of excellent hay, though the season was unfavorable. All on an upland farm of about 110 acres, which maintained during the summer over 60 head of cattle. So much for manure, subsoiling, fine culture, draining, rotation, etc.-Annual Register.

H.

\section{STIRRING THE SOIL.}

Every observant farmer must have noticed the crust which forms on the surface of newly-stirred soils, after lying a few days to the action of the dews. A much heavier crust is formed by each shower of rain which falls. Good and successful cultivation requir's that this newly-formed crust be often and repeatedly broken by the hoe, harrow, or other instrument.

A striking instance in proof of the importance of this practice has just been stated by an extensive furmer. He planted a ficld of broom corn, and, by way of banter, told the man who assisted him that each should choose a row as nearly alike :s possible, and each should hoe his row, and the measured amount of erop vin each should be the proof which was hoed best. Our inform. ant stated the result in substance as follows: "Determined not to be beaten, I hoed my row, well, once a week the summer through. I had not seen my assistant hoe his at all, but had observed that for a long time he was up in the morning before me. At l'nglh I found him before sunrise, hoeing his broomcorn, and I asked him how often he hoed it; he answered, 'Once a day, regu. larly.' The result of the experiment was, his row beat mine by nearly double the amount."-Ibid. 


\section{N D E X.}

A.

$\begin{array}{rr} & \\ & \text { PAAT } \\ . & 9 \\ . & 11\end{array}$

Agriculture History of..........

Ashes..................... 41

Apple Culture, Profits of ........ 146

B.

Bones, how to prepare them..... 37

Barley ...................... 110

Buck wheat..................... 113

Beans ...................... 115

Beet........................ 12s

Broom Corn .................... 136

C.

Crops, What they take from the Soil 27 " Rotation of ........... 48, 97

" Farm.... ............. 100

"How to Estimate............ 150

Composts...................... 45

Capital.....................

Corn, Indian................. 100

Carrot ...................... 127

Cotton..................... 134

Chinese Sugar-Cane ........... 135

D.

Drains, Construction of.......... 55

Draining...................... 51 " Ten Reasons for. ........ 52

" Conditions requiring.... 53

" Practical Directions for. 53

" Will it Pay?.......... 58

F.

Fences ...............61, 91 " Iron. ................. 63

" Hurdle .................. 66

"s Are they Necessary?..... 70

Facts about Weeds.............. 153

Farm Management, Essay on.... 82

Furn Crops ................. 100

Farming, Unprofitable........... 152

" Suceessful. ......... 153
G. Guano ................. ${ }_{85}^{\text {PANM }}$

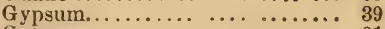

Gates...................... 91

Grains, Edible. ............... 100

Grain, How to Shock............. 114

Grasses..................... 129

H.

Hedges ................... 66

Harrow ..................... 76

Hoe. Horse ................ 78

Hemp .................... 187

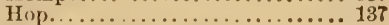

How to Estimate Crops.......... 150

I.

Irrigation ................... 46

Implements ................. 73

"6 List and prices of.... 85

" Choice of ........... 92

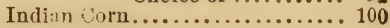

K.

Kohl Rabi 126

I.

Lime.................... 88

Livestock..................... 85

" Maintenance of....... 87

Land, How to Measure......... 149

M.

Manures, Necessity of......... 25 "6 Classification and De-

scription of...... 28

6. Management of ....... 42,94

Marl ...................... 38

Mowers...................... s1

Miliet.................... 114, 131

Measuring Land ............... 149

Weasures, Weights and........... 151

Maintenance of Livestock....... 87 
N.

Night Suil.

Number of Plants to the Acre.... 15u

O.

Oat........................ 108

Orchards, Laying out............ 140 6 Soll and Situation for . . 144

Plants, Food of............... 26

Plow....................... 73

Pea.. .................... 117

Pea-nut....................... 118

Potato...................... 118

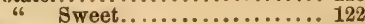

Parsnep................... 128

R.

Rotation, Theory of............ 48 6. Benefits of........... 49,97

Roller, Field.................. 79

Rake, Horse . . . . . . . . . . . . . . . . 8!

Reapers.................... 81

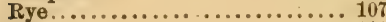

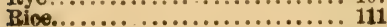

S.

Soils, Classification of........... ${ }^{\text {PAn }} 13$

" Analysis of ............ 16

" Physical Properties of..... 18

" Improvement of. ......21,93

" Importance of stirring the. 154

Subsoils.................... 28

Salt. $\ldots \ldots \ldots \ldots \ldots . \ldots \ldots$

Seeds..................... 86

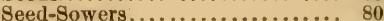

Sweet Potato................. 122

Sugar-Cane .................. 135

¿6 Chinese................ 135

Successful Farming.............. 153

Stirring the Soil.............. 154

T.

Turnip................... 125

U.

Urine...................... 88

Unprofitable Farming ........... 152

W.

Wheat...................... 104

Weights and Measures ........... 114

Weeds, Facts about............. 158 

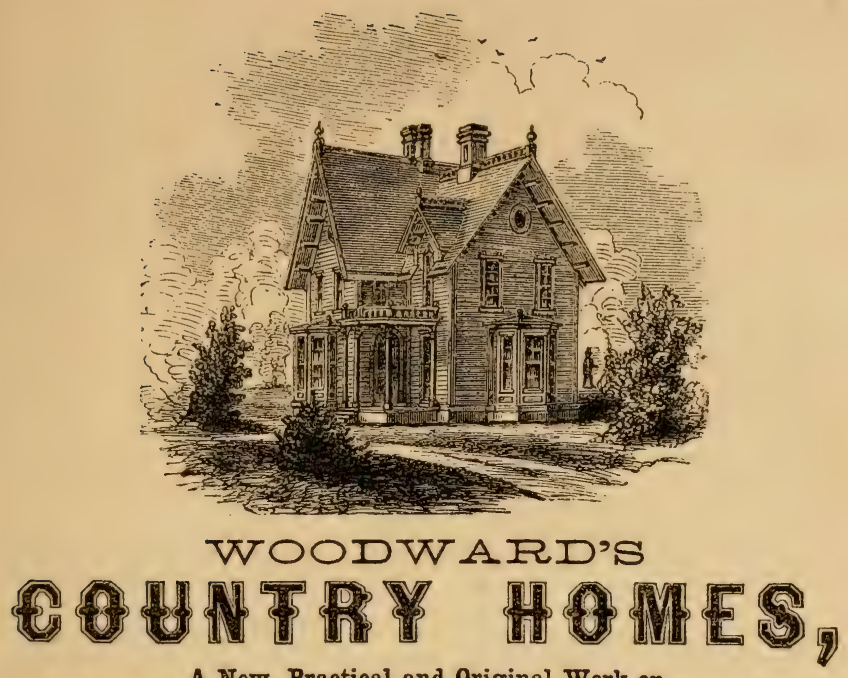

A New, Practical and Original Work on

RURAL ARCHITECTURE,

Elegantly Illustrated with

\section{Designs and Plans of Houses of Moderate Cost,}

Including Stables and Out-Buildings, with a Chapter

on the Construction of Balloon Frames.

Price, $\$ 150$ mailed free to any Address.

This work contains between its covers more practical information than can in many cases be sifted out of thousands of folios. The Messrs. Woodward are architects of note, and their work we warmly commend to our readers.-Ithaca, $N$. $Y$., Journal.

Contains a large number of very chaste and beautiful designs for snug, comfortable homes. The chapter, on what is termed Balloon Framing, with the clear diagrams, is worth alone to country builders, the whole cost of the book.

We have long known th-se gentlemen as architects, and we regard them as among the most reliable and skilful men in the profession. Their new work on "Country Homes," ought to be in the hands of every man that builds or contemplates building a home.-Scientific American.

GE0. E. \& F. W. WOODWARD, PUBLISHERS, 


\section{AGRACULURAL PAPERS}

Files of the following papers can always be found in this office, and subscriptions received for them. It comprises, so far as we know, all the Agricultural and Horticultural periodicals in the country.

\section{MONTHLY.}

The Horticulturist-New York City,......... $\$ 2.50$ The Gardener's Monthly - Philadelphia, ............ 2.00 Hovey's Magazine of Horticulture-Boston,........ 2.00 American Agriculturist-New York, .............. 1.50 Maryland Farmer and Mechanic-Baltimore......... 1.50

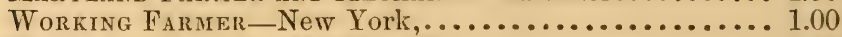
Wisconsin FarMier-Madison, Wis.,..................... 1.50

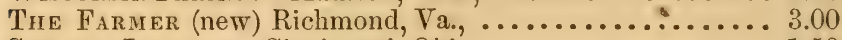
Sorgho Journal-Cincinnati, Olio, ................ 1.50 Southern Cultivator-Athens, Georgia, ........... 2.00

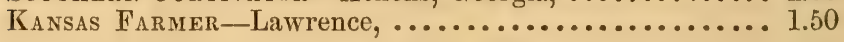

\section{WHEKIY.}

Cultivator and Country Gentleman-Albany, ...... 2.50

Prairie FarMer-Chicago, ..................... 2.00

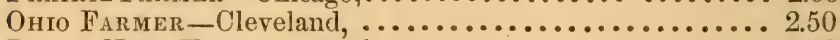

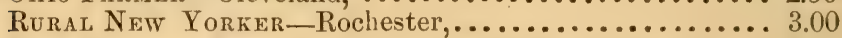

New England Farmer-Boston, ................ 2.50

Boston Cultivator- "

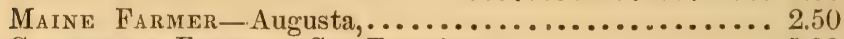

California Farmer - San Francisco,................ 5.00

Iowa Homestead-Des Moines,................. 2.50

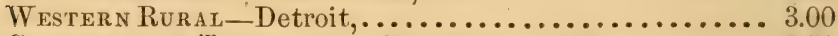

Germantown 'Telegraph-Germantown, Pa., ........ 2.50

\section{SEMI-MONTHLY.}

Coleman's Rural World_St. Louis,............. 2.00 Miner's Rural Amepican-Clinton, N. Y.,............ 1,50

In addition to the above, we receive subscriptions to

Harper's Monthly Magazine...................\$4.00

" WeEKLY, ............................. 4.00)

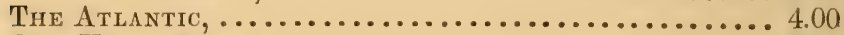

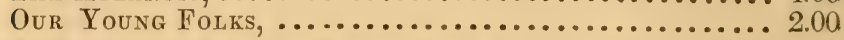

And all other papers and periodicals published.

Select your papers, remit us the amount by postal order, and the business will be transacted promptly.

\section{GOD. L. E. W. WOODWARD,} 37 Park Rovo, Nero York. 


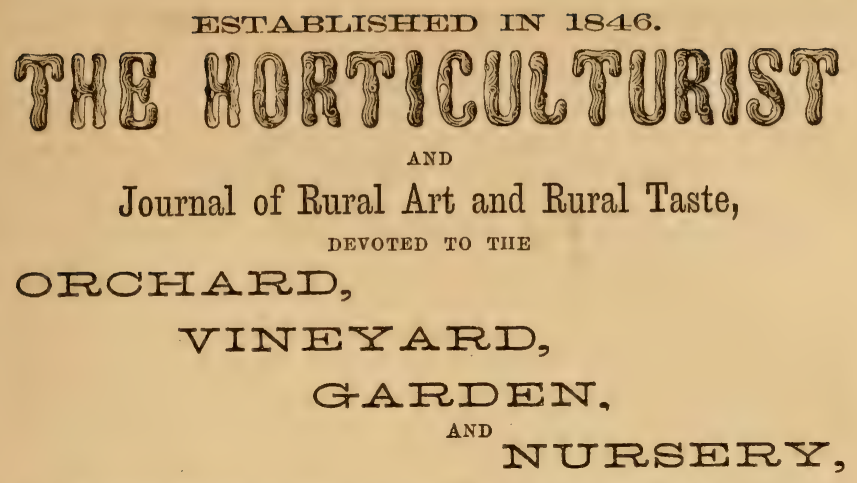

To Cuiture under Glass, Landscape Gardening, Rural Architecture, and the Embellishment and Improvement of Country, Suburban and city Homes.

Published Monthly, and forming a handsomely Illustrated Annual Volume of 400 royal octaro pages, by the best practical talent in the country.

\section{T E R S :}

Two Dollars and Fifty Cents a Year-Twenty-five Cents a Number.

\section{GEO. E. \& F. W. WOODWARD, PUBLISHERS, $3 \%$ Park Row, New York.}

New and Revised Editions just published by Geo, E. \& F.W.Woodward, 37 Park Row, N. Y.

\section{THE HOUSE.}

A New Manual of Rural Architecture; or, How to Build Dwellings, Barns, Stables and Out Buildings of all kinds; with a chapter on Churches and SchoolHouses. Cloth, \$1.50.

\section{THE GARDE N.}

A New Manual of Practical Horticulture; nr, How to Cultivate Vegetables, Fruits and Flowers; with a chapter on Ornamental Trees and Shrubs. Cloth, \$1.00.

\section{TH E F A R M.}

A New Mancar of Practical Agriculture; or, How to Cultivate all the Field Crops; with an Essay on Farm Management, etc. Cloth, \$1.00.

\section{THE BAR N-YARD.}

A New MANual of Cattle, Horse and Sheep Husbandry; or, How to Breed and Rear the various species of Domestic Animals, Cloth, \$1.00. Either of the above sent, post-paid, on receipt of price. 


\title{
Agricultural, Horticultural and Architectural
}

$$
\text { BOOKS, }
$$

\author{
For Sale at Publisher' Prices at the Office of the \\ Forticulturist, or mailed, post paid.
}

\section{Orders executed for Bcoks, Papers and Periodicals on any subject.}

\section{Grape Culture.}

Chnriton on Grape Culture under Glass............................\$ 75

Fuller's Grape Culturist............................................ 150

Harasthy Grape Culture, $W$ ine and Wine Making.................... 500

Phin on Grape Culture........................................... 150

Reemelin's Vire Dresser's Manual................................... 75

\section{Fruit Culture.}

Barry's Fruit Garden............................................. 175

Bridgeman's Fruit Cultivators' Manual.............................. 75

Cole's American Fruit Book................................... ... 75

Downing's Fruits and Fruit Trees of America, ......................... 300

Eastwood on Cranberry........................................ 75

Elliot's Western Fruit Grower's Guide............................. 150

Fleld's Pear Culture............................................ 125

Fuller on Strawberry ............................................ 20

Hovey's Fruits of America, colored plates, 2 vols...................... 3500

Pardee on Strawberry ........................................ 75

\section{Flowvers.}

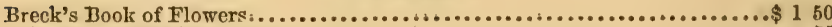

Bridgenian's Florists' Guide...................................... 75

Buist's Flower Garden Directory................................ 1 50

Iatdies' Flower Garden Companion, etited by Downing................. 2 (10)

Parlor Gardener .............................................. 100

Rand's Flowers for Parlor and Garden................................ 300

Slieleton Leaves and Phantom Boquets... . . . . . . . . . . . . . . . . . . . 200

Wax Flowers, and how to make them............................. 200

Trees, \&c.

Brotwne's Trees of America...................................... 600

Warder's Hedges and Evergreens................................. 150

\section{Rural Architecture.}

Allen's Rural Architecture...................................\$1 50

Cleveland's Villas and Cottages..................................... 300

Cummings' Designs for Street Frunts, Sububan Houses and Cottages, with

full exterior and interior details, 382 designs and 714 illustrations..... 1000

Downing's Cottage Architecture............................... 250

Downing's Country Houses.......................................... 60

Hatfie'd's American House Carpenter................................ 350

Holly's Country Seats. .......................................... 450

Leuchar's How to Build and Ventilate Hot-houses....................... 150

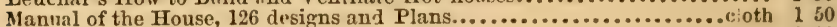

Silloway's Modern Carpentry ................................... 200

Sloan's Homestead Architecture, 200 Engravings..................... 400

Sloan's Ornamental Houses, 26 Colored Engravings.................... 300

Vaux's Villas and Cottages, nearly 400 Engravings....................... 300

Woodward's Country Homes.................................... 1 50

Woodward's Graperies and Horticultural Buildings.................... 150 


\section{Agricultural, Horticultural and Architectural Books.}

\section{Landscape Gardening.}

Downing's Landscape Gardening.................................\$ 650

Kern's Landscape Gardening..................................... 200

Kemp's " " 6 . .................................... 200

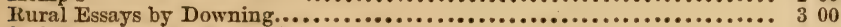

Smith's Landscape Gardening.................................... 160

\section{Gardening, Horticulture, Agriculture, \&c.}

Allen's American Farm Book...................................\$1 50

Allen's Domestic Arimals......................................... \& 00

American Rose Culturist......................................... 30

American Bird Fancier............................................ 30

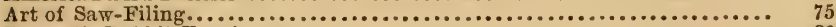

Bement's Rabbit Fancier........................................... 30

Bement's American Poulterer's Companion................................. 200

Boursingault's Rural Economy................................... 160

Boston Machin ist, (W. Fitzgerald) ................................. 75

Brandt's Age of Horses, (English or German) ...................... 50

Brilgeman's Kitchen Gardeners' Instructor............................ 75

Bridgeman's Young Gardeners' Assistant.......................... 200

Brown's Field Book of Manures.................................... 150

Buist's Family Kitchen Gardener....................................... 100

Burr's Field and Garden Vegetables of America........................ 500

Canary Birds, Manual for Birdkeepers............................. 50

Carpenters' and Joiners' Handbook................................. 75

Cobbett's American Gardener. ...................................... 75

Cole's Veterinn rian............................................ 75

Coleman's Agriculture........................................... 400

Darlington's American Weeds and Useful Plants.................... 175

Dana's Muck Manual.............................................. 150

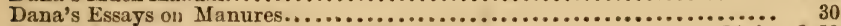

Dadd's Anatomy and Physiology of the Horse............................. 350

Dadd's Horse Doctor............................................ 150

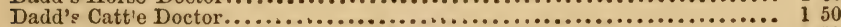

Davies Preparation and Mounting of Microscopic Objects............... 150

Farmers' Every Day Book, octavo, 650 pages.......................... 300

Flint on Grasses and Forage Plants.................................. 250

Flint on Milch Cows.......................................... 250

Flora's Interpreter and Fortuna Flora, (Mrs. Hale)................... 150

French's Farm Drainage ...................................... 150

Garlick's Treatise on Propagation of Fish $\ldots \ldots \ldots \ldots \ldots \ldots \ldots \ldots \ldots \ldots \ldots \ldots \ldots \ldots \ldots \ldots$. 25

Gray's Manual of Botany...................................... 450

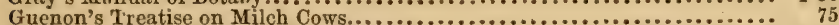

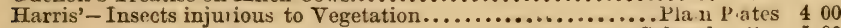

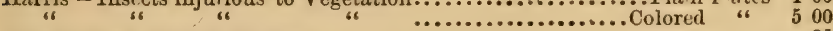

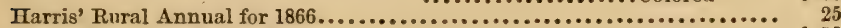

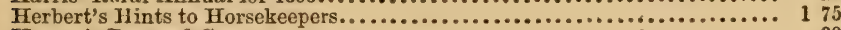

Hooper's Dog and Gun ................................................ 30

How to Get a Farm, and where to Find it.......................... 175

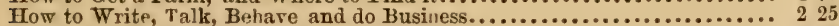

Ik Marvel's Firm of Edgewood................................... 200

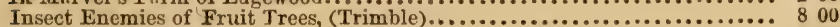

Jennings on Cattle $. . \ldots \ldots \ldots \ldots \ldots \ldots \ldots \ldots \ldots \ldots \ldots \ldots \ldots \ldots \ldots \ldots \ldots \ldots \ldots \ldots \ldots \ldots . . \ldots 200$

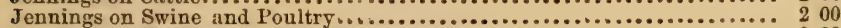

Jennings on the Horse and his Diseases.............................. 200

Johnston's Elements of Agricultural Chemistry $\ldots \ldots \ldots \ldots \ldots \ldots \ldots \ldots \ldots \ldots \ldots \ldots . \ldots \ldots$

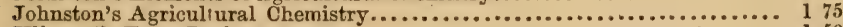

Klippart's Farm Drainage........................................ 150

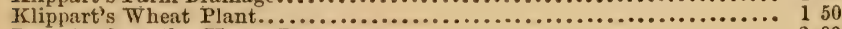

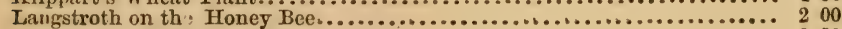

. Tiebig's Natural Laws of Husbandry ............................... 150

Liebig's Familiar Letters on Chemistry $\ldots \ldots \ldots \ldots \ldots \ldots \ldots \ldots \ldots \ldots \ldots \ldots \ldots \ldots \ldots \ldots \ldots \ldots$

Linsley's Morgan Horses ....................................... 150 


\section{Agricuitural, Hurticultural and Architectural Books.}

Manual of Agriculture, Emerson \& Flint.

" of Flax Culture............................................... 50

"6 of Hop Culture............................................... 40

" of the Farm.................................................. 100

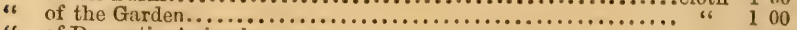

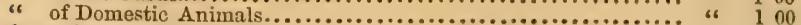

Mayhew's illustrated Horse Doctor...................................... 350

Mayhew's "6 Horse Management.................................. 3 50

Mayhew's Practical Book-Keeping for Farmers............................. 90

Blanks for do do

MeMahon's American Gardener........................................... 3 30

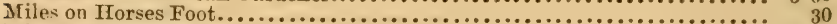

Miss Hall, Coolery and Domestic Economy.............................. I 50

Miss Beecher's Domestic Receipt Book................................. 150

Mis Beecher's Domestic Economy.......................................... 150

Morrell's American Shepherd........................................... I 50

Munn's Practical Land Drainer............................................. 75

New Clock and Watch Maker's Manual.................................... 200

No ton's Scientific Agriculture.............................................. ${ }_{75}$

Onion Culture.............................................. ${ }^{25}$

Orchard House Culture, by C. Mr. Hovey............................. 125

Our Farm of Four Acres, paper, 30 cents ; bound............................. 60

Our Farm of Two Acres................................................ ${ }_{20}$

Quinby's Itystery of Bee-keeping.............................................. 175

Portfolio Paper File, (Country Gentleman).............................. 150

Pedder's Land Measurer, for Farmers...................................... 60

Phenomena of Plant Life, (Geo. H. Grindon)......................... 100

Randall's Fine Wool Sheep Husbandry............................... i 00

Randall's Sheep Husbandry.......................................... 150

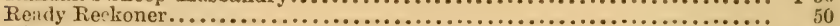

Richardson, On Dogs................................................ ${ }^{2}$

Rivers' Orchard House........................................... 50

Schenck's Gardeners' Text-13ook..................................... 75

Shepherds' Own Book.................................................... 225

Skillful Housemife........................................................ ${ }^{75}$

Stewart's Stable-Book................................................... 150

Saunders' Domestic Poultry............................................... 30 cloth 60

Sparrowgrass Papers............................................. 200

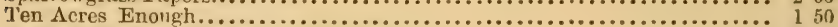

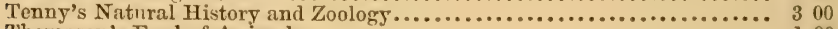

Thompson's Food of Animals........................................... 100

Tobacen Culture..................................................... ${ }_{2} 5$

Todd's Young Farmer's Manual........................................... 150

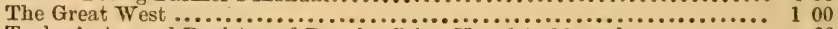

Tucker's Annual Register of Rural Aff iirs, Nos. 1 to 12 , each.............. 30

Tucker's Rural Affiirs, Four Bound Vols., each containing three numbers of the Annual Register, printed on larger and finer paper, per vol....

Turner's Cotton Planter's Manual......................................

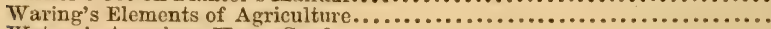

Watson's American Home Garden.......................................

Wet Days at Edgewood, by Ik Marrel..................................

Wetherell on the Manufacture of Vinegar..................................

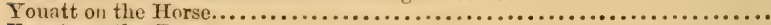

Youatt on the Dog.................................................

Youatt and Martin, On Cattle........................................

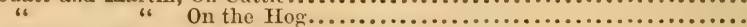

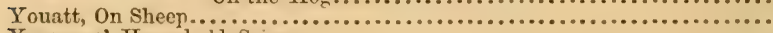

Youmans' Household Science.............................................

Youmans' New Chemistry........................................ 


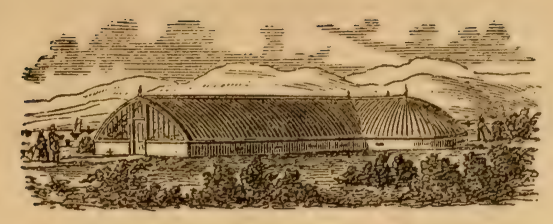

\section{WOODWA R D S GRAPERS}

AND

\section{HORTICULTURAL BUILDINGS,}

By GEO, E. \& F, W. WOODWARD, Architects \& Horticulturists.

A new, practical and original Work on the Design and Construction of all classes of Horticultural Buildings, including

Hotbeds, Propagating Houses, Hot and Cold Graperies, Orchard Houses, Conservatories, \&c.,

With the best modes of Heating, \&c.

ELEGANTIX ILLUSTRATFI.

Being the result of an extensive professional practice.

\section{Price $\$ 150$, Failed Free to any Adidress.}

This neatly printed and finely illustrated work upon Horticultural Buildings mives fuli information upon the position and form of houses, manner of construction, heating, \&c. Its plain directions for the erection and manntrement of these structures, will command for it a wide sale, and being the result of the practical expericnce of well-known architects, its value as a hand-book to guide the novice will be highly respected.-Maine Farmer,

\section{GEO. E. \& F. W. WOODWARD,}

PUBLISHERS,

3y Park Row, N. Y. 


\section{TFE \\ DELAWARE GRAPE.}

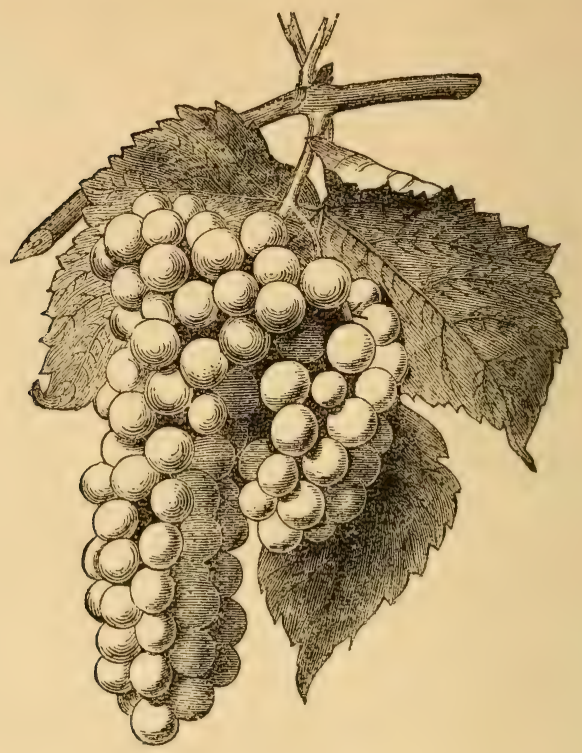

\section{A MAGNIFICENTLY COLORED PLATE,}

ON HEAVY ROYAL PAPER, FULL SIZE,

Being the finest thing of the kind ever Published in this country.

Price per copy, mailed free, securely packed, Tinee Dollars.

\section{GEO. E. \& F. W. WOODWARD,}

PUBLISHERS, 37 Park Row, New York. 8 





\section{LIBRARY OF CONGRESS

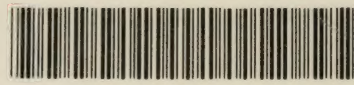 00025862430}

